Mapping Habitat for Multiple Species in the Desert Southwest

Open-File Report 2014-1134 



\section{Mapping Habitat for Multiple Species in the Desert Southwest}

By Richard D. Inman, Kenneth E. Nussear, Todd C. Esque, Amy G. Vandergast, Stacie A. Hathaway, Dustin A. Wood, Kelly R. Barr, and Robert N. Fisher

Open-File Report 2014-1134

U.S. Department of the Interior

U.S. Geological Survey 


\section{U.S. Department of the Interior \\ SALLY JEWELL, Secretary}

\section{U.S. Geological Survey \\ Suzette M. Kimball, Acting Director}

U.S. Geological Survey, Reston, Virginia: 2014

For more information on the USGS-the Federal source for science about the Earth,

its natural and living resources, natural hazards, and the environment-visit

http://www.usgs.gov or call 1-888-ASK-USGS

For an overview of USGS information products, including maps, imagery, and publications, visit $h$ ttp://www.usgs.gov/pubprod

To order this and other USGS information products, visit http://store.usgs.gov

Suggested citation:

Inman, R.D., Nussear, K.E., Esque, T.C., Vandergast, A.G., Hathaway, S.A., Wood, D.A., Barr, K.R., and Fisher, R.N, 2014, Mapping habitat for multiple species in the Desert Southwest: U.S. Geological Survey Open-File Report 20141134, 92 p., http://dx.doi.org/10.3133/ofr20141134..

ISSN 2331-1258 (online)

Any use of trade, firm, or product names is for descriptive purposes only and does not imply endorsement by the U.S. Government.

Although this information product, for the most part, is in the public domain, it also may contain copyrighted materials as noted in the text. Permission to reproduce copyrighted items must be secured from the copyright owner. 


\section{Contents}

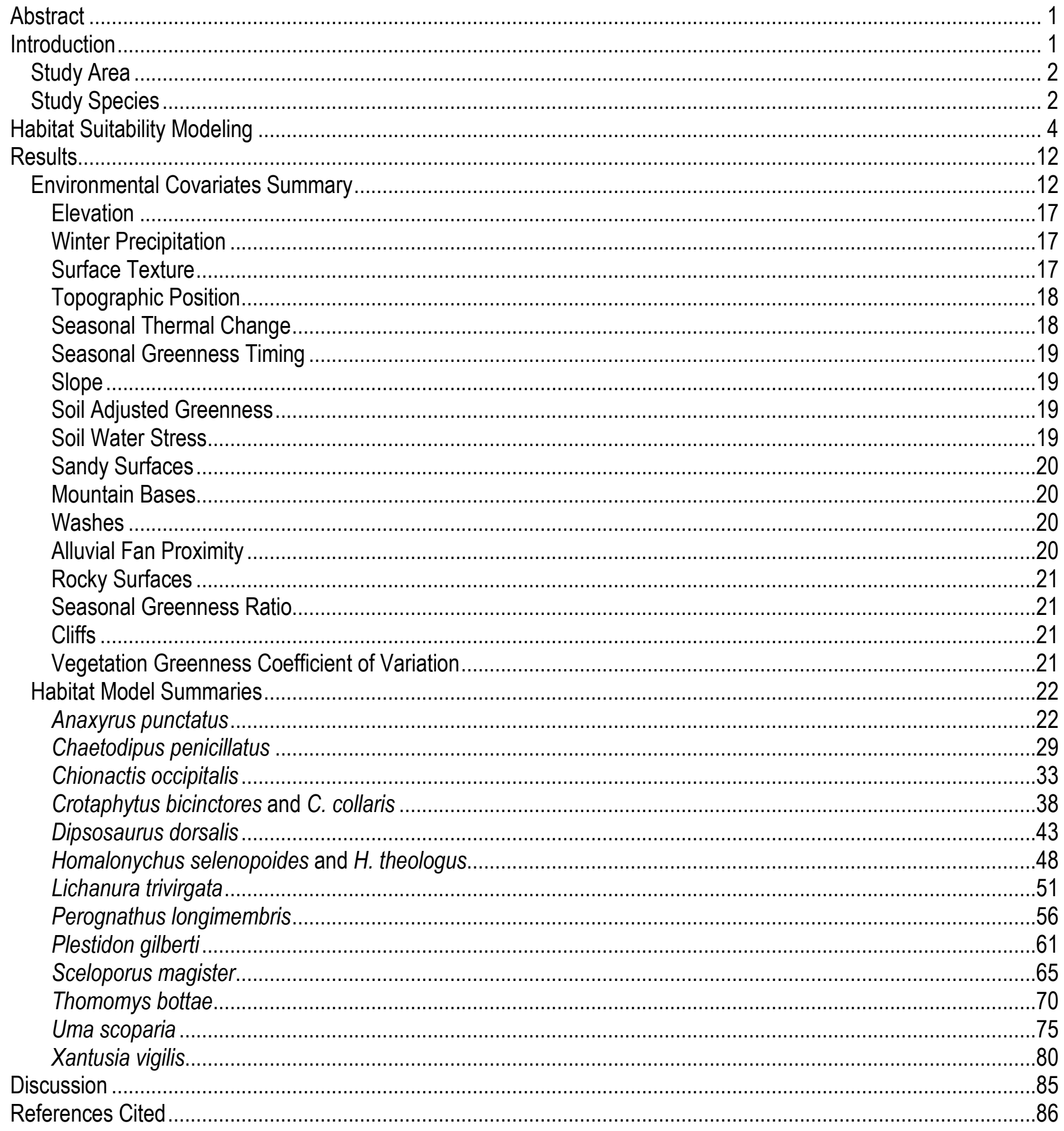




\section{Figures}

Figure 1. Representative species response curves across hypothetical environmental covariate gradients ............. 14

Figure 2. Map showing standard error $(\sigma / N)$ among the selected models for Anaxyrus punctatus

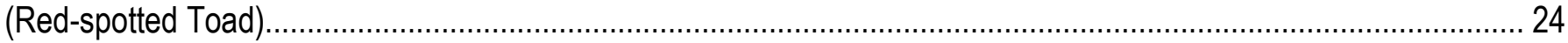

Figure 3. Map showing maximum habitat suitability among the selected models for Anaxyrus punctatus

(Red-spotted Toad)............................................................................................................................ 25

Figure 4. Generalized response curves and histograms for Anaxyrus punctatus (Red-spotted Toad) for

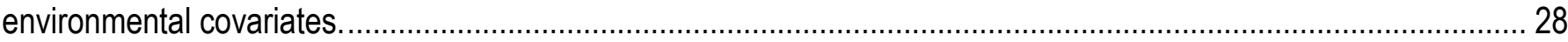

Figure 5. Map showing average habitat suitability among the selected models for Chaetodipus penicillatus

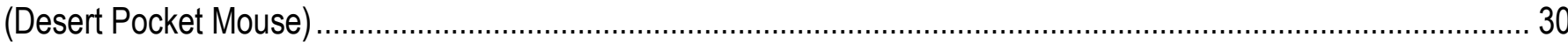

Figure 6. Generalized response curves and histograms for Chaetodipus penicillatus (Desert Pocket Mouse) for

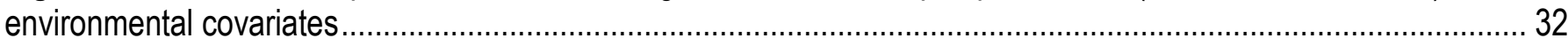

Figure 7. Map showing standard error $(\sigma / \mathrm{N})$ among the selected models for Chionactis occipitalis

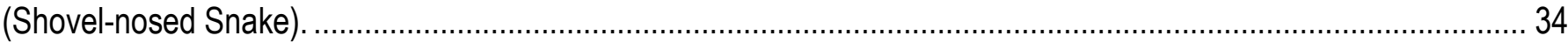

Figure 8. Map showing average habitat suitability among the selected models for Chionactis occipitalis

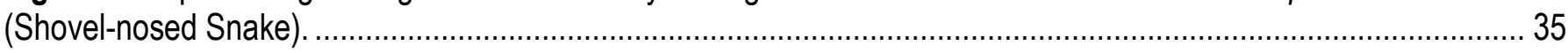

Figure 9. Generalized response curves and histograms for Chionactis occipitalis (Shovel-nosed Snake) for

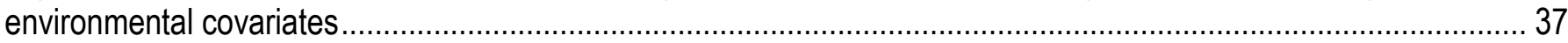

Figure 10. Map showing standard error $(\sigma / N)$ among the selected models for the Crotaphytus spp. group (collared lizards)

Figure 11. Map showing average habitat suitability among the selected models for the Crotaphytus spp. group (collared lizards)

Figure 12. Generalized response curves and histograms for the Crotaphytus spp. group (collared lizards) for environmental covariates.

Figure 13. Map showing standard error $(\sigma / N)$ among the selected models for Dipsosaurus dorsalis

(Desert lguana).....

Figure 14. Map showing average habitat suitability among the selected models for Dipsosaurus dorsalis (Desert Iguana)

Figure 15. Generalized response curves and histograms for Dipsosaurus dorsalis (Desert Iguana) for environmental covariates.

Figure 16. Generalized response curves and histograms for Homalonychus genus (Homalonychus spiders) for environmental covariances

Figure 17. Map showing average habitat suitability among the selected models for Homalonychus spiders.............50

Figure 18. Map showing standard error $(\sigma / \mathrm{N})$ among the selected models for Lichanura trivirgata (Rosy Boa)........ 52

Figure 19. Average habitat suitability among the selected models for Lichanura trivirgata (Rosy Boa) .....................53

Figure 20. Generalized response curves and histograms for Lichanura trivirgata (Rosy Boa) for environmental covariates

Figure 21. Map showing standard error $(\sigma / \mathrm{N})$ among the selected models for Perognathus longimembris (Little Pocket Mouse).....

Figure 22. Average habitat suitability among the selected models for Perognathus longimembris (Little Pocket Mouse)

Figure 23. Generalized response curves and histograms for Perognathus longimembris (Little Pocket Mouse) for environmental covariates.

Figure 24. Map showing average habitat suitability among the selected models for Plestidon gilberti

(Gilbert's Skink)

Figure 25. Generalized response curves and histograms for Plestidon gilberti (Gilbert's Skink) for environmental covariates 
Figure 26. Map showing standard error $(\sigma / \mathrm{N})$ among the selected models for Sceloporus magister (Desert Spiny Lizard).

Figure 27. Average habitat suitability among the selected models for Sceloporus magister (Desert Spiny Lizard) .... 67

Figure 28. Generalized response curves and histograms for Sceloporus magister (Desert Spiny Lizard) for environmental covariates.

Figure 29. Map showing standard error $(\sigma / N)$ among the selected models for Thomomys bottae (Botta's Pocket Gopher).

Figure 30. Map showing average habitat suitability among the selected models for Thomomys bottae (Botta's Pocket

Gopher)

Figure 31. Generalized response curves for Thomomys bottae (Botta's Pocket Gopher)

for environmental covariates.

Figure 32. Map showing standard error $(\sigma / \mathrm{N})$ among the selected models for Uma scoparia

(Mojave Fringe-toed Lizard)

Figure 33. Map showing average habitat suitability among the selected models for Uma scoparia

(Mojave Fringe-toed Lizard)

Figure 34. Generalized response curves and histograms for Uma scoparia (Mojave Fringe-toed Lizard) for environmental covariates.

Figure 35. Map showing standard error $(\sigma / N)$ among the selected models for Xantusia vigilis

(Desert Night Lizard).

Figure 36. Map showing average habitat suitability among the selected models for Xantusia vigilis (Desert Night Lizard).

Figure 37. Generalized response curves and histograms for Xantusia vigilis (Desert Night Lizard) for environmental covariates

\section{Tables}

Table 1. Species for which habitat models were derived, the number of observation records used, the Area Under the receiver operator characteristic Curve (AUC), the Boyce Index (BI), and the resulting amount of suitable habitat predicted from the averaged model for each species

Table 2. Environmental covariates used in developing habitat suitability models (mean, standard deviation, minimum and maximum for study area)

Table 3. Correlation coefficients for positive association (lower left) and significance (p-values; upper right) "among habitat suitability models.

Table 4. Relative contributions, prevalence, and average importance for environmental covariates included in habitat models 


\section{Conversion Factors and Datums}

\section{Conversion Factors}

\begin{tabular}{|c|c|c|}
\hline Multiply & By & To obtain \\
\hline \multicolumn{3}{|c|}{ Length } \\
\hline meter (m) & 3.281 & foot $(\mathrm{ft})$ \\
\hline kilometer (km) & 0.6214 & mile (mi) \\
\hline kilometer (km) & 0.5400 & mile, nautical (nmi) \\
\hline meter $(\mathrm{m})$ & 1.094 & yard (yd) \\
\hline \multicolumn{3}{|c|}{ Area } \\
\hline square kilometer $\left(\mathrm{km}^{2}\right)$ & 247.1 & acre \\
\hline
\end{tabular}

Temperature in degrees Celsius $\left({ }^{\circ} \mathrm{C}\right)$ may be converted to degrees Fahrenheit $\left({ }^{\circ} \mathrm{F}\right)$ as follows:

$$
{ }^{\circ} \mathrm{F}=\left(1.8 \mathrm{x}^{\circ} \mathrm{C}\right)+32
$$

Temperature in degrees Fahrenheit $\left({ }^{\circ} \mathrm{F}\right)$ may be converted to degrees Celsius $\left({ }^{\circ} \mathrm{C}\right)$ as follows: ${ }^{\circ} \mathrm{C}=\left({ }^{\circ} \mathrm{F}-32\right) / 1.8$

\section{Datums}

Vertical coordinate information is referenced to the North American Vertical Datum of 1988 (NAVD 88).

Horizontal coordinate information is referenced to the North American Datum of 1983 (NAD 83).

Elevation as used in this report, refers to distance above the vertical datum. 


\title{
Mapping Habitat for Multiple Species in the Desert Southwest
}

By Richard D. Inman, Kenneth E. Nussear, Todd C. Esque, Amy G. Vandergast, Stacie A. Hathaway, Dustin A. Wood, Kelly R. Barr, and Robert N. Fisher

\begin{abstract}
Many utility scale renewable energy projects are currently proposed across the Mojave Ecoregion. Agencies that manage biological resources throughout this region need to understand the potential impacts of these renewable energy projects and their associated infrastructure (for example, transmission corridors, substations, access roads, etc.) on species movement, genetic exchange among populations, and species' abilities to adapt to changing environmental conditions. Understanding these factors will help managers select appropriate project sites and possibly mitigate for anticipated effects of management activities. We used species distribution models to map habitat for 15 species across the Mojave Ecoregion to aid regional land-use management planning. Models were developed using a common $1 \times 1$ kilometer resolution with maximum entropy and generalized additive models.

Occurrence data were compiled from multiple sources, including VertNet (http://vertnet.org/index.php), HerpNET (http://www.herpnet.org), and MaNIS (http://manisnet.org), as well as from internal U.S. Geological Survey databases and other biologists. Background data included 20 environmental covariates representing terrain, vegetation, and climate covariates. This report summarizes these environmental covariates and species distribution models used to predict habitat for the 15 species across the Mojave Ecoregion.
\end{abstract}

\section{Introduction}

Many species of endemic plants and animals inhabit the Desert Southwest of the United States and compete for resources and space in a rapidly changing landscape. Some of these species are federally or locally listed as sensitive, threatened or endangered in the region, primarily due to loss and fragmentation of habitat. Continued pressures from urbanization, utility-scale renewable energy development, altered landscape conditions and climate space resulting from climate change may cause additional declines in biodiversity and species abundance. When tasked with managing biological resources throughout this region, agency personnel must understand the potential impacts of these pressures on the biological communities under their stewardship to make appropriate decisions.

Tools, such as habitat suitability models, can help inform managers about some of the potential impacts of these future pressures by identifying areas where one or more key species exist, and can provide insight to potential outcomes of land-use changes. Habitat suitability models, or species distribution models (SDMs), as they are often called, can be quantitative, spatially explicit models that relate species occurrence to environmental predictors thought to influence or define the suitability of habitat for the species (Franklin 2010). These models can be ecologically complex or very simple, and can be modeled at many scales. Habitat suitability models also are used for tasks such as the design of conservation and monitoring programs, evaluating the efficacy or potential effects of proposed 
management actions, and in recovery planning for threatened or endangered species (Graham and others, 2004; Elith and Leathwick, 2009). Additionally, SDMs are being used for species richness assessments (Elith and others, 2006; Franklin, 2010) and the evaluation of potential changes in species distributions resulting from climate change (Araújo and Williams, 2000; Guisan and Zimmermann, 2000; Pearson and Dawson, 2003; Franklin, 2010).

Habitat models are now often built with presence-only data (as absence data for many species are often unavailable) because of the increased availability of historical records of species occurrence (Elith and Leathwick, 2007; Frey, 2009; Newbold, 2010), recent adaptations of software that use only presence data to model habitat (for example, MaxEnt; Phillips and others, 2006), and studies using different methods of generating pseudo-absence that are used in more traditional modeling frameworks (Engler and others, 2004). Although models using presence-only observation records are generally thought to be less accurate in defining species-environment relationships (Guisan and Zimmermann, 2000; Austin, 2002), new methods can be very accurate at discriminating habitat from non-habitat across many spatial scales (Elith and Graham, 2009). Our objectives were to show the geographic distributions of habitat for a broad taxonomic range of species and for species-environment relationships. We used two methods for deriving presence-only SDMs, and averaged them for each species to derive predictions of habitat suitability across our study area. This report provides the methods and results for the habitat models developed as part of a scientific response to management needs for evaluating areas where species and their potential habitats overlap in context of genetic diversity and renewable energy development throughout the Mojave Desert (Vandergast and others, 2013).

\section{Study Area}

Our study area included the Mojave Desert (as defined by the U.S. Environmental Protection Agency (EPA) Mojave Basin and Range Level III Ecoregion [Commission for Environmental Cooperation Working Group, 1997]) and a $10 \mathrm{~km}$ buffer area around its periphery. The total area, $150,000 \mathrm{~km}^{2}$, includes elevations ranging from $146 \mathrm{~m}$ below sea level (Death Valley, Calif.) to more than 3,633 $\mathrm{m}$ above sea level (Mount Charleston, Nev.), and is characterized by broad valleys separated by rugged mountain ranges and alluvial fan complexes. Precipitation ranges from 100 to $350 \mathrm{~mm} / \mathrm{yr}$ and shows a strong longitudinal gradient with most precipitation in the Western Mojave Desert occurring in the winter, and most precipitation in the eastern and southern parts occurring in the late summer and winter (Turner, 1982). Summer precipitation, however, is highly variable and normally does not exceed winter precipitation. Extreme variation in air temperature is evident throughout the year with observed temperatures well over $54{ }^{\circ} \mathrm{C}$ in summer months and below $0{ }^{\circ} \mathrm{C}$ in winter months. Vegetation communities vary widely from barren salt flats and playas at the lowest elevations, through a variety of shrublands, chaparral, woodlands, forests, and a fractional amount of alpine habitat on the highest peaks (Brown, 1982; Sawyer and others, 2009).

\section{Study Species}

The 15 species covered in this report are: Anaxyrus punctatus (Red-spotted Toad), Chaetodipus penicillatus (Desert Pocket Mouse), Chionactis occipitalis (Shovel-nosed Snake), Crotaphytus bicinctores (Great Basin Collared Lizard), Crotaphytus collaris (Eastern Collared Lizard), Dipsosaurus dorsalis (Desert Iguana), Homalonychus selenopoides and Homalonychus theologus (Homalonychus spiders), Lichanura trivirgata (Rosy Boa), Perognathus longimembris (Little Pocket Mouse), Plestiodon gilberti (Gilbert's Skink), Sceloporus magister (Desert Spiny Lizard), Thomomys bottae (Botta's Pocket Gopher), Uma scoparia (Mojave Fringe-toed Lizard), and Xantusia vigilis (Desert 
Night Lizard). Because of the recent reorganization of the Crotaphytus genus, we assumed that many of the observation records for $C$. collaris were incorrectly classified (many $C$. collaris are now $C$. bicinctores). However, we assumed that in terms of habitat, few, if any, differences would be observed between the species within our study area. We therefore combined the two species into a single taxon for modeling. We also combined the two species of Homalonychus spiders into a single taxon to increase sample size, thus reducing the 15 species to 13 taxa for which we modeled habitat (table 1). In general, these 13 taxa represented small, ground dwelling animals, which may be impacted by renewable energy development at a population scale (for example, potential loss of populations or loss of connectivity among populations).

Table 1. Species for which habitat models were derived, the number of observation records used, the Area Under the receiver operator characteristic Curve (AUC), the Boyce Index (BI), and the resulting amount of suitable habitat predicted from the averaged model for each species.

\begin{tabular}{lcccc}
\hline \multicolumn{1}{c}{$\begin{array}{c}\text { Species } \\
\text { (abbreviation) }\end{array}$} & $\begin{array}{c}\text { Occurrence in } \\
\text { model }\end{array}$ & AUC & BI & $\begin{array}{c}\text { Suitable } \\
\text { habitat } \\
\text { (square kilometers) }\end{array}$ \\
\hline Anaxyrus punctatus (ANPU) & 150 & 0.83 & 0.89 & 87,510 \\
Chaetodipus penicillatus (CHPE) & 99 & 0.87 & 0.22 & 53,988 \\
Chionactis occipitalis (CHOC) & 231 & 0.79 & 0.64 & 85,397 \\
Crotaphytus bicinctores/collaris & 88 & 0.77 & 0.58 & 100,293 \\
(CRBI/CRCO) & 343 & 0.82 & 0.59 & 95,914 \\
Dipsosaurus dorsalis (DIDO) & 20 & 0.82 & 0.21 & 62,058 \\
Homalonychus selenopoides/theologus & 75 & 0.91 & 0.87 & 59,521 \\
(HOTH/HOSE) & 302 & 0.78 & 0.75 & 98,515 \\
Lichanura trivirgata (LITR) & 83 & 0.86 & 0.59 & 60,983 \\
Perognathus longimembris (PELO) & 472 & 0.72 & 0.33 & 111,731 \\
Plestidon gilberti (PLGI) & 186 & 0.83 & 0.51 & 104,675 \\
Sceloporus magister (SCMA) & 78 & 0.90 & 0.54 & 30,127 \\
Thomomys bottae (THBO) & 332 & 0.78 & 0.05 & 106,994 \\
Uma scoparia (UMSC) & & & & \\
Xantusia vigilis (XAVI) & & & \\
\hline
\end{tabular}




\section{Habitat Suitability Modeling}

We compiled observation records from online public databases for museum collections including VertNet (http://vertnet.org/index.php), HerpNET (http://www.herpnet.org), and MaNIS (http://manisnet.org), as well as other sources (including the California Natural Diversity Database, Joshua Tree National Park, Edwards Air Force Base, the Conservation Biology Institute, internal U.S. Geological Survey [USGS] databases, and other biologists). Because the taxonomy for many of our species was recently revised, we used both historical and current scientific names during searches. Duplicate records and those lacking sufficient locality information (that is those with no site name or GPS coordinates, or estimated precision error of greater than $1.5 \mathrm{~km}$ ) were removed. For each species, we developed conceptual models of habitat needs to identify the environmental covariates thought to influence their geographic distribution. We considered a total of 20 environmental covariates (table 2), which were derived prior to developing habitat models. Prior to creating each of the layers, a spatial mask was used to eliminate impermeable surfaces, such as urban areas and extensive roadways, as well as reservoirs, lakes, and other major water bodies, as all of our species were terrestrial obligates. This mask was derived from the National Land Change Database (NLCD) 2006 Percent Developed Imperviousness layer, downloaded from the Multi-Resolution Land Characteristics Consortium (Fry and others, 2011) and the National Hydrography Dataset (at a 1:24,000 scale; Simley and Carswell, 2009). Models were conducted using a common $1 \times 1 \mathrm{~km}$ resolution raster grid. Grid cells with more than 20 percent of their surface area covered by at least 20 percent imperviousness were categorized as urban. 
Table 2. Environmental covariates used in developing habitat suitability models (mean, standard deviation, minimum and maximum for study area).

\begin{tabular}{|c|c|c|c|c|c|}
\hline $\begin{array}{l}\text { Environmental } \\
\text { covariate } \\
\text { layer }\end{array}$ & Description & Mean & $\begin{array}{l}\text { Standard } \\
\text { deviation }\end{array}$ & Minimum & Maximum \\
\hline $\begin{array}{l}\text { alluvial fan } \\
\text { proximity }\end{array}$ & $\begin{array}{l}\text { Alluvial fans were defined as areas with less than } 10 \text { degrees slope and topographic position less than } 11.5 \text { at } \\
\text { a } 30 \mathrm{~m} \text { spatial resolution. We used a fine scale filter to remove areas that were comprised of three or fewer } 30 \\
\text { m cells, and calculated Euclidean distance to any } 30 \mathrm{~m} \text { cell defined as an alluvial fan. The value given to each } \\
1 \mathrm{~km} \text { cell was the mean of all Euclidean distances for the } 30 \mathrm{~m} \text { cells contained within it. }\end{array}$ & $4,717.7$ & $5,098.2$ & 0.0 & $39,221.6$ \\
\hline cliffs & $\begin{array}{l}\text { Cliffs were defined at a } 30 \mathrm{~m} \text { spatial scale as areas with slope greater than } 25 \text { degrees. The value given to each } \\
1 \mathrm{~km} \text { cell was the percent of } 30 \mathrm{~m} \text { cells contained within it defined as cliffs. Prior to use in habitat models, this } \\
\text { layer was normalized using an arcsine-square root transformation. }\end{array}$ & 0.07 & 0.17 & 0.0 & 1.0 \\
\hline elevation & $\begin{array}{l}\text { Elevation in meters above sea level, derived from a } 30 \mathrm{~m} \text { National Elevation Dataset Digital Elevation Model } \\
\text { (USGS). The value given to each } 1 \mathrm{~km} \text { cell is the average of all } 30 \mathrm{~m} \text { cells within it. }\end{array}$ & $1,012.51$ & 473.44 & -84.8 & $4,061.8$ \\
\hline mountain bases & $\begin{array}{l}\text { Mountain bases were defined as } 30 \mathrm{~m} \text { cells that }(1) \text { had less than } 10 \text { degrees slope, }(2) \text { had a profile curvature } \\
\text { value between }-6.0 \times 10^{-4} \text { and }-1.8 \times 10^{-4} \text {, and }(3) \text { surface roughness between } 0.7 \times 10^{-8} \text { and } 5.8 \times 10^{-8} \text {. Profile } \\
\text { curvature is the curvature in the direction of steepest slope and is expressed as meters }{ }^{-1} \text { (a curvature of } 0.05 \\
\text { corresponds to a radius of curvature of } 20 \mathrm{~m}) \text {. Negative values are associated with concave terrain features, } \\
\text { such as canyons and mountain bases. Profile curvature and surface roughness thresholds were derived as the } \\
\text { mean } \pm 1 \text { standard deviation of values at } 50 \text { locations defined a priori as mountain bases. The value given to } \\
\text { each } 1 \mathrm{~km} \text { cell is the percent of } 30 \mathrm{~m} \text { cells contained within it that were defined as mountain bases. Prior to } \\
\text { use in habitat models, this layer was normalized using an arcsine-square root transformation. }\end{array}$ & 0.05 & 0.08 & 0.0 & 0.9 \\
\hline rocky surfaces & $\begin{array}{l}\text { Rocky surfaces were identified from summer night time Land Surface Temperature (LST) and elevation at a } \\
\text { spatial scale of } 250 \mathrm{~m} \text {. MODIS MOD11 A1 nighttime LST 8-day global data were downscaled to } 250 \mathrm{~m} \text { and } \\
\text { regressed against elevation to remove the elevation trend. Residuals were categorized into "rock" and "non- } \\
\text { rock" categories using } 100 \text { known sample locations in Nevada and California. The MODIS MOD11A1 Land } \\
\text { Surface Temperature (LST) 8-day Global } 1 \mathrm{~km} \text { data were averaged for } 6 \text { periods during the summers of } 2001 \\
-2010 \text { nighttime LST. The dates used to define the summer periods were July } 12 \text {, July } 20 \text {, July } 28 \text {, August } 5 \text {, } \\
\text { August } 13 \text {, and August } 21 \text {. The averaged LST product was downscaled by regressing using a Generalized } \\
\text { Additive Model (GAM) against seven environmental predictor covariates, all of which were derived at a } 250 \\
\mathrm{~m} \text { spatial scale. These covariates included: solar beam irradiance (W/km2), average of the black sky albedo } \\
\text { for the same time periods as the LST, maximum horizon level, elevation, aspect, slope and an average of the } \\
\text { Normalized Difference Vegetation Index (NDVI) for the same time periods. The value given for each } 1 \mathrm{~km} \\
\text { cell is the percentage covered by } 250 \mathrm{~m} \text { cells identified as rock. Prior to use in habitat models, this layer was } \\
\text { transformed using the arcsine-square root transformation. }\end{array}$ & 0.11 & 0.23 & 0.0 & 1.0 \\
\hline
\end{tabular}



spatial scale of $250 \mathrm{~m}$. MODIS MOD11A1 nighttime LST 8-day global data were downscaled to $250 \mathrm{~m}$ and regressed against elevation to remove the elevation trend. Residuals were categorized into sand and non-sand categories using 100 known sample locations in Nevada and California. The MODIS MOD11A1 Land Surface Temperature (LST) 8-day Global $1 \mathrm{~km}$ data were averaged for six periods during the summers of 2001-2010 night LST. The dates used to define the summer periods were July 12, July 20, July 28, August 5, August 13, and August 21. The averaged LST product was downscaled by regressing using a Generalized Additive Model (GAM) against seven environmental predictor covariates, all of which were derived at a 250 $\mathrm{m}$ spatial scale. These covariates included: solar beam irradiance $\left(\mathrm{W} / \mathrm{km}^{2}\right)$, average of the black sky albedo for the same time periods as the LST, maximum horizon level, elevation, aspect, slope and an average of the Normalized Difference Vegetation Index (NDVI) for the same time periods. The predictions from this GAM were mapped at a $250 \mathrm{~m}$ spatial scale. We used elevation in a separate regression model against the predictions from the previous GAM model to remove the trend of elevation on surface temperature. The residuals from this regression were mapped, and provided an estimate of the deviation in night LST from what would be expected by elevation alone. This deviation captures much of the variability in surface temperature due to substrate type and texture. We used known sample locations to derive a threshold in the mapped residuals to assign each $250 \mathrm{~m}$ cell as either "sand" or "not-sand". The value given for each $1 \mathrm{~km}$ cell is the percentage covered by $250 \mathrm{~m}$ cells labeled as sand. Prior to use in habitat models, this layer was transformed using the arcsine-square root transformation.

seasonal greenness timing

Seasonal greenness timing represents the period of the year when vegetation greenness reaches its maximum, and was defined as the date of the maximum value of the Normalized Difference Vegetation Index (MODIS MOD13Q1 Global $250 \mathrm{~m}$ 16-day index of NDVI; vegetation greenness). Dates ranged from early spring to late summer, and the average of 2001 to 2010 for the dates March 6, March 22, April 7, April 23, May 9, May 25 , June 10 , June 26 , and July 12 were used.

seasonal greenness ratio

Seasonal greenness contrasts spring and winter (growing and senescent) vegetation greenness from MODIS MOD13Q1 16-day L3 Global 250 m NDVI data. The yearly spring (average of March 22, April 7, April 23, and May 9) and winter (average of December 3, December 19, January 1, and January 17) NDVI were contrasted using the formula: (SpringNDVI-WinterNDVI) $/(1+($ SpringNDVI+WinterNDVI)). The value given to each $1 \mathrm{~km}$ cell was the average of 2001 to 2010 .

seasonal thermal Seasonal thermal inertia was defined as the difference between summer and winter daytime MODIS change MOD11A1 Land Surface Temperature (LST) 8-day Global $1 \mathrm{~km}$ for six periods in the summer and six periods in the winter during 2001-2010. The summer (July 12, July 20, July 28, August 5, August 13, and August 21) and winter (December 11, December 19, December 27, January 1, January 9, and January 17h) periods were contrasted to identify areas with greater seasonal fluctuation in LST. The value for each $1 \mathrm{~km}$ cell is the average of the yearly differences $\left({ }^{\circ} \mathrm{C}\right)$ between the summer and winter daytime LST for 2001 to 2010. 


\section{Environmenta}

covariate

layer

soil adjusted

greenness

Soil adjusted greenness is an index of vegetation greenness that has been modified to reduce the influence of soil color on vegetation greenness (Qi and others, 1994), and was derived from Landsat5 Thematic Mapper imagery at a $30 \mathrm{~m}$ spatial scale for fall (September-November) in 2010 for the NIR and red Landsat5 bands. The mSAVI was computed for fall (September-November) in 2010. The value for any given $1 \mathrm{~km}$ cell is the average of all mSAVI values for all of the overlapping $30 \mathrm{~m}$ cells. The value given to each $1 \mathrm{~km}$ cell is the average of all $30 \mathrm{~m}$ cells contained within it

soil water stress Soil water stress is an index of the in situ top layer soil moisture, and was derived as the mean of the Shortwave and Infrared Water Stress Index (SIWSI; Fensholt and Sandholt, 2003) for 46 dates (January 1, January 9, January 17, January 25, February 2, February 10, February 18, February 26, March 6, March 14 March 22, March 30, April 7, April 15, April 23, May 1, May 9, May 17, May 25, June 2, June 10, June 18, June 26, July 4, July 12, July 20 July 28, August 5, August 13, August 21, August 29, September 6, September 14, September 22, September 30, October 8, October 16, October 24, November 1, November 9 , November 17, November 25, December 3, December 11, December 19, and December 27) in each year from 2001 to 2010 using the MODIS MOD09A1 surface reflectance 8-day Global data product. Prior to calculating the SIWSI, each of the MODIS MOD09A1 surface reflectance 8-day Global $500 \mathrm{~m}$ data products was aggregated to a spatial scale of $1 \mathrm{~km}$. The value for each $1 \mathrm{~km}$ cell in this layer is the mean across all years and dates.

soil water stress coefficient of

variation

water stress coefficient of variation covariate layer represents the coefficient of variation in the Shortwave and Infrared Water Stress Index (SIWSI) for 46 dates in each year from 2001 to 2010. The value for each $1 \mathrm{~km}$ cell in this layer is the coefficient of variation across all years and dates.

summer surface temperature

surface texture Summer surface temperature was derived from the MODIS MOD11A1 daytime Land Surface Temperature (LST) 8-day Global $1 \mathrm{~km}$ data product for summer (July 12, July 20, July 28, August 5, August 13, and August 21) in 2001 to 2010 . The value for each $1 \mathrm{~km}$ cell is the average of all dates and years.

Surface texture was modeled by taking the difference between the mean daytime and nighttime surface temperatures for 6 periods in the summer during the years of 2001-2010. Surface temperatures were obtained from MODIS MOD11A1 Land Surface Temperature 8-day Global $1 \mathrm{~km}$ data products for daytime and nighttime during the summer dates of July 12, July 20, July 28, August 5, August 13, and August 21. The value for each $1 \mathrm{~km}$ cell is the average of the yearly differences between the daytime and nighttime temperatures $\left({ }^{\circ} \mathrm{C} * 100\right)$ for the dates listed above.

topographic position

We used methods described in Morre and others (1991; terrain wetness index) to calculate topographic position at a $90 \mathrm{~m}$ spatial scale using the area of the hillslope per unit contour length that drains into a given area, and the local surface topographic slope, which is estimated as ( $\Delta$ vertical elevation) / ( $\Delta$ horizontal distance) from a $30 \mathrm{~m}$ National Elevation Dataset Digital Elevation Model (USGS). The value for each $1 \mathrm{~km}$ cell is the average of the $90 \mathrm{~m}$ cells contained within it.

\section{Mean}

Standard deviation

Minimum Maximum

0.07

0.11

$-0.8$

0.8 


\begin{tabular}{|c|c|c|c|c|c|}
\hline $\begin{array}{l}\text { Environmental } \\
\text { covariate } \\
\text { layer }\end{array}$ & Description & Mean & $\begin{array}{l}\text { Standard } \\
\text { deviation }\end{array}$ & Minimum & Maximum \\
\hline $\begin{array}{l}\text { vegetation } \\
\text { greenness }\end{array}$ & $\begin{array}{l}\text { Vegetation greenness was defined as the average of the Normalized Difference Vegetation Index (NDVI) } \\
\text { across } 23 \text { dates (January 1, January 17, February 2, February 18, March 6, March 22, April 7, April 23, May } \\
9 \text {, May 25, June 10, June 26, July 12, July 28, August 13, August 29, September 14, September 30, October } \\
16 \text {, November 1, November 17, December 3, and December 19) in each year from } 2001 \text { to 2010, obtained } \\
\text { from the MODIS MOD13Q1 16-day L3 Global NDVI data product. The value for each } 1 \mathrm{~km} \text { cell is the mean } \\
\text { all dates and years. }\end{array}$ & $1,761.06$ & 810.44 & -738.2 & $7,575.6$ \\
\hline $\begin{array}{l}\text { vegetation } \\
\text { greenness } \\
\text { coefficient of } \\
\text { variation }\end{array}$ & $\begin{array}{l}\text { Vegetation greenness coefficient of variation is the coefficient of variation in the Normalized Difference } \\
\text { Vegetation Index (NDVI) across } 23 \text { dates (January 1, January 17, February 2, February } 18 \text {, March } 6 \text {, March } \\
22 \text {, April 7, April 23, May 9, May 25, June 10, June 26, July 12, July 28, August 13, August } 29 \text {, September } \\
\text { 14, September 30, October 16, November 1, November 17, December 3, and December 19) in each year from } \\
2001 \text { to } 2010 \text {, obtained from the MODIS MOD13Q1 16-day L3 Global NDVI data product. The value for } \\
\text { each } 1 \mathrm{~km} \text { cell is the mean all years. }\end{array}$ & 0.21 & 0.18 & 0.0 & 10.0 \\
\hline washes & $\begin{array}{l}\text { The density of washes was estimated by identifying "wash like" features at } 30 \mathrm{~m} \text { spatial scale, and calculating } \\
\text { the density }\left(\mathrm{m} / \mathrm{km}^{2}\right) \text { in each } 1 \mathrm{~km} \text { cell. Wash-like features were delineated using methods described in } \\
\text { Montgomery and Foufoula-Georgiou (1993) in areas defined as alluvial fans. }\end{array}$ & 597.08 & 863.21 & 0.0 & $5,575.0$ \\
\hline $\begin{array}{l}\text { winter } \\
\text { precipitation }\end{array}$ & $\begin{array}{l}\text { Yearly average of the cumulative winter season precipitation, in 100th of an inch, for a } 30 \text {-year period. We } \\
\text { derived winter precipitation from average monthly winter (November-April) precipitation climatic normals } \\
\text { calculated from conditions between } 1961 \text { and } 1990 \text {. An inverse distance weighted interpolation method for } \\
\text { climate covariates was used from Nalder and Wien (1998) and was conducted at a spatial scale of } 90 \mathrm{~m} \text {. The } \\
\text { value for each } 1 \mathrm{~km} \text { cell is the average of all overlapping } 90 \mathrm{~m} \text { cells. }\end{array}$ & 198.11 & 92.63 & 20.4 & 867.9 \\
\hline
\end{tabular}


Habitat models were created using Generalized Additive Models (GAM) with the package mgcv (version 1.7-6; Wood, 2011) in R (version 2.13.1; R Core Development Team, 2011) and maximum entropy (MaxEnt - version 3.3.3e, Phillips and others, 2006) methods from presence-only observation records at a spatial resolution of $1 \mathrm{~km}$. Considerable differences exist between the GAM and MaxEnt models, each having its own advantages. The GAM modeling framework was chosen because of its ease of interpretation, and because GAM models can be evaluated by many well-understood metrics (such as generalized cross validation, AIC, BIC, and explained deviance; Wood, 2006), while MaxEnt models use machine learning methods and cannot easily be compared with information criteria, such as AIC or BIC. However, MaxEnt models have been shown to use correlated input data better than other methods, and can incorporate very complex non-linear response functions (Elith and others, 2011). A substantial difference between MaxEnt and GAM models is that MaxEnt models use large random selections (that is, 10,000) of the study area to characterize the range of background values for each of the covariates, while GAM models require the use of true or pseudo-absences (Mateo and others, 2010; Lobo and Tognelli, 2011; Stokland and others, 2011). The use of large random samples of background values enables the MaxEnt software to compare the distributions of environmental covariates for the entire study area to distributions of the same covariates at locations where the species of interest is present (Elith and others, 2011), and allows it to estimate the probability of an occurrence data value at a specific location given the environmental covariates. In contrast, the GAM modeling framework is often used as a Resource Selection Function (RSF), wherein the use of true absence data are required to capitalize on places where the organism of interest does not occur. We used the GAM modeling framework to conduct a population level assessment assessing used (presences) and unused areas (absences), but instead of using true absences, we derived an equal number of pseudo-absences (Hirzel and others, 2002; Phillips and others, 2009; Stokland and others, 2011) that were selected at random from all locations where a species was not observed. The binomial GAM models were created using Restricted Maximum Likelihood (REML) for each species, and we considered all habitat models that contained up to five of the environmental covariates from the suite of covariates identified in the conceptual models for each species. Interaction terms or covariates that were highly correlated were not included. We kept models simple to maximize their interpretability, to improve their generalization across the study area, and to minimize over-fitting (Collingham and others, 2000; Rushton and others, 2004). We also reduced over-fitting by using the average of 20 replications of sampling without replacement of the observation records for each model. For many species, the observation records were spatially aggregated, and often confined to smaller portions of the study area, which is often the case for museum specimens (Mateo and others, 2010; Newbold, 2010). To avoid model bias caused by aggregated data, we used a geographically weighted resampling method for each of the 20 replications of sampling without replacement, and used a gamma control parameter of 1.3 (which is used for additional smoothing) (Wood, 2006) for all GAM models. The resampling method used a grid (10 km cell size) placed across the study area to identify areas where spatially aggregated observations occurred. In these cells, random selections of no more than three occurrences were used in each replication. 
To evaluate model performance, a random sample of 20 percent of the observation records and an equally sized random sample of the pseudo-absences were withheld each iteration. This dataset was used to derive the Area Under the receiver operating characteristic Curve (AUC) (Fielding and Bell, 1997; Cumming, 2000) and Boyce Index (BI) (Boyce and others, 2002) test statistics. In addition, AIC (Anderson and others, 2000; Burnham and Anderson, 2002) and BIC (Posada and Buckley, 2004) test statistics for the 20 replications of each model were calculated, and the number of replications where a given model had a $\triangle \mathrm{AIC}$ or $\triangle \mathrm{BIC}$ of 0 were summed to identify the models that consistently had high AIC and BIC performance. We selected a candidate suite of approximately 9 models for each species by assessing the relative performance using the AIC, BIC, explained deviance (Wood, 2006), BI, AUC, and the standard deviation in BI and AUC across the 20 replicates. We selected models that consistently had the lowest $\mathrm{AIC}$ or BIC, had high discrimination ability (AUC), high deviation from randomness (BI), high explained-deviance, and low variance in BI and AUC statistics. Models were excluded if the environmental covariates showed unrealistic response curves or predictions; for example, the threshold feature used by MaxEnt models can yield rapidly reversing responses that are typically uncharacteristic of how animals interact with environmental gradients (Shcheglovitova and Anderson, 2013; Syfert and others, 2013).

The selected GAM models for each species (approximately 9) also were derived as MaxEnt models, thus creating as many as 18 possible models for each species. MaxEnt models were run with 20 bootstrap replications, while randomly withholding 20 percent of the observation records for each replication. The performance and general plausibility of each of the MaxEnt models were evaluated using several methods, including AUC, BI, test gain (Phillips and Dudik, 2008), marginal and solitary response curves (Phillips and Dudik, 2008), as well as the environmental covariate contributions (Phillips and others, 2006). Marginal response curves illustrate how environmental covariates affect the predicted habitat suitability score in relation to the other predictors, and are used to assess speciesenvironment relationships for the environmental covariates (Phillips and Dudik, 2008). As with the evaluation of GAM models, MaxEnt models with unrealistic marginal and solitary response curves were not selected for review. The percent contribution was measured as the relative increase in training gain across all bootstrapped replications (Phillips and others, 2006), and provided a general measure of how important a given environmental covariate was in terms of the model fitting process.

Finally, we reviewed each of the possible 18 models for each of the species by examining maps of the predicted habitat and response curves, and evaluating them in context of our knowledge of the species. We ranked the selected models for their overall accuracy and goodness-of-fit, and chose a subset of models from the 18 and averaged their outputs to create a final habitat suitability map for each species. For example, we only chose 14 of the 18 models for $D$. dorsalis to include in the final averaged habitat suitability map. One minor exception to this procedure was for A. punctatus, wherein we considered each of the selected models to be too restrictive in their range, and thus used the maximum of all models to create the final map. For all species, we rescaled each model to the range [0 1] prior to averaging to ensure that all models had equal weight in the final map using a linear data transformation. 
Selected areas were spotchecked to ensure that the map predictions were not unrealistic, especially in areas where few data were available, but where we (or our collaborators) had local knowledge. We also assessed the performance of the averaged model with the AUC statistic and BI plots derived from the entire set of observation records for each species. For AUC, we created a test set of absence points that was a random sample of background points with a size equal to the number of observation records, thus keeping the prevalence ratio at 1:1. The BI plots were evaluated to provide additional information on model robustness and deviation from randomness. We also assessed a measure of model agreement by creating a map of the standard error $(\sigma / N)$ in habitat suitability scores among the selected models for each species. Although not a measure of model error, these agreement maps provide a general measure of model uncertainty across the landscape and show areas where the selected models agree (or disagree) with respect to habitat suitability. When compared with the final averaged habitat suitability maps, the agreement maps highlight relationships that indicate whether our selected models agree more on high or low suitability habitat. We assess the similarity in habitat suitability among the species by taking the Pearson's correlation coefficient for positive association of habitat suitability across the entire study area for each pair of taxa. Correlation coefficients and their significance are reported, and correlations greater than 0.5 are highlighted.

The relationship between habitat suitability and environmental covariates should ideally be explained by known ecological relationships between the organism of interest and its environment (Guisan and Zimmerman, 2000; Austin, 2002; Guisan and Thuiller, 2005), and thus we relate each of the environmental covariates back to literature where possible, and propose relevant explanations for most of the environmental covariates in our averaged habitat suitability maps. We also derive relative contributions for each of the covariates to assess the explanatory power of each predictor covariate for each species, and compare the strength of each of the covariates among species. The relative contributions for each covariate were derived by taking the average percent contribution (see Elith and others, 2011) across all MaxEnt models for a given species. Separately, we derive an index of average importance, which is the average of all relative contributions for each covariate layer. This index of average importance provides a measure with which to rank each of the environmental covariates. We also derive averaged response curves by holding each covariate at their mean of the study area, and calculating their linear contributions (Wood, 2006) from a saturated GAM model with all covariates represented in the selected models. These response curves illustrate the relationship between a given covariate and a species' habitat suitability, and are shown with histograms of the covariate across the study area for comparison. Although our primary objective was to derive predictive models of habitat suitability, appropriate knowledge of habitat preference and ecological context can inform the model building process to reduce overfitting on spurious environmental covariates and can improve the interpretability of SDMs (Austin, 2002; Guisan and Thuiller, 2005).

Finally, we reclassified the averaged habitat suitability map into a binary representation of suitable habitat using the fifth quantile of habitat suitability scores from the observation records. This definition of suitable habitat assumes that not all observation records are in areas with suitable habitat, but rather, a small proportion (that is, 5 percent) may actually be located in unsuitable habitat. This method results in a smaller proportion of the study area being classified as suitable habitat than the more commonly used method of selecting the minimum habitat score from the observation records (Liu and others, 2005). For each species, we report the total square kilometers of suitable habitat under this definition, and the habitat suitability score used for this threshold. 


\section{Results}

Our habitat models used between 20 (H. selenopoides \& H. theologus spiders) and 472 ( $S$. magister; table 1) observation records and had AUC scores that ranged from 0.72 (S. magister) to 0.91 (L. trivirgata; table 1). The mean AUC score among all species was 0.82, suggesting high model performance overall (Elith and others, 2006). The average of the total area of suitable habitat for the 13 taxonomic groups was $81,362 \mathrm{~km}^{2}\left(\sigma=24,307 \mathrm{~km}^{2}\right)$, and ranged from $30,127 \mathrm{~km}^{2}$ for U. scoparia to $111,731 \mathrm{~km}^{2}$ for $S$. magister. Habitat suitability models for C. penicillatus, C. occipitalis, D. dorsalis, and $U$. scoparia were positively correlated with one another ( $>0.5$; table 3$)$. Similarly, L. trivirgata, $S$. magister, $T$. bottae, $P$. longimembris, and $X$. vigilis also were correlated with one another $(\mathrm{r}>0.5$; table 3). $P$. gilberti and $D$. dorsalis were negatively correlated $(\mathrm{r}=-0.64, \mathrm{~N}=1,000, \mathrm{p}<0.001)$, indicating a geographic separation for these two throughout the study area. The remaining species (A. punctatus, and the single taxonomic group for the two species of Crotaphytus) were not strongly correlated with any others.

Species response curves for each of the environmental covariates varied substantially among the species, but between the two modelling frameworks (GAM and MaxEnt), remained mostly similar. The MaxEnt models often had more complex response curves with multiple thresholds and several minima and maxima, while the GAM response curves were (by design) more generalized, and were limited to four broad patterns: (1) increasing or decreasing, (2) single minima or maxima, (3) single threshold, and (4) double threshold (fig. 1). Species with correlated habitat maps tended to have similar species response curves, and environmental covariates that were present in multiple models for the same species were generally similar in shape.

Agreement maps $(\sigma / \mathrm{N})$ for each species showed a wide range of patterns between model uncertainty and habitat suitability. The geographic areas showing the least agreement among models for each of the species tended to be those with high elevations or those in playas. This is likely due to several of the vegetation layers, which often had extreme values at high elevations, and on playas during periods when they were wet. None of the species included here are reported to occur on playas, and therefore we did not attempt to rectify these differences. Only two models were selected for $C$.

penicillatus and $P$. gilberti, thus making the standard error among the selected models incalculable. We also did not calculate a standard error map for the Homalonychus spiders because we only used a single MaxEnt model to represent habitat.

\section{Environmental Covariates Summary}

Of the 20 environmental covariate layers considered in this study, three [soil water stress coefficient of variation (CV), vegetation greenness, and summer surface temperature] were not included in any of the selected models for the species covered here. The remaining 17 covariate layers (alluvial fan proximity, cliffs, elevation, mountain bases, rocky surfaces, sandy surfaces, seasonal greenness timing, seasonal greenness ratio, seasonal thermal change, slope, soil adjusted greenness, soil water stress, surface texture, topographic position, vegetation greenness $C V$, washes, winter precipitation) were included in at least one model, although relative contributions (table 4) and response curves varied considerably. Each of the environmental covariates are discussed in order of relative contribution. Methods used to derive each of the environmental covariates are given briefly, and in more detail in table 2 . 
Table 3. Correlation coefficients for positive association (lower left) and significance (p-values; upper right) among habitat suitability models.

[Correlation coefficients greater than 0.5 are shown in two shades of gray, representing two associated groups. Two groups of species had similar habitat suitability distributions: Dipsosaurus dorsalis, Chionactis occipitalis, Chaetodipus penicillatus, and Uma scoparia (light gray); Sceloporus magister, Lichanura trivirgata, Thomomys bottae, Perognathus longimembris, and Xantusia vigilis (dark gray). Species abbreviations are shown in table 1]

\begin{tabular}{|c|c|c|c|c|c|c|c|c|c|c|c|c|c|}
\hline & ANPU & CHOC & CHPE & CRBI/CRCO & DIDO & HOTH/HOSE & LITR & PELO & PLGI & SCMA & ТНВО & UMSC & XAVI \\
\hline ANPU & & 1.000 & 0.001 & 0.000 & 0.853 & 0.000 & 0.000 & 1.000 & 0.001 & 0.988 & 1.000 & 1.000 & 1.000 \\
\hline СHOC & -0.47 & & 0.000 & 1.000 & 0.000 & 0.107 & 0.035 & 0.000 & 1.000 & 0.574 & 0.000 & 0.000 & 0.000 \\
\hline CHPE & 0.10 & 0.41 & & 1.000 & 0.000 & 0.000 & 0.000 & 0.000 & 1.000 & 0.994 & 0.000 & 0.000 & 1.000 \\
\hline CRBI/CRCO & 0.21 & -0.51 & -0.27 & & 1.000 & 0.000 & 0.149 & 1.000 & 0.000 & 0.000 & 1.000 & 1.000 & 0.073 \\
\hline DIDO & -0.03 & & & -0.38 & & 0.000 & 1.000 & 0.896 & 1.000 & 1.000 & 0.999 & 0.000 & 1.000 \\
\hline HOTH/HOSE & 0.27 & 0.04 & 0.21 & 0.29 & 0.32 & & 0.000 & 1.000 & 1.000 & 0.000 & 1.000 & 0.000 & 0.000 \\
\hline LITR & 0.19 & 0.06 & 0.20 & 0.03 & -0.13 & 0.25 & & 0.000 & 0.000 & 0.000 & 0.000 & 1.000 & 0.000 \\
\hline PELO & -0.41 & 0.38 & 0.11 & -0.24 & -0.04 & -0.11 & 0.19 & & 0.000 & 0.000 & 0.000 & 0.147 & 0.000 \\
\hline PLGI & 0.07 & -0.41 & -0.15 & 0.21 & -0.64 & -0.32 & 0.36 & 0.38 & & 0.000 & 0.000 & 1.000 & 0.006 \\
\hline SCMA & -0.07 & -0.01 & -0.08 & 0.21 & -0.27 & 0.33 & & 0.29 & 0.17 & & 0.000 & 1.000 & 0.000 \\
\hline ТНво & -0.37 & 0.27 & 0.12 & -0.26 & -0.10 & -0.31 & 0.18 & & 0.45 & 0.14 & & 0.368 & 0.000 \\
\hline UMSC & -0.16 & & & -0.22 & & 0.15 & -0.19 & 0.03 & -0.36 & -0.27 & 0.01 & & 1.000 \\
\hline XAVI & -0.32 & 0.25 & -0.29 & 0.05 & -0.26 & 0.12 & 0.30 & 0.47 & 0.13 & & 0.30 & -0.30 & \\
\hline
\end{tabular}



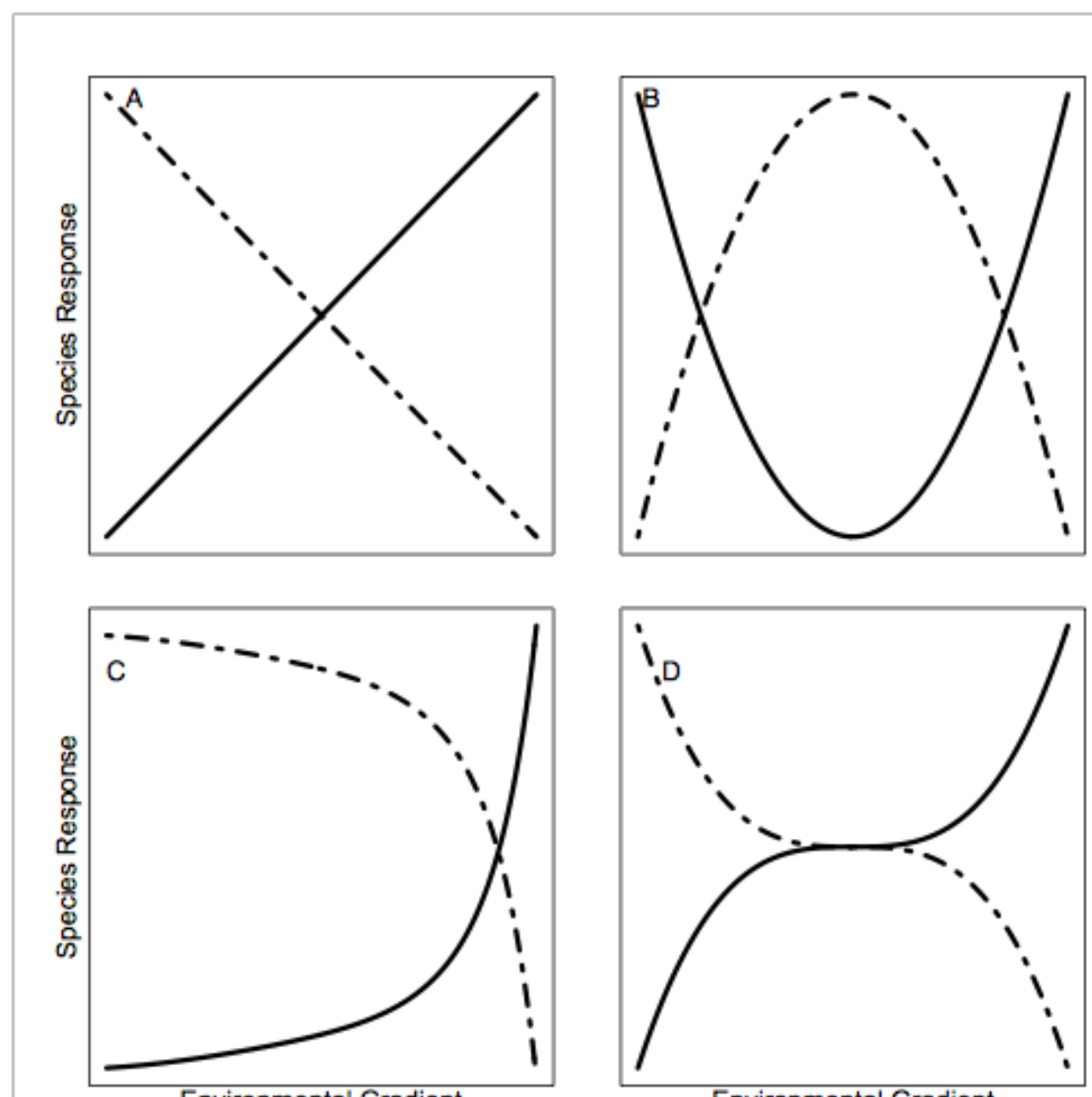

Environmental Gradient

Environmental Gradient

Figure 1. Representative species response curves across hypothetical environmental covariate gradients. Species response curves generally fell into one of the following broad patterns: $(A)$ increasing or decreasing, $(B)$ single minima or maxima, $(C)$ single thresholded, and (D) double thresholded. Positive (A, C and D; solid) and negative ( $A, C$, and $D$; dashed) responses were less common than unimodal with single minima (solid) or maxima (dashed). Species response curves represent the generalized relationship between an environmental covariate and species occurrence. 
Table 4. Relative contributions, prevalence, and average importance for environmental covariates included in habitat models.

[Relative contributions were derived by taking the average percent contribution across all MaxEnt models for a given species. The average of these relative contributions was used as the average importance for each species. Species abbreviations are shown in table 1. Prevalence represents the number of species models each covariate was included in which each covariate appeared]

\begin{tabular}{|c|c|c|c|c|c|c|c|c|c|}
\hline $\begin{array}{l}\text { Environmental } \\
\text { covariate } \\
\text { layer }\end{array}$ & ANPU & $\mathrm{CHOC}$ & CHPE & CRBI/CRCO & DIDO & HOTH/HOSE & LITR & Prevalence & $\begin{array}{c}\text { Average } \\
\text { importance }\end{array}$ \\
\hline elevation & 19 & 27 & 45 & 10 & 61 & 0 & 33 & 11 & 26.3 \\
\hline $\begin{array}{c}\text { winter } \\
\text { precipitation }\end{array}$ & 6 & 0 & 8 & 0 & 14 & 0 & 22 & 8 & 18.0 \\
\hline surface texture & 40 & 42 & 22 & 4 & 18 & 33 & 0 & 10 & 14.6 \\
\hline $\begin{array}{l}\text { topographic } \\
\text { position }\end{array}$ & 0 & 22 & 0 & 29 & 2 & 29 & 4 & 10 & 12.8 \\
\hline $\begin{array}{c}\text { seasonal } \\
\text { thermal } \\
\text { change }\end{array}$ & 0 & 0 & 23 & 0 & 2 & 0 & 22 & 8 & 6.3 \\
\hline $\begin{array}{l}\text { seasonal } \\
\text { greenness } \\
\text { timing }\end{array}$ & 0 & 6 & 0 & 12 & 2 & 23 & 3 & 9 & 4.6 \\
\hline slope & 0 & 0 & 0 & 35 & 0 & 0 & 1 & 5 & 4.5 \\
\hline $\begin{array}{l}\text { soil adjusted } \\
\text { greenness }\end{array}$ & 32 & 0 & 0 & 0 & 0 & 0 & 0 & 1 & 2.5 \\
\hline $\begin{array}{l}\text { soil water } \\
\text { stress }\end{array}$ & 3 & 2 & 0 & 5 & 0 & 0 & 0 & 8 & 2.4 \\
\hline sandy surfaces & 0 & 0 & 0 & 0 & 1 & 0 & 0 & 2 & 2.1 \\
\hline $\begin{array}{l}\text { mountain } \\
\text { bases }\end{array}$ & 0 & 0 & 2 & 1 & 0 & 0 & 5 & 7 & 2.1 \\
\hline washes & 0 & 0 & 0 & 0 & 0 & 15 & 0 & 8 & 1.7 \\
\hline $\begin{array}{l}\text { alluvial fan } \\
\text { proximity }\end{array}$ & 0 & 0 & 0 & 4 & 0 & 0 & 8 & 2 & 0.9 \\
\hline rocky surfaces & 0 & 0 & 0 & 0 & 0 & 0 & 0 & 1 & 0.4 \\
\hline $\begin{array}{l}\text { seasonal } \\
\text { greenness } \\
\text { ratio }\end{array}$ & 0 & 0 & 0 & 0 & 0 & 0 & 0 & 4 & 0.4 \\
\hline cliffs & 0 & 0 & 0 & 0 & 0 & 0 & 1 & 2 & 0.2 \\
\hline $\begin{array}{l}\text { vegetation } \\
\text { greenness } C V\end{array}$ & 0 & 1 & 0 & 0 & 0 & 0 & 0 & 1 & 0.1 \\
\hline
\end{tabular}




\begin{tabular}{|c|c|c|c|c|c|c|c|c|}
\hline Layer & PELO & PLGI & SCMA & THBO & UMSC & XAVI & Prevalence & $\begin{array}{c}\text { Average } \\
\text { importance }\end{array}$ \\
\hline elevation & 0 & 1 & 51 & 5 & 35 & 55 & 11 & 26.3 \\
\hline $\begin{array}{c}\text { winter } \\
\text { precipitation }\end{array}$ & 49 & 73 & 0 & 61 & 1 & 0 & 8 & 18.0 \\
\hline surface texture & 1 & 9 & 0 & 0 & 18 & 2 & 10 & 14.6 \\
\hline $\begin{array}{l}\text { topographic } \\
\text { position }\end{array}$ & 36 & 0 & 15 & 14 & 2 & 14 & 10 & 12.8 \\
\hline $\begin{array}{c}\text { seasonal thermal } \\
\text { change }\end{array}$ & 8 & 0 & 11 & 4 & 7 & 5 & 8 & 6.3 \\
\hline $\begin{array}{c}\text { seasonal } \\
\text { greenness timing }\end{array}$ & 2 & 0 & 4 & 7 & 0 & 1 & 9 & 4.6 \\
\hline slope & 0 & 0 & 0 & 8 & 3 & 11 & 5 & 4.5 \\
\hline $\begin{array}{l}\text { soil adjusted } \\
\text { greenness }\end{array}$ & 0 & 0 & 0 & 0 & 0 & 0 & 1 & 2.5 \\
\hline soil water stress & 1 & 5 & 2 & 0 & 6 & 7 & 8 & 2.4 \\
\hline sandy surfaces & 0 & 0 & 0 & 0 & 27 & 0 & 2 & 2.1 \\
\hline mountain bases & 1 & 10 & 6 & 0 & 0 & 3 & 7 & 2.1 \\
\hline washes & 1 & 0 & 4 & 0 & 0 & 1 & 8 & 1.7 \\
\hline $\begin{array}{l}\text { alluvial fan } \\
\text { proximity }\end{array}$ & 0 & 0 & 0 & 0 & 0 & 0 & 2 & 0.9 \\
\hline rocky surfaces & 0 & 0 & 6 & 0 & 0 & 0 & 1 & 0.4 \\
\hline $\begin{array}{l}\text { seasonal } \\
\text { greenness ratio }\end{array}$ & 2 & 0 & 0 & 2 & 1 & 1 & 4 & 0.4 \\
\hline cliffs & 0 & 2 & 0 & 0 & 0 & 0 & 2 & 0.2 \\
\hline $\begin{array}{c}\text { vegetation } \\
\text { greenness } C V\end{array}$ & 0 & 0 & 0 & 0 & 0 & 0 & 1 & 0.1 \\
\hline
\end{tabular}




\section{Elevation}

Elevation was included in habitat models for all but two of our study taxa, and had the highest average importance (26.3 percent; table 4 ) of the environmental covariates considered here. However, the relationship between habitat suitability and elevation is not a causal one in itself, but the result of interacting physical and biological factors that covary with elevation. Elevation is related to climate (temperature, precipitation, humidity, etc.), soil, substrate type, and the vegetation community of an area, and has been shown to be a reliable predictor of species distributions across many taxa (Merriam, 1890; Franklin, 1995). Elevation is less helpful for identifying ecological relationships between organisms and their environment, but because of its explanatory power, we elected to include it. The only taxa where elevation was not included in any of the selected models were the Homalonychus spider group and $P$. longimembris. Very little information is known about the two spider species, and few observations were available for identifying strong covariate relationships. These observations suggested that Homalonychus spiders occur between elevations of 300 and 1,400 m. In contrast, P. longimembris appear to occur over a broad range of elevations from -70 to $2,700 \mathrm{~m}$. This wide range likely obscured any explanatory power that elevation may have imparted.

\section{Winter Precipitation}

Winter precipitation represents the cumulative precipitation from October 1 through March 31, averaged across 30 years. This covariate was included in habitat models for 8 of the 13 taxa, and showed the second highest average importance value (18.0 percent; table 4). Many of the taxa included in this study are herbivorous, feeding primarily on herbaceous grasses and forbs. The germination and growth of many grasses and forbs in the Mojave Desert are influenced heavily by winter precipitation (Beatley, 1976; Turner and Randall, 1989). Therefore, we hypothesized that many of the herbivorous species modeled here would be positively associated with winter precipitation. We also expected that many of our insectivorous species (such as $X$. vigilis) might be positively associated with high winter precipitation because of the increased abundance of insect forage resulting from spring production of annual plants that may drive mass insect production events (Swetnam and Lynch, 1993). The final averaged models for all 4 herbivorous taxa and 4 of the 9 facultative and obligate carnivores included winter precipitation. $P$. gilberti, which primarily eats small arthropods, had the highest average relative contribution for winter precipitation among the study species. This positive relationship suggests a preference for areas with more winter rainfall, although this was unlikely a preference for areas with high herbaceous production for foraging, but rather, a preference for areas across a wide elevational range (sea level to more than 2,000 m) near areas with high surface moisture, such as near streams or springs.

\section{Surface Texture}

Surface texture broadly reflects the dominant surface mechanical composition, and is an indication of the effective grain size for soil and rock fragments (Scott Nowicki, University of Nevada, Las Vegas, oral commun., 2011). This index is broadly determined by the thermophysical characteristics of its surface substrate material, which reflects the material type and composition, temperature holding capacity, particle size, and induration of an area. These characteristics are directly related to the range of vegetation that can occur in a given area, and as such, have a strong influence on the species composition there. In addition, many species appear to prefer specific particle sizes that vary among species (for example, lizards; Pianka, 1966). We modeled the size of surface particles to use for a proxy for surface texture. Particle size was modeled as a function of the thermal properties of the 
substrate surface. In general, areas with smaller particle sizes including little to no bedrock cover show greater diurnal thermal variation than rocky areas with extensive bedrock and boulders (Pratt, 1979; Kahle, 1987; Wang and others, 2004). Therefore, areas with greater differences between daytime and nighttime surface temperatures are more likely to be sandy or have small particle sizes than areas with smaller daytime and nighttime summer differences. This property is magnified during the hot summer months when the available solar energy is at a maximum. We used this property to create a covariate representing surface texture throughout our study area

The surface texture covariate was included in habitat models for 10 of the 13 taxa, and showed the third highest average importance of the environmental covariates (14.6 percent; table 4). In general, species that tend to occur on rocky and bouldery surfaces show preferences for areas with a low surface texture index, which is indicative of areas that carry greater diurnal thermal inertia. Species that occur in areas with sandy or loamy soils tend to show preferences for areas with high surface texture index values.

\section{Topographic Position}

Topographic position represents an index of the landscape terrain shape and connectivity of an area, and was calculated as the amount of surface water that could drain into a given $1 \mathrm{~km}$ cell given an impermeable surface. High values are indicative of dry lakebeds, valley bottoms, and surface flow pinch points, such as the apexes of alluvial fans. Low values represent ridges and mountain tops, or other areas where theoretical waterflow would be minimal.

The topographic position covariate showed the fourth highest average importance (12.8 percent; table 4), and was included in habitat models for 10 of the 13 taxa. Response curves for topographic position varied considerably across taxa, with some taxa showing a preference for specific values (that is, $C$. bicinctores and $C$. collaris and $S$. magister), others showing a preference for a broad range of values ( $P$. gilberti and $T$. bottae), and others showed a preference for values above a certain threshold (D. dorsalis and $X$. vigilis), and yet others exhibited a preference for high values $(C$. occipitalis and $C$. penicillatus). Generally, none of our taxa showed preference for low values, suggesting that most of our study species do not occupy mountainous terrain.

\section{Seasonal Thermal Change}

Seasonal thermal change represents the similarity in summer and winter surface temperatures for a given area, and is a measure of the intra-year variability in surface temperature. High values, which represent areas with greater differences between the summer and winter daytime surface temperature, tended to occur on valley bottoms in the northern latitudes of the study area. In contrast, places with low values were high elevation, south-facing slopes, where summer and winter daytime temperatures were more similar.

The seasonal thermal change covariate was included in habitat models for 8 of the 13 taxa, and showed the fifth highest average importance of the environmental covariates (6.3 percent; table 4). Most taxa showed preferences for areas with low seasonal temperature differences, suggesting an avoidance of the high latitudes. However, three of the eight species (S. magister, U. scoparia, and X. vigilis) showed unique response curves for seasonal thermal change, with preferences for moderate values, and avoidance of the two extremes. 


\section{Seasonal Greenness Timing}

Seasonal greenness timing represents the period of the year when vegetation greenness reaches its maximum. We used the date where the maximum value of the Normalized Difference Vegetation Index (NDVI; vegetation greenness) was observed to represent the date of peak vegetation greenness. Vegetation green-up as measured by NDVI has been used to distinguish multiple vegetation communities, including shrubland, grassland, and mixed shrub communities (Peters and others, 1997; Weiss and others, 2004), and the timing of greenness has been shown to correlate with elevation gradients (Crimmins and others, 2009) and vegetation communities (van Leeuwen and others, 2010). Riparian areas and pinyon-juniper communities tended to have later dates of peak vegetation greenness. Prior to use, this covariate was transformed to a nominal index of 1-9, representing the dates identified above.

The seasonal greenness timing covariate was included in habitat models for 8 of the 13 taxa, and showed the sixth highest average importance of the environmental covariates (4.6 percent; table 4). Most species had increased habitat suitability in areas where vegetation greenness peaked later in the season, although C. occipitalis and the Homalonychus spiders showed preferences for areas where vegetation greenness peaked earlier in the season.

\section{Slope}

Slope was included in habitat models for 5 of the 13 taxa, and was the seventh highest in terms of average importance (4.5 percent; table 4). Of the five habitat models where slope was included, three showed relative contributions less than 10 percent, suggesting that slope provides relatively little explanatory power for most of our study species. The notable exceptions were the Crotaphytus lizards (C. bicinctores and $C$. collaris) and $X$. vigilis, which had relative contributions greater than 10 percent. Although Crotaphytus lizards prefer higher slopes and areas with greater rock abundance, desert night lizards prefer flat areas with little surface relief.

\section{Soil Adjusted Greenness}

Soil adjusted greenness represents vegetation greenness that has been adjusted to minimize the influence of soil color and spectral properties (for example, albedo) on vegetation greenness measurements (Qi and others, 1994). Soil adjusted greenness had the eighth highest average importance of the covariates (2.5 percent; table 4), and was included in habitat models for only 1 of the 13 taxa. Although not used in models for any of the other taxa, soil adjusted greenness provided the second highest relative contribution for A punctatus, and the modeled response suggested a prevalence in areas with moderate to high vegetation greenness.

\section{Soil Water Stress}

Soil water stress represents an index of the in situ top layer soil moisture (Fensholt and Sandholt, 2003). Soil water stress was included in habitat models for 8 of the 13 taxa, but only showed an average importance of 2.4 percent (table 4), with the highest relative contribution for $X$. vigilis (7 percent, table 4), which preferred areas with high soil water moisture. In contrast, the Crotaphytus lizards preferred areas with low soil water moisture. 


\section{Sandy Surfaces}

Sandy surfaces represents the percentage of each $1 \mathrm{~km}$ cell that was categorized as sand. We categorized sand using three separate modeling steps: (1) MODIS MOD11A1 nighttime Land Surface Temperature (LST) 8-day data were downscaled from the original spatial resolution of $1 \mathrm{~km}$ to $250 \mathrm{~m}$ using a geographically weighted generalized additive model with seven environmental predictor covariates (solar beam irradiance, average of the black sky albedo for the same time periods as the LST, maximum horizon level, elevation, aspect, slope and an average of the NDVI); (2) the downscaled MODIS LST data were regressed against elevation to remove the elevation trend; and (3) the residuals from the elevation regression were categorized into sand and non-sand categories using 100 known sample locations in Nevada and California. Sandy surfaces was only represented in habitat models for 2 of the 13 taxa, and had an average importance of 2.1 percent (table 4) among all species, and a relative contribution of less than 1 percent in D. dorsalis, but 27 percent in U. scoparia (table 4). U. scoparia was the only aeolian obligate in our study species and showed a preference for areas with higher coverage of sandy surfaces.

\section{Mountain Bases}

Mountain bases represents the transition areas between steep mountain slopes and flatter valleys, and include unique combinations of precipitation, temperature, and soil types. Our environmental covariate mountain bases represented the percentage of each $1 \mathrm{~km}$ cell that was categorized as a mountain base. We considered mountain bases to be areas that (1) have less than 10 degrees slope; (2) have a slightly negative profile curvature; and (3) had surface roughness between $0.7 \times 10^{-8}$ and $5.8 \times$ $10^{-8}$. The mountain bases covariate was included in habitat models for 7 of the 13 taxa, and had an average importance of 2.1 percent, although the highest relative contribution was for $P$. gilberti (10 percent; table 4), which showed a preference for areas categorized as the bases of mountains. $L$. trivirgata also showed a preference for areas categorized as the bases of mountains, and had a relative contribution from mountain bases of 5 percent (table 4).

\section{Washes}

The washes layer represents the relative density of washes per square kilometer in alluvial fan areas. The washes covariate had the twelfth highest average importance (1.7 percent; table 4), and was included in habitat models for 8 of the 13 taxa. In the Homalonychus spiders habitat model, washes provided a 15 percent relative contribution, although in the remaining 5 taxa, washes provided less than 4 percent relative contribution (table 4 ).

\section{Alluvial Fan Proximity}

Alluvial fans are fan shaped deposits of soil and sediments that have been carried by surface water from upslope terrain. These deposits tend to form gradients in particle size from coarse to fine when moving down slope. This environmental covariate represents the distance in meters to the nearest cell categorized as an alluvial fan. The alluvial fan proximity covariate was included in habitat models for only 2 of the 13 taxa, and had an average importance of 0.9 percent. However, in the habitat models for L. trivirgata, alluvial fan proximity had a relative contribution of 8 percent, which was the fourth highest contribution for this species. Across all study species, alluvial fan proximity provided lower explanatory power than we had hypothesized, likely due to the coarse spatial scale at which we modeled habitat. 


\section{Rocky Surfaces}

Rocky terrain is a fundamental component of habitat for many of our study species, and includes varying landform features that offer a wide range of surface conditions including caves, outcrops, ridges, peaks, and boulders. The rocky surfaces covariate represents the percentage of each $1 \mathrm{~km}$ cell that was categorized as rock. We categorized areas as rock using three separate modeling steps: (1) MODIS MOD11A1 nighttime LST, 8-day global data were downscaled from the original spatial resolution of $1 \mathrm{~km}$ to $250 \mathrm{~m}$ using a geographically weighted generalized additive model with seven environmental predictor covariates (solar beam irradiance, average of the black sky albedo for the same time periods as the LST, maximum horizon level, elevation, aspect, slope, and an average of the NDVI); (2) we regressed the downscaled MODIS LST data against elevation to remove the elevation trend; and (3) we categorized residuals from the elevation regression into rock and non-rock categories using 100 known sample locations in Nevada and California. The rocky surfaces covariate was included in habitat models for only 1 of the 13 taxa, had an average importance of less than 0.4 percent, and was among the lowest 5 environmental covariates.

\section{Seasonal Greenness Ratio}

The phenology of desert plants has been related to the composition and resource use of the organisms in an ecosystem (Esler and Rundel, 1999), and is highly dependent on winter precipitation. In a similar effort, Wallace and Thomas (2008) show that the green-up potential, or relative difference between spring greenness in a dry year and a wet year, is related to the ground cover of annuals at multiple sites in the Mojave Desert. We contrasted spring and winter vegetation greenness in order to capture the geographic variation in greenness between two separate seasons (periods when annuals were growing and winter when only perennials were present) in the Mojave Desert. The seasonal greenness ratio covariate was included in habitat models for 4 of the 13 taxa; however, in each of the 4 taxa, relative contributions were less than 2 percent, resulting in an average importance of 0.4 percent (table 4).

Cliffs

Cliff-like landform features were hypothesized to represent habitat for several of our study species, such as L. trivirgata and S. magister. The cliffs covariate represented the percentage of each 1 $\mathrm{km}$ cell that was categorized as containing cliffs and was included in habitat models for 2 of the 13 taxa. Due to its low average importance (0.2 percent; table 4$)$, the cliffs covariate was not considered an important covariate for predicting habitat of these species.

\section{Vegetation Greenness Coefficient of Variation}

The variability of vegetation greenness throughout each year was hypothesized to represent the availability of forage for many of our study species, and was calculated as the coefficient of variation in the NDVI across 23 dates in each year from 2001 to 2010. The vegetation greenness coefficient of variation covariate was included in habitat models for only 1 of the 13 taxa, and had the lowest average importance ( 0.1 percent; table 4$)$ of the 17 environmental covariates. 


\section{Habitat Model Summaries}

\section{Anaxyrus punctatus}

Conceptual Model.-A. punctatus occur in a wide range of semi-aquatic habitats in and around springs or water catchments (Stebbins, 1951; Ferguson and Lowe, 1969; Creusere and Whitford, 1976; McClanahan and others, 1994), in canyons with rocky substrates (Sullivan, 2005), and in rocky upland habitats or floodplains with elevations up to 2,000 m (Stebbins, 1951; Ferguson and Lowe, 1969; McClanahan and others, 1994; Sullivan, 2005). A. punctatus often stray away from water sources to burrow in soil or rock crevices (McClanahan and others, 1994), and are known to be active during precipitation events (Tevis, 1966; Ferguson and Lowe, 1969; McClanahan and others, 1994). These observations of habitat preference were translated to covariate layers representing rocky surfaces, surface texture, topographic position, mountain bases, and washes to account for terrain characteristics. We expected to see high suitability habitat in areas with high values of rocky surfaces, high values of surface texture, low values of topographic position, high values of mountain bases, and high values of washes.

We evaluated several covariate layers depicting surface-water characteristics for this semiaquatic species including soil water stress, vegetation greenness, soil adjusted vegetation greenness, seasonal greenness ratio, vegetation greenness timing, and winter precipitation. We expected our models of habitat suitability to have high suitability in areas with low soil water stress (corresponding to high water availability), high vegetation greenness, high soil adjusted vegetation greenness, high seasonal greenness ratio (corresponding to high spring and high winter vegetation), low to medium seasonal greenness timing (corresponding to early and mid-season maximum greenness), and high winter precipitation. Although the water-holding capacity of soil has been shown to be a good predictor of $A$. punctatus habitat suitability (Dayton and Fitzgerald, 2006), we were unable to use any direct measures of the water-holding capacity of soil. Instead, we used the covariate layer representing soil water stress, which has been correlated with in situ top layer soil moisture in large portions of African semiarid deserts (Fensholt and Sandholt, 2003).

A. punctatus have been documented in areas with early onset of spring (warmer) air temperatures (Tevis, 1966; Ferguson and Lowe, 1969). We included the covariate layers summer temperature and seasonal thermal change to express these habitat characteristics. We hypothesized that areas with low summer temperatures and low seasonal thermal variation would be more suitable for $A$. punctatus because $A$. punctatus are poikilotherms, and must select microhabitats with tolerable climates rather than relying on metabolic thermoregulation. Bradford and others (2003) found habitat of $A$. punctatus to be associated with high vegetation canopy cover over water and adjacent land. We represented riparian canopy cover with our soil adjusted greenness, which was derived for autumn 2010, during the time of year when riparian vegetation is more pronounced from surrounding areas in order to improve the discrimination of riparian areas. 
Habitat Model Results. - Although a single GAM model had the highest AUC among the selected models, we included two additional GAM models because of their high AIC and BIC scores, as well as their high BI scores and ideal BI curves. These three selected models also were run as MaxEnt models, resulting in a total of six models that we reviewed. All six models were included in the final averaged model, which represented five covariate layers-elevation, soil water stress, surface texture, soil adjusted greenness, and winter precipitation. The most prevalent covariates were surface texture, soil adjusted greenness, and elevation, and each were included in all six selected models. The least prevalent covariate layers were winter precipitation and soil water stress, which were included in only two of the six models. The surface texture layer provided the highest relative contribution in each of the MaxEnt models (40 percent), followed by soil adjusted greenness (32 percent), elevation (19 percent), winter precipitation (6 percent), and soil water stress ( 3 percent).

The final averaged model had an AUC score of 0.83 and a BI score of 0.89 (table 1). There was high agreement (that is, a low standard error) across the six selected models, with a few notable exceptions in large dry lakebeds and low elevation areas, such as the lower portions of Death Valley National Park and along the Colorado River (fig. 2). The averaged A. punctatus habitat suitability model was reclassified into high and low habitat suitability, and resulted in $87,510 \mathrm{~km}^{2}$ of suitable habitat based on the fifth quantile of the observation records (break value $=0.35$; fig. 3 ). 


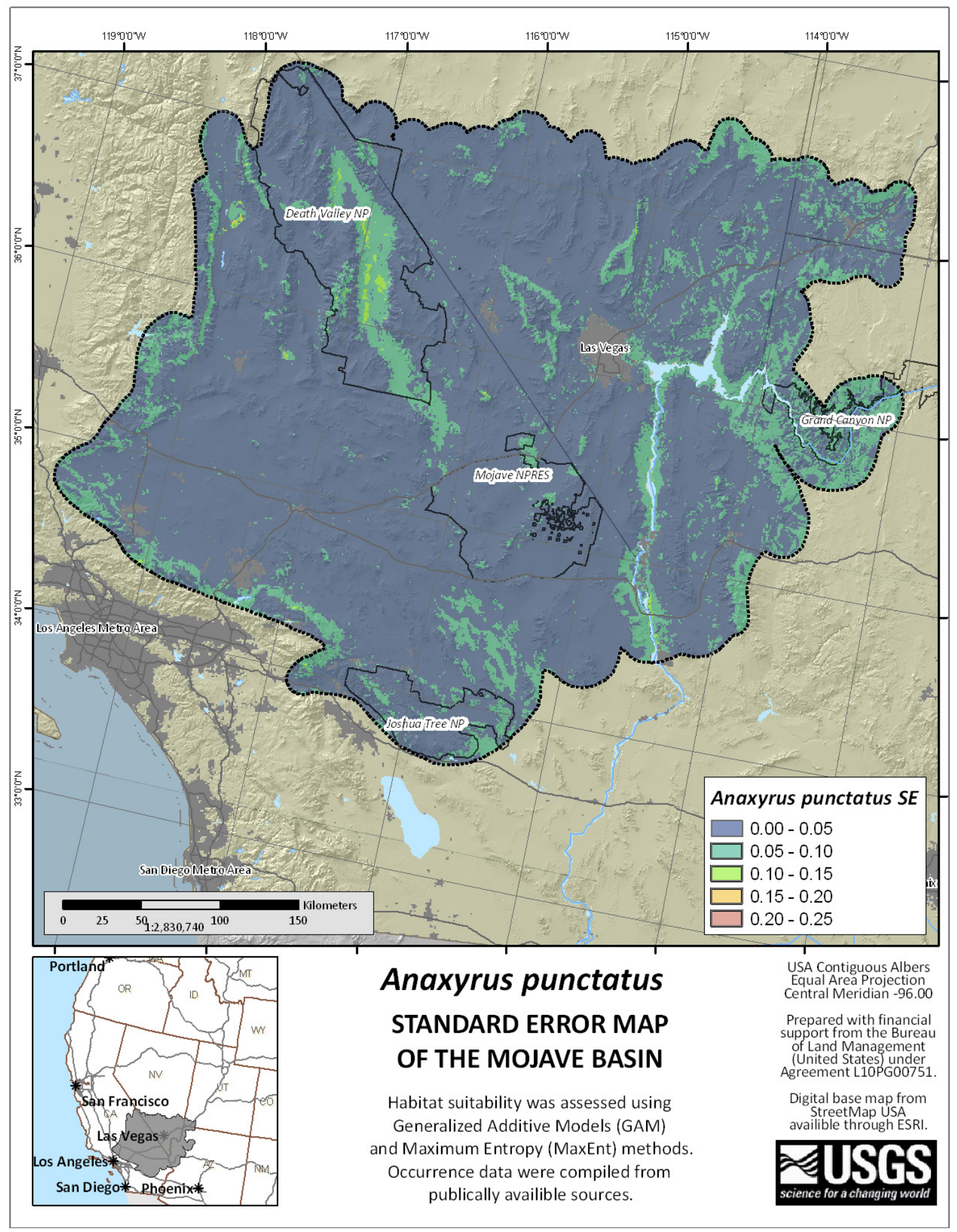

Figure 2. Map showing standard error $(\sigma / N)$ among the selected models for Anaxyrus punctatus (Red-spotted Toad). Areas where the selected models provided similar habitat suitability scores are shown in blue, and areas with low similarity are shown in red. Although not a measure of true model error, these agreement maps provide a general measure of model uncertainty across the landscape and show areas where the selected models agree (or disagree) with respect to habitat suitability. 


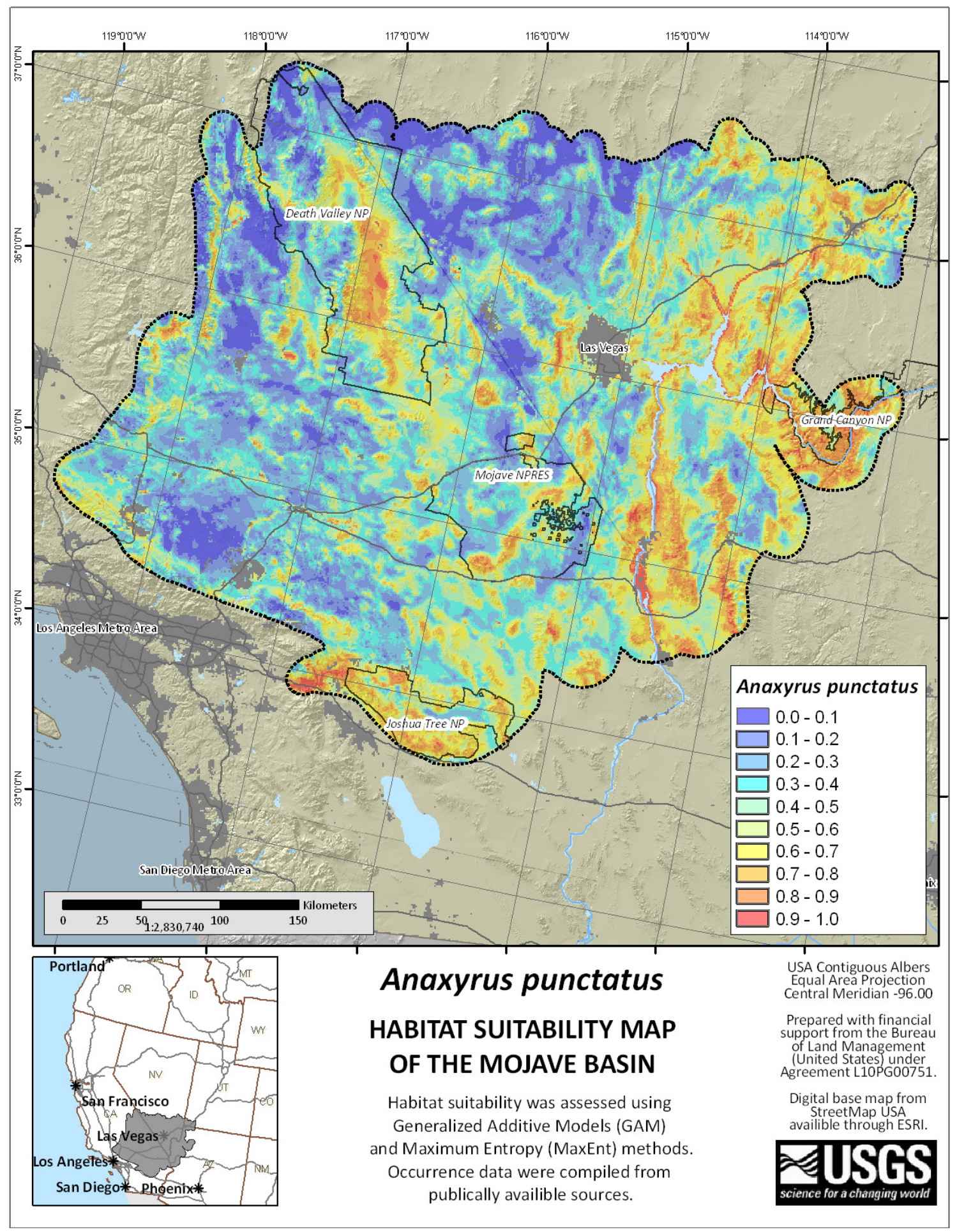

Figure 3. Map showing maximum habitat suitability among the selected models for Anaxyrus punctatus (Redspotted Toad). Values range from from $0 \sim 1$, and correspond to an index of habitat suitability, where areas with high suitability are shown in red; areas with low suitability are shown in blue. 
Habitat Model Discussion.-Available data were insufficient to derive an adequate environmental covariate representing all possible springs and water catchments in the Mojave Desert, which are thought to be the single best indicators of $A$. punctatus habitat (Stebbins, 1951). As a proxy for surface water presence, we investigated several covariate layers depicting surface-water characteristics including winter precipitation, soil water stress, vegetation greenness, soil adjusted vegetation greenness, seasonal greenness ratio, and vegetation greenness timing. Of these layers, only soil adjusted greenness was included in all selected models and had a relative contribution of 32 percent (table 4). This layer showed that $A$. punctatus habitat suitability was lower when soil adjusted greenness was extremely low, indicative of dry lakebeds and areas with little or sparse vegetation, and higher when values were greater than 0 (fig. 4C). This is congruent with observations of $A$. punctatus, which are not known to occupy habitats with dry lakebeds or areas with sparse vegetation.

The most influential environmental covariate was surface texture, which also was included in all selected models and had a relative contribution of 40 percent. The response curves suggested that $A$. punctatus tend to occur in areas with low values of surface texture, indicative of rocky surfaces, and tend to avoid areas with high values, which represent sandy and silty surfaces (fig. 4B). Areas with values greater than 20 included surfaces with mixed particle sizes, including bedrock, boulders, and rocks, but also likely including smaller patches of coarse sandy soils as well. The surface texture layer was included in the selected models although our rocky surfaces layer was not. The rocky surfaces layer was a representation of areas containing extensive surficial rock (that is, bedrock), and was an indicator of the amount of surficial bedrock present in an area. The selection of surface texture over rocky surfaces was likely due to the prevalence of $A$. punctatus in areas adjacent to extensive bedrock and in areas with mixed surface particle sizes. Extensive bedrock can provide extra runoff resulting in areas of temporary surface-water accumulation that provide $A$. punctatus with foraging areas while also accommodating cover sites in nearby rocky soils for periods of inactivity. In the Mojave Desert, areas with low surface texture values (that is, less than 20) include features such as canyons and rock outcrops where solar radiation, wind patterns, and surface material have a strong influence on the surface radiant temperature (Carlson and others, 1981) and create highly variable environments such as crevices and chasms that are more thermally stable throughout each day during the summer months. This has been corroborated by field biologists who have found that $A$. punctatus tend to prefer canyons with rocky substrates (Sullivan, 2005), or rocky upland habitats (Stebbins, 1951; Ferguson and Lowe, 1969; McClanahan and others, 1994). 
The elevation layer also was included in each of the selected models, had a relative contribution of 20 percent, and habitat suitability decreased as elevation increased (fig. 4A). However, the relationship between habitat suitability and elevation is likely not a causal one in itself, but instead is the result of interacting physical and biological factors that co-vary with elevation. Including elevation as an environmental covariate often masks the relationship between habitat suitability and other covariates because elevation is related to the climate (temperature, precipitation, humidity, etc.), soil, substrate type, and vegetation community of an area. However, because of its relationship to these important covariates, elevation can often statistically explain a large portion of a species' geographic distribution (Franklin, 1995). We included elevation because our intent was to create accurate predictions of habitat suitability across the Mojave Desert Ecoregion for the purpose of evaluating influences of habitat loss due to construction of new alternative energy facilities.

The covariate layers, winter precipitation and soil water stress, provided the least explanatory power among the environmental covariates we selected ( 6 and 3 percent, respectively), and were included in only two of the six habitat models. We expected winter precipitation to have a large influence on habitat suitability for $A$. punctatus due to the transient nature of water exchange between amphibians and their environment (Tracy, 1976). However, our winter precipitation layer was correlated with elevation $(\mathrm{r}=0.71, \mathrm{~N}=1,000, \mathrm{p}<0.001)$, and therefore the low prevalence and low relative contribution (6 percent) of winter precipitation in the selected models is understandable; when combined with elevation, winter precipitation provided very little additional explanatory power in $A$. punctatus habitat. We also expected the soil water stress layer would have a high relative contribution to A. punctatus habitat than it did (3 percent) due to A. punctatus' need for surface water. However, although the soil water stress layer has been shown to be related to the in situ top layer soil moisture in semiarid regions of Senegal (Fensholt and Sandholt, 2003), it has not been evaluated in the Mojave Desert, and may not be an important predictor of A. punctatus habitat. 

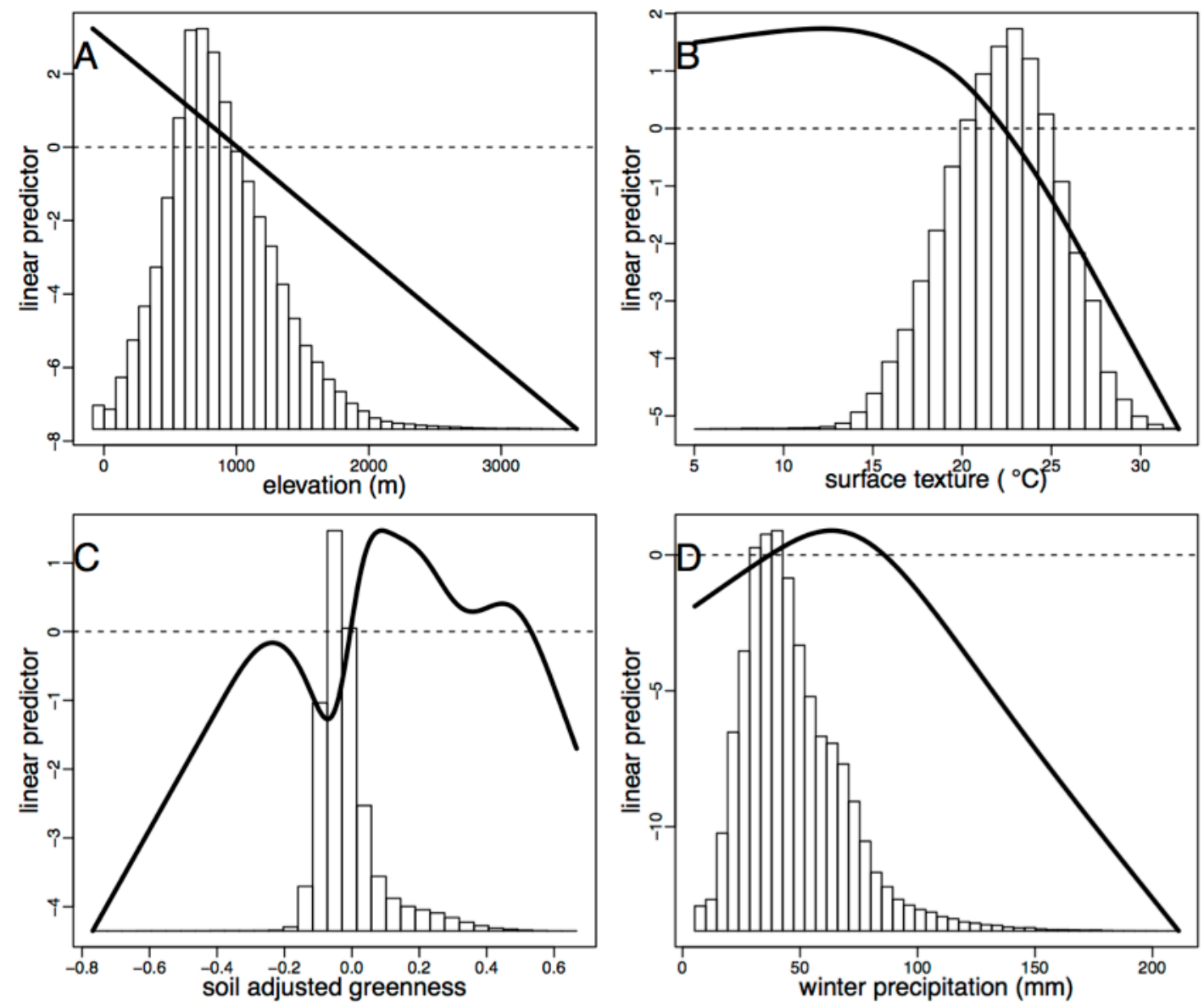

Figure 4. Generalized response curves and histograms for Anaxyrus punctatus (Red-spotted Toad) for environmental covariates. Histograms are derived from a random sample of the study area and illustrate the distribution of covariates across the landscape. Response curves are derived from a single model that is inclusive of all covariates represented in the selected models for $A$. punctatus, where each of the covariates is held at their study area mean. The dotted line shows linear predictor value of 0 . 


\section{Chaetodipus penicillatus}

Conceptual Model.-C. penicillatus tends to occur in or around areas with mildly sloping valleys, low hills with washes, and open sandy deserts, often with coarse sandy soils (Bailey, 1931; Hall, 1981; Hoffmeister, 1986). Others have found that several rodent species (primarily the Chaetodipus, Dipodomys, and Peromyscus genera) could be distinguished in terms of habitat use with a suite of environmental covariates including slope, rockiness, soil texture, vegetation cover, and precipitation (Suarez-Gracida and Alverez-Casteneda, 2009). C. penicillatus are often found in sparsely vegetated areas with perennial plant species, such as Larrea tridentata (creosote bush), Cylindropuntia spp. (cholla), Cercidium spp. (palo verde), and Ambrosia spp. (burroweed) (Hoffmeister, 1986), or on the edges of alluvial fans with Yucca spp. (yucca), Prosopis spp. (mesquite), Bouteloua spp. (grama grass), and Argemone spp. (prickly poppy) (Hoffmeister, 1986). We used vegetation greenness and soil adjusted greenness to capture the geographic variation in perennial vegetation sparseness, and vegetation greenness coefficient of variation and seasonal greenness ratio to capture the yearly and seasonal persistence of green vegetation. An additional vegetation covariate, vegetation greenness timing, was used to represent the timing of peak of vegetation greenness. The layer alluvial fan proximity was used to represent the proximity to alluvial fan edges, and layers slope, surface texture, topographic position, and mountain bases were used to represent terrain and landform features.

Habitat Model Results. - We selected 9 GAM models to run as MaxEnt models, resulting in a total of 18 models that we reviewed. Only two of the MaxEnt models and none of the GAM models were included in the final averaged model, which represented five covariate layers. Of these five layers, surface texture, seasonal thermal change, and elevation were included in both of the selected models, and winter precipitation and mountain bases were included in only one model. The relative contribution for each layer was 45 percent (elevation), 23 percent (seasonal thermal change), 22 percent (surface texture), 8 percent (winter precipitation), and 2 percent (mountain bases). The two models included in the final averaged model were selected because they discriminated habitat in areas where no presence points were available, but where we had local knowledge of presence. There was general agreement across the two selected models, although we did not calculate a standard error map due to low sample size. The final habitat suitability model was the average of the two selected models, and had an AUC score of 0.87 and BI of 0.22 (table 1). The averaged model was reclassified into high and low habitat suitability, which resulted in $53,988 \mathrm{~km}^{2}$ of suitable habitat based on the fifth quantile of the observation records (break value $=0.25$ ). Areas of suitable habitat were limited to southeastern Mojave Desert, and throughout much of the Baker Sink landform in Death Valley National Park (fig. 5). 


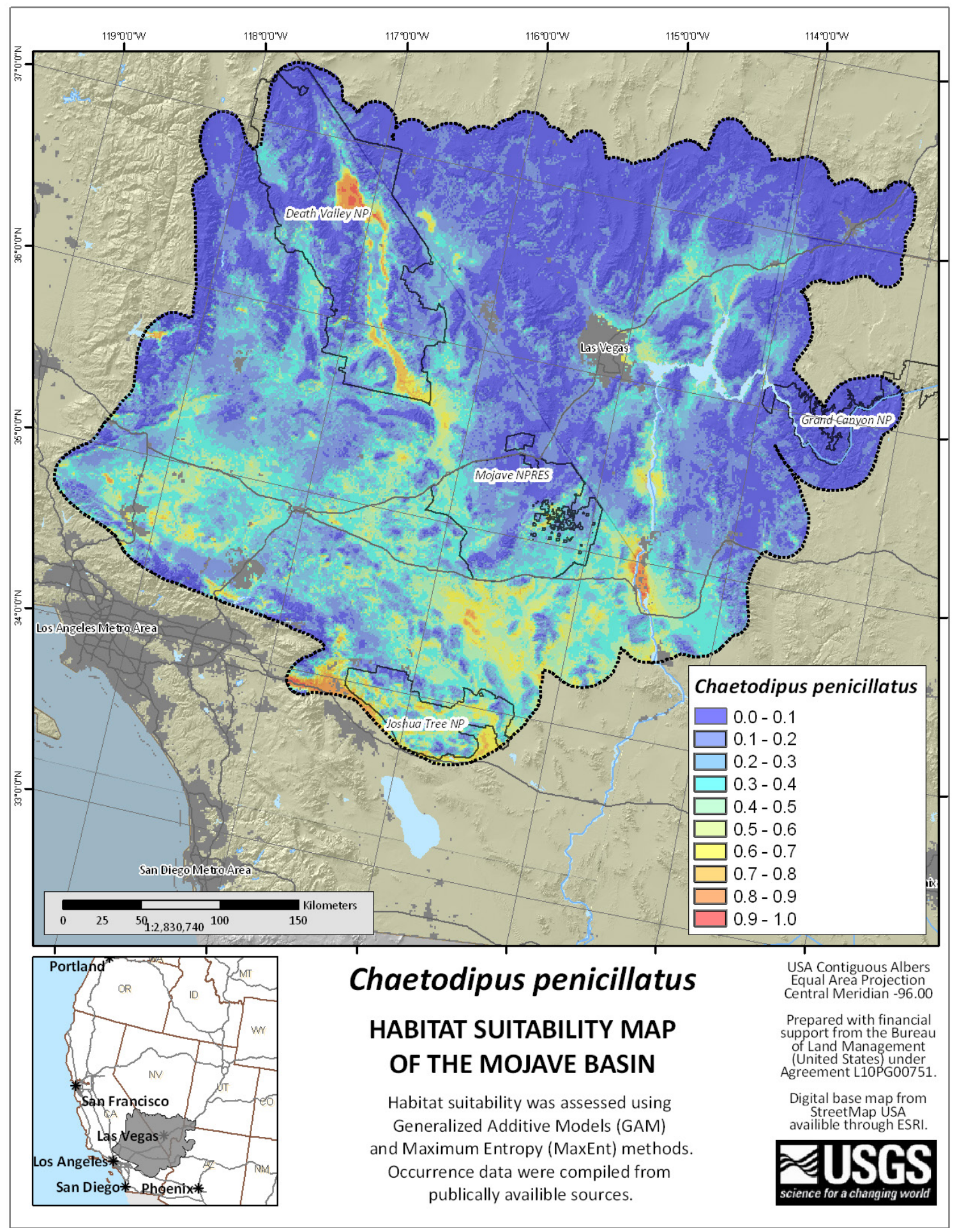

Figure 5. Map showing average habitat suitability among the selected models for Chaetodipus penicillatus (Desert Pocket Mouse). Values range from $0 \sim 1$, and correspond to an index of habitat suitability, where areas with high suitability are shown in red; areas with low suitability are shown in blue. 
Habitat Model Discussion.-We hypothesized that habitat suitability of $C$. penicillatus would be related to broad environmental covariates representing vegetation and landforms due to the range of habitat types that $C$. penicillatus are known to occupy. However, the covariate layers in the two selected models for C. penicillatus (surface texture, seasonal thermal change, mountain bases, elevation, and winter precipitation) did not include any of the layers describing vegetation conditions, suggesting that our vegetation layers were not as important for predicting C. penicillatus habitat suitability as we expected. Elevation had the greatest explanatory power ( 45 percent contribution) in both of the selected models, and the model response suggested an avoidance of high elevation areas (fig. 6A). Elevation was highly correlated with winter surface temperature $(r=-0.95, \mathrm{~N}=1,000, \mathrm{p}<0.001),(\mathrm{r}=-0.95, \mathrm{~N}=$ $1,000, \mathrm{p}<0.001$ ), and therefore we did not include both in any of our models, but instead used one or the other. Models using elevation instead of winter surface temperature generally performed better than the converse. However, examination of models with winter surface temperature indicate that $C$. penicillatus has high habitat suitability in areas with winter temperatures ranging between 12 and $20^{\circ} \mathrm{C}$. This range includes temperatures known to induce torpor in this species $\left(10-15^{\circ} \mathrm{C}\right.$; Bartholomew and Cade, 1957).

Our layer representing seasonal change in surface temperature provided the second highest relative contribution to $C$. penicillatus habitat (23 percent), and the modeled response suggested that areas with less seasonal change were more suitable than areas with greater seasonal change (fig. 6B). Throughout our study area, areas with low seasonal thermal change tended to be areas with very mild winters and moderate summers, in contrast to areas with cold winters, which provided the greatest seasonal thermal change. The later conditions occurred primarily in the northern latitudes in areas with high solar exposure, such as high elevation valley bottoms.

We hypothesized that surface texture would be an important factor in C. penicillatus habitat due to field observations of fossorial activities in coarse sandy soils throughout its range (Bailey, 1931; Findley and others, 1975; Hoffmeister 1986). Our models supported this, with surface texture being included in each of the two selected models and with 22 percent relative contribution overall. In each case, the surface texture layer showed decreased habitat suitability in areas with surface bedrock or other rocky surfaces, and an increase in habitat suitability in areas with sandier surfaces (fig. 6C). This preference for areas without large rocks or large areas of exposed bedrock also was supported by the mountain bases layer, and although it only provided 2 percent relative contribution, with decreased habitat suitability in areas characterized by mountain bases (fig. 6D). Combined, the surface texture and mountain bases layers provide support for previous assertions that $C$. penicillatus prefer flat to mildly sloping valleys with open, coarse, and sandy soils (Bailey, 1931; Hall, 1981; Hoffmeister, 1986).

In terms of diet, C. penicillatus depends heavily on spring annual plants for food during the breeding season, which is closely tied to the timing and amount of winter precipitation (Beatley, 1976; Turner and Randall, 1989). We found a positive correlation between the winter precipitation layer and C. penicillatus habitat suitability, with a peak between 76 and $101 \mathrm{~mm}$ of winter precipitation (fig. 6E). This peak suggests that although more winter precipitation can be better, areas with winter precipitation greater than $127 \mathrm{~mm}$, such as mountain ranges, provide lower habitat suitability than valleys. 

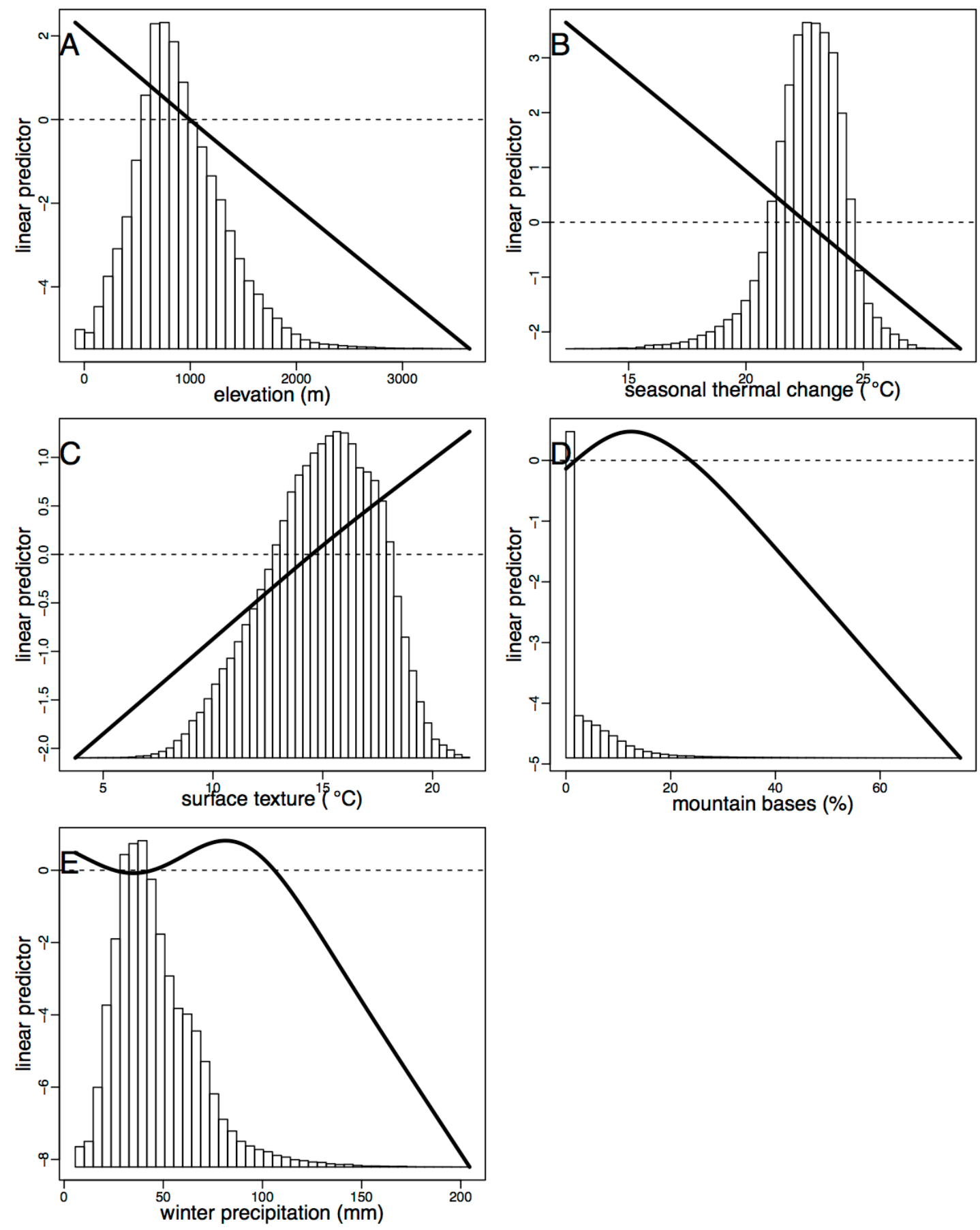

Figure 6. Generalized response curves and histograms for Chaetodipus penicillatus (Desert Pocket Mouse) for environmental covariates. Histograms are derived from a random sample of the study area and illustrate the distribution of covariates across the landscape. Response curves are derived from a single model that is inclusive of all covariates represented in the selected models for $C$. penicillatus, where each of the covariates is held at their study area mean. The dotted line shows linear predictor value of 0 . Only the five highest contributing covariates are shown. 


\section{Chionactis occipitalis}

Conceptual Model. - C. occipitalis typically occur in dry, sandy areas that are relatively flat and low in elevation, such as valley bottoms and alluvial fans (Klauber, 1951; Funk, 1967; Stebbins, 2003). Phil Medica (U.S. Geological Survey, oral commun., 2011) stated that sand dunes may be suitable if sufficient vegetation is present, as they are not often found in sand dunes or areas with extensive sand and void of vegetation altogether (Klauber, 1951). We included the environmental covariate layers surface texture and sandy surfaces to capture the preference for sandy areas and sand dunes, and the layers alluvial fan proximity, topographic position, washes, and mountain bases to represent valley bottoms and other relatively flat, low elevation areas.

Like all ectotherms, $C$. occipitalis behavior is affected by the temperature of its immediate environment, and requires specific temperatures for activity (Klauber, 1951). Throughout most of its range, $C$. occipitalis is generally nocturnal and is active when air temperatures are between $70^{\circ}$ and $90^{\circ} \mathrm{F}$ (Rosen and others, 1996). We included summer surface temperature to represent the geographic variation in summer environmental temperatures. To capture the avoidance of areas with little or no vegetation, we used vegetation greenness coefficient of variation and seasonal greenness ratio to capture the yearly persistence of green vegetation. We also included vegetation greenness timing, soil water stress, and winter precipitation to represent the availability of water.

Habitat Model Results. - We selected 6 models from among the suite of possible GAM models to run as MaxEnt models, resulting in a total of 12 models that we reviewed. All 12 models were included in the final averaged model, which represented six covariate layers - surface texture, topographic position, elevation, soil water stress, seasonal greenness timing, and vegetation greenness coefficient of variation. The three most important environmental covariates were surface texture, elevation, and topographic position, with a prevalence in 12, 10, and 10 total models and relative contributions of 42, 27, and 22 percent, respectively. The layer seasonal greenness timing was present in 6 of the 12 selected models, and provided a relative contribution of 6 percent, although vegetation greenness was present in only 2 of the 12 models, and provided a relative contribution of only 1 percent.

Both GAM and MaxEnt models were included in the final candidate suite because there were few differences among the paired models. Across all models, there was moderate consistency in habitat suitability scores throughout the entire study area, with slight disagreement among models in some of the low elevation areas, such as Death Valley National Park and outside of Phelan, Calif. (fig. 7). The final habitat model was the average of the 12 selected models, which had an AUC score of 0.79 and a BI score of 0.64 (table 1). The averaged $C$. occipitalis habitat suitability model was reclassified into high and low habitat, and resulted in $85,397 \mathrm{~km}^{2}$ of suitable habitat based on the fifth quantile of the observation records (break value $=0.26$; fig. 8). 


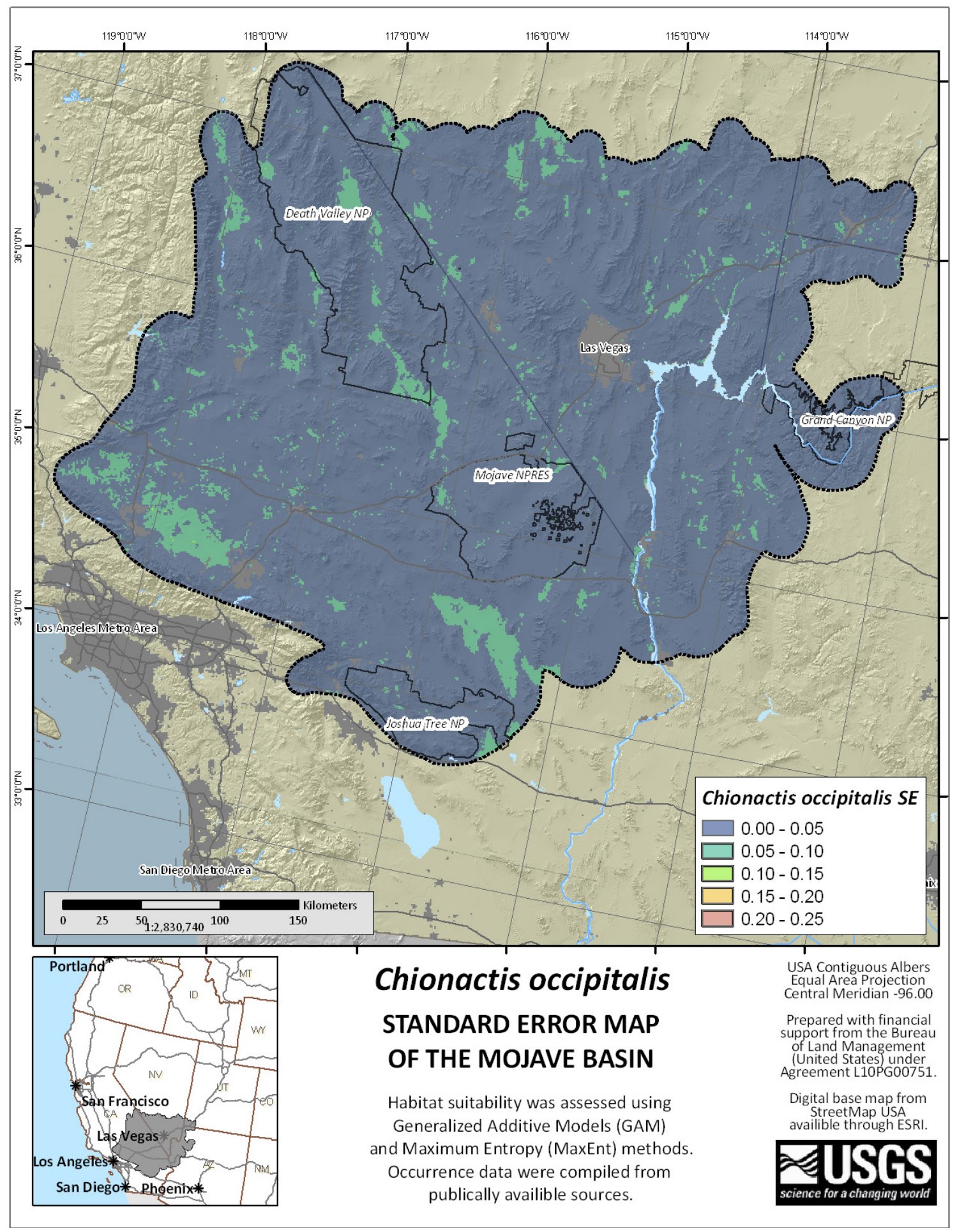

Figure 7. Map showing standard error $(\sigma / N)$ among the selected models for Chionactis occipitalis (Shovel-nosed Snake). Areas where the selected models provided similar habitat suitability scores are shown in blue, and areas with low similarity are shown in red. Although not a measure of true model error, these agreement maps provide a general measure of model uncertainty across the landscape and show areas where the selected models agree (or disagree) with respect to habitat suitability. 


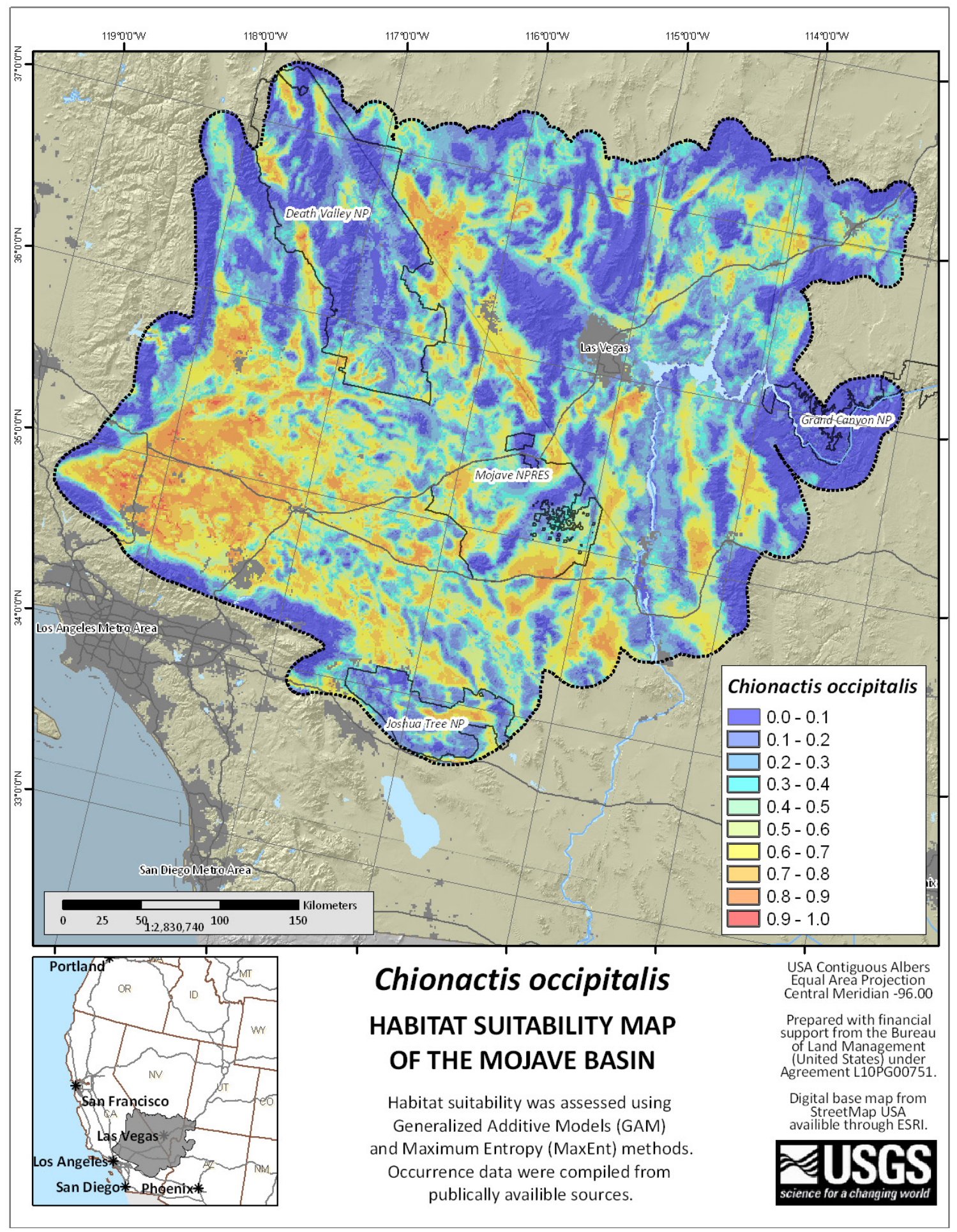

Figure 8. Map showing average habitat suitability among the selected models for Chionactis occipitalis (Shovelnosed Snake). Values range from $0 \sim 1$, and correspond to an index of habitat suitability, where areas with high suitability are shown in red; areas with low suitability are shown in blue. 
Habitat Model Discussion. - We hypothesized that C. occipitalis would be associated with covariate layers representing sandy surfaces and flat areas due to their preference for alluvial fans and valley bottoms (Klauber, 1951; Funk, 1967; Stebbins, 2003). As expected, surface texture and topographic position were among the best predictors of $C$. occipitalis habitat, with $C$. occipitalis habitat suitability being positively related to fine-textured soils, such as sand, and negatively related to more rocky surfaces, such as bedrock and areas with large boulders (fig. 9A). Topographic position showed high habitat suitability occurring in areas with high values, such as alluvial fans and valley bottoms (fig. 9B). Combined, these two covariates suggest that $C$. occipitalis were associated with sandy valley bottoms, alluvial fans, and playa margins (to the exclusion of the playas themselves that are void of vegetation). The elevation layer showed a decreasing relationship with $C$. occipitalis habitat suitability at elevations greater than $1,000 \mathrm{~m}$, and a peak in suitability between 400 and 1,000 m (fig. 9C). Above $1,000 \mathrm{~m}$ and below $400 \mathrm{~m}$ elevation, habitat suitability for C. occipitalis was minimal. Areas of high habitat suitability also were associated with high soil water stress (fig. 9D), indicating a preference for areas with more surface water.

Seasonal greenness timing was negatively associated with habitat suitability, suggesting that areas where vegetation reaches peak greenness earlier have higher suitability than areas where peak vegetation greenness occurs later in the year (fig. 9F). These areas tended to have Mojave mixed scrub with a low density of perennial vegetation, and a high density of grasses and other annual vegetation with earlier growth seasons. The other vegetation layer represented in the final averaged model was vegetation greenness coefficient of variation. High variability in vegetation greenness was negatively related to C. occipitalis habitat suitability (fig. 9E), suggesting a preference for areas with more stable vegetation. 

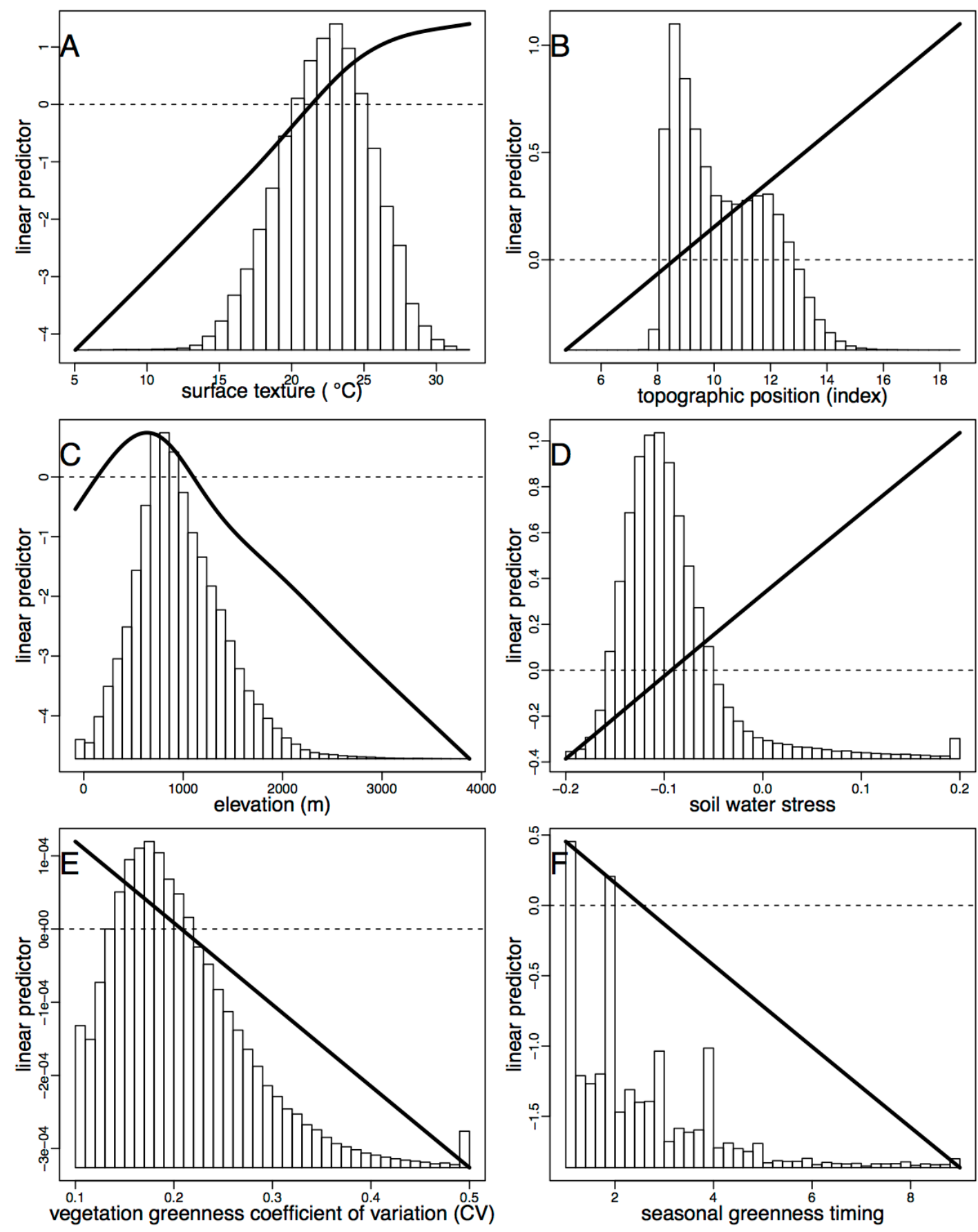

Figure 9. Generalized response curves and histograms for Chionactis occipitalis (Shovel-nosed Snake) for environmental covariates. Histograms are derived from a random sample of the study area and illustrate the distribution of covariates across the landscape. Response curves are derived from a single model that is inclusive of all covariates represented in the selected models for $C$. occipitalis, where each of the covariates is held at their study area mean. The dotted line shows linear predictor value of 0 . Only the six highest contributing covariates are shown. 


\section{Crotaphytus bicinctores and C. collaris}

Conceptual Model.- C C. bicinctores and C. collaris (collared lizards) are associated with a wide range of habitats, but are primarily found in areas that contain boulders, rocky surfaces, and other rock-like formations (McGuire, 1996; Stebbins, 2003). We included environmental covariates of surface texture, rocky surfaces, mountain bases, topographic position, washes, surface roughness, and slope to capture areas with rocky habitat. In many parts of the Mojave, C. bicinctores are found in areas with sparse vegetation at elevations less than 3,000 m (McGuire, 1996; Stebbins, 2003), and do not often occur in areas with riparian vegetation, alluvial fans, or flat valley bottoms (McGuire, 1996; Stebbins, 2003). To capture the association with sparsely vegetated areas, we included vegetation greenness, and vegetation greenness coefficient of variation and seasonal greenness ratio were used to capture the yearly persistence of green vegetation. We also included vegetation greenness timing and soil water stress to represent areas without riparian vegetation.

Habitat Model Results.-We selected five models from among the suite of possible GAM models to run as MaxEnt models, resulting in a total of 10 models that were reviewed by our collaborators. All 10 models were included in the final averaged model, and in combination, included eight covariate layers - surface texture, slope, topographic position, elevation, vegetation greenness timing, rocky surfaces, soil water stress, and alluvial fan proximity. The environmental covariate slope was included in all selected models, and had a relative contribution of 35 percent. Similarly, topographic position was included in all selected models and had a contribution of 29 percent, and seasonal greenness timing was included in 6 of the 10 models, and had a relative contribution of 13 percent. Elevation was included in 4 of the 10 models, and had a relative contribution of 10 percent. The remaining four covariates were each included in only 2 of the 10 models, and had contributions of 5 percent (soil water stress), 4 percent (surface texture), 4 percent (alluvial fan proximity), and 1 percent (rocky surfaces).

The final averaged habitat suitability model had an AUC score of 0.77 and a BI score of 0.58 (table 1). There was substantial disagreement among the selected models across the entire study area (fig. 10), with most of the disagreement occurring primarily in areas of high elevation. The averaged collared lizard habitat suitability model was reclassified into high and low habitat, and resulted in $100,293 \mathrm{~km}^{2}$ of suitable habitat based on the fifth quantile of the observation records (break value $=0$. 44; fig. 11). 


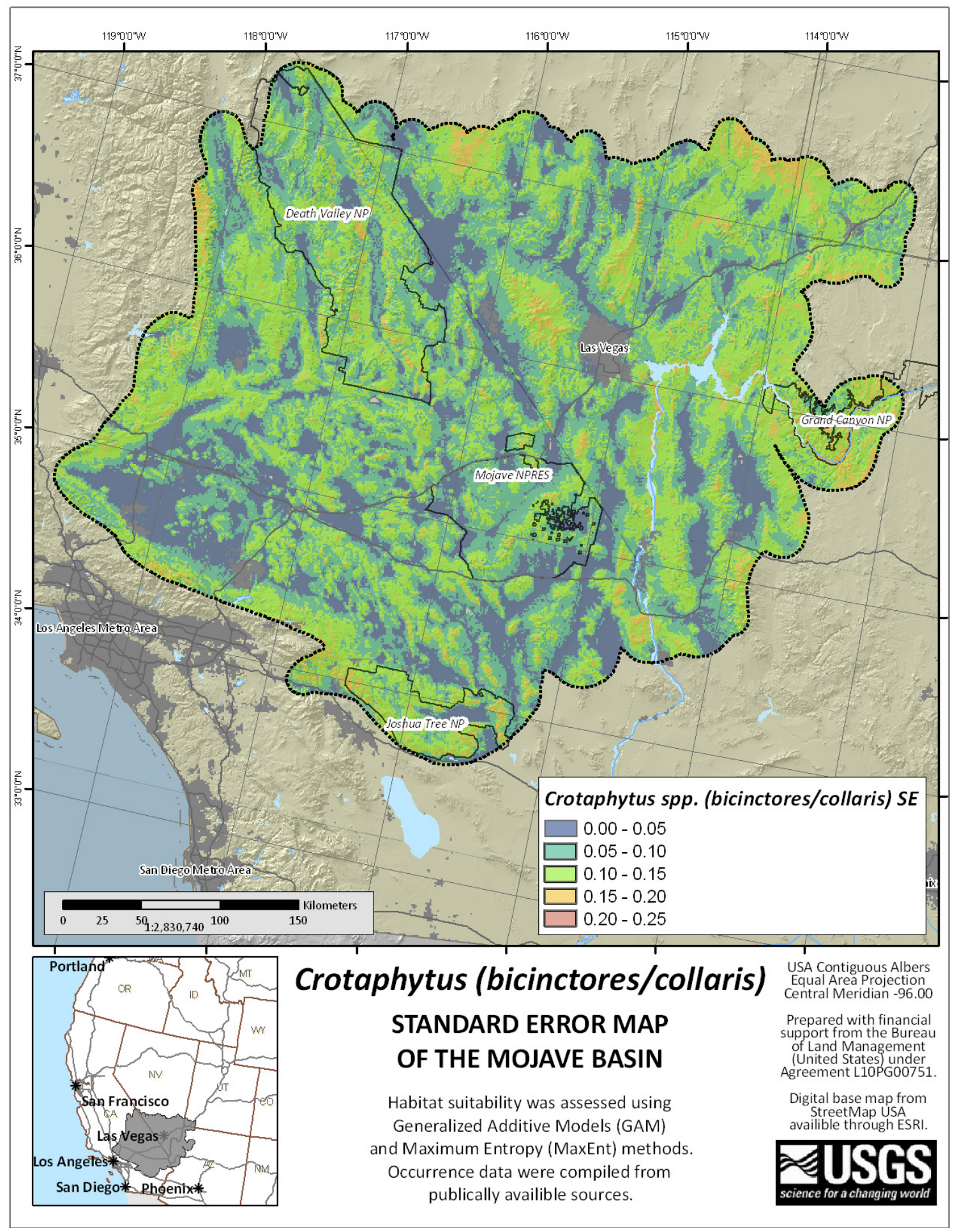

Figure 10. Map showing standard error $(\sigma / \mathrm{N})$ among the selected models for the Crotaphytus spp. group (collared lizards). Areas where the selected models provided similar habitat suitability scores are shown in blue, and areas with low similarity are shown in red. Although not a measure of true model error, these agreement maps provide a general measure of model uncertainty across the landscape and show areas where the selected models agree (or disagree) with respect to habitat suitability. 


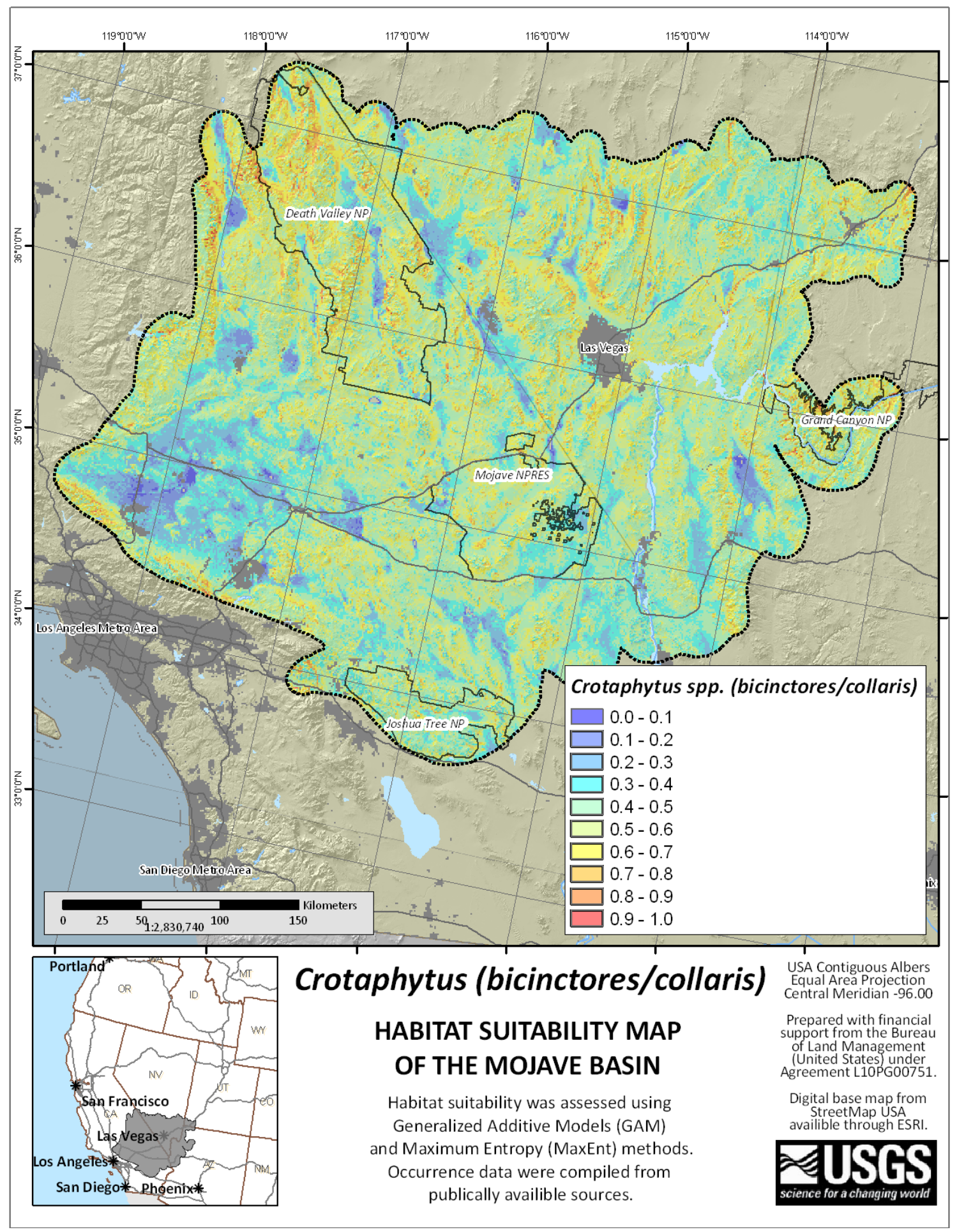

Figure 11. Map showing average habitat suitability among the selected models for the Crotaphytus spp. group (collared lizards). Values range from $0 \sim 1$, and correspond to an index of habitat suitability, where areas with high suitability are shown in red; areas with low suitability are shown in blue. 
Habitat Model Discussion.-We hypothesized that C. bicinctores and C. collaris would be highly associated with environmental covariates depicting boulders, rocky surfaces, and bedrock, but instead we found that the layers slope and topographic position provided the greatest explanatory power among the environmental covariates we considered. Collared lizard habitat suitability was positively related to slope such that areas with slope greater than 5 degrees showed high habitat suitability (fig. 12A), suggesting an avoidance of flatter areas. The modeled response for the topographic position layer suggested an avoidance of low (mountain tops and ridges) and high (high drainage areas, such as dry lakebeds and valley bottoms) values (fig. 12B), and a preference for moderate values (transition zones between mountain bases and alluvial fans). Although these two covariates describe broad topographic and terrain features, they are likely too coarse to identify the rocky features (that is, boulders, small cliffs, and outcrops) that collared lizards use as habitat at an individual level. Areas with rocks and boulders tend to occur in association with moderate slope or in areas that have high topographic position values (that is, alluvial fans, but not dry lakebeds), and as such, collared lizard habitat suitability was better near valley edges and at the apexes of alluvial fans.

Of the layers describing vegetation, seasonal greenness timing had the highest contribution (13 percent) and showed an increase in habitat suitability in areas where peak vegetation greenness occurred later in the season (fig. 12C). These areas tended to be low to mid-elevation mixed desert scrub and southwestern warm temperate forests, although the seasonal greenness timing layer did not directly model vegetation community types. Instead, it was a proxy for the interaction of vegetation phenology and vegetation greenness (van Leeuwen and others, 2010), and was only broadly related to vegetation community type. Generally, collared lizards are associated with sparsely vegetated areas, although $C$. collaris are often found in desert scrub, sagebrush, and semi-desert grasslands (Jones and Lovich, 2009).

The response curves for the elevation layer suggested that habitat suitability for collared lizards was higher at low elevations (fig. 12D), which was supported by a lack of observations in our dataset at high elevation areas. However, collared lizards also are not present in the valley bottoms of Death Valley and other areas with elevations less than $250 \mathrm{~m}$, suggesting that the linear trend with elevation was over-generalized. In several of the MaxEnt models, Crotaphytus habitat suitability was correlated with areas between 250 and $1,500 \mathrm{~m}$, suggesting an avoidance of the lowest elevations in the study area. The layers soil water stress, surface texture, alluvial fan proximity, and rocky surfaces all had relative contributions of less than 5 percent, and as such were not as important in predicting habitat suitability as were slope, topographic position, seasonal greenness timing, and elevation. We expected the rocky surfaces and surface texture layers to provide greater relative contributions to habitat suitability than we observed, although neither of these were able to capture the boulder fields, isolated rock outcrops, or other small rocky features at the fine spatial scale needed to represent Crotaphytus habitat. Future efforts to model surface texture at finer spatial scales may improve habitat model performance for collared lizards, which had some of the poorest performing models ( $\mathrm{AUC}=0.77$, averaged model) among the 13 groups we analyzed. 

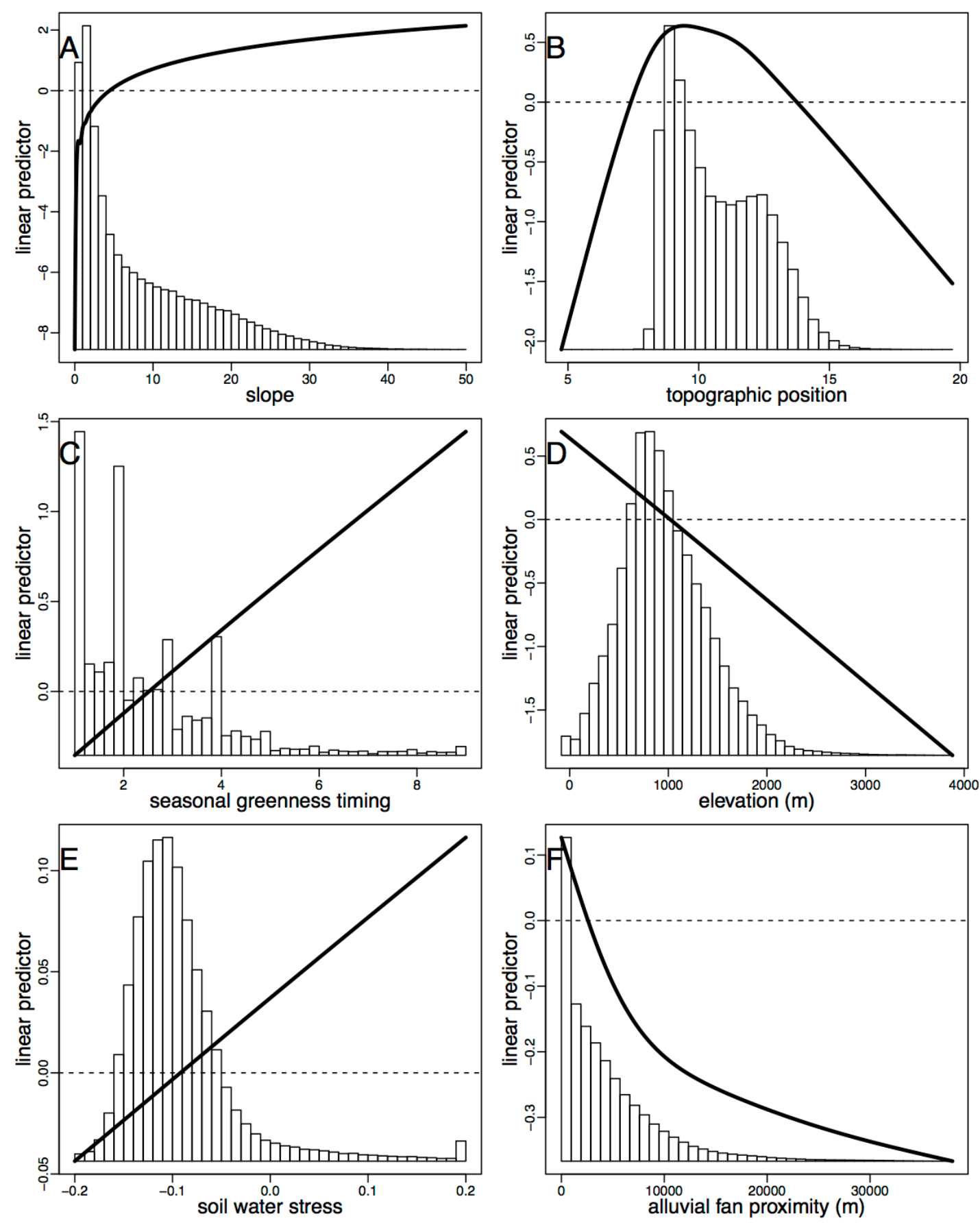

Figure 12. Generalized response curves and histograms for the Crotaphytus spp. group (collared lizards) for environmental covariates. Histograms are derived from a random sample of the study area and illustrate the distribution of covariates across the landscape. Response curves are derived from a single model that is inclusive of all covariates represented in the selected models for the Crotaphytus spp., where each of the covariates is held at their study area mean. The dotted line shows linear predictor value of 0 . Only the six highest contributing covariates are shown. 


\section{Dipsosaurus dorsalis}

Conceptual Model. - D. dorsalis occur in lowland habitats (for example, usually at elevations less than 1,200 m) that are open, flat, and dominated by sand or clay (Norris, 1953; Krekorian, 1977; Stebbins, 2003). Frequently incised by washes and arroyos, the intervening lower bajadas have only minimal amounts of scattered rocks (Norris, 1953; Stebbins, 2003), and allow D. dorsalis to dig burrows and underground retreats, which they use as shelter from extreme temperatures and predation (Norris, 1953). We included the environmental covariates of surface texture, sandy surfaces, washes, seasonal thermal change, and alluvial fan proximity to capture these habitat characteristics. Larrea tridentata (Creosote bush) frequently dominates desert iguana habitats (Norris, 1953; Stebbins, 2003), where they use the creosote bush as food when in flower and as shelter during periods of excessive heat in the spring and summer months. We used our environmental covariates vegetation greenness, seasonal greenness ratio, and seasonal greenness timing to capture habitat preferences for areas with open desert scrub. D. dorsalis are not usually found in canyons or steep rocky terrain (Norris, 1953). We therefore used elevation, slope, and topographic position to identify areas that do not have high elevations, canyons, or steep terrain.

Habitat Model Results. - We selected nine models from among the suite of possible GAM models to derive as MaxEnt models, resulting in a total of 18 models that we reviewed. Fourteen models were included in the final averaged model, which represented eight covariate layers-elevation, surface texture, winter precipitation, topographic position, seasonal greenness timing, seasonal thermal change, sandy surfaces, and washes. The environmental covariate elevation was included in all 14 models and showed a relative contribution of 70 percent. Surface texture (18 percent) and winter precipitation (14 percent) both showed high relative contributions, and were included in 12 and 8 of the 14 selected models, respectively. The remaining five covariate layers, topographic position, seasonal greenness timing, seasonal thermal change, sandy surfaces, and washes, showed relative contributions of 3, 2, 2, 1, and $<1$ percent, respectively. The covariate layers, topographic position, washes, and sandy surfaces, were each included in only 2 of the 14 models, and seasonal thermal change was included in 6 of the 14 models, and seasonal greenness timing was included in 8 of the 14 models.

There was high agreement across all selected models (fig. 13). The final averaged habitat suitability model for $D$. dorsalis had an AUC score of 0.82 and a BI score of 0.59 (table 1), and was reclassified into high and low suitability habitat, resulting in $95,914 \mathrm{~km}^{2}$ of suitable habitat based on the fifth quantile of the observation records (break value=0. 21; fig. 14). 


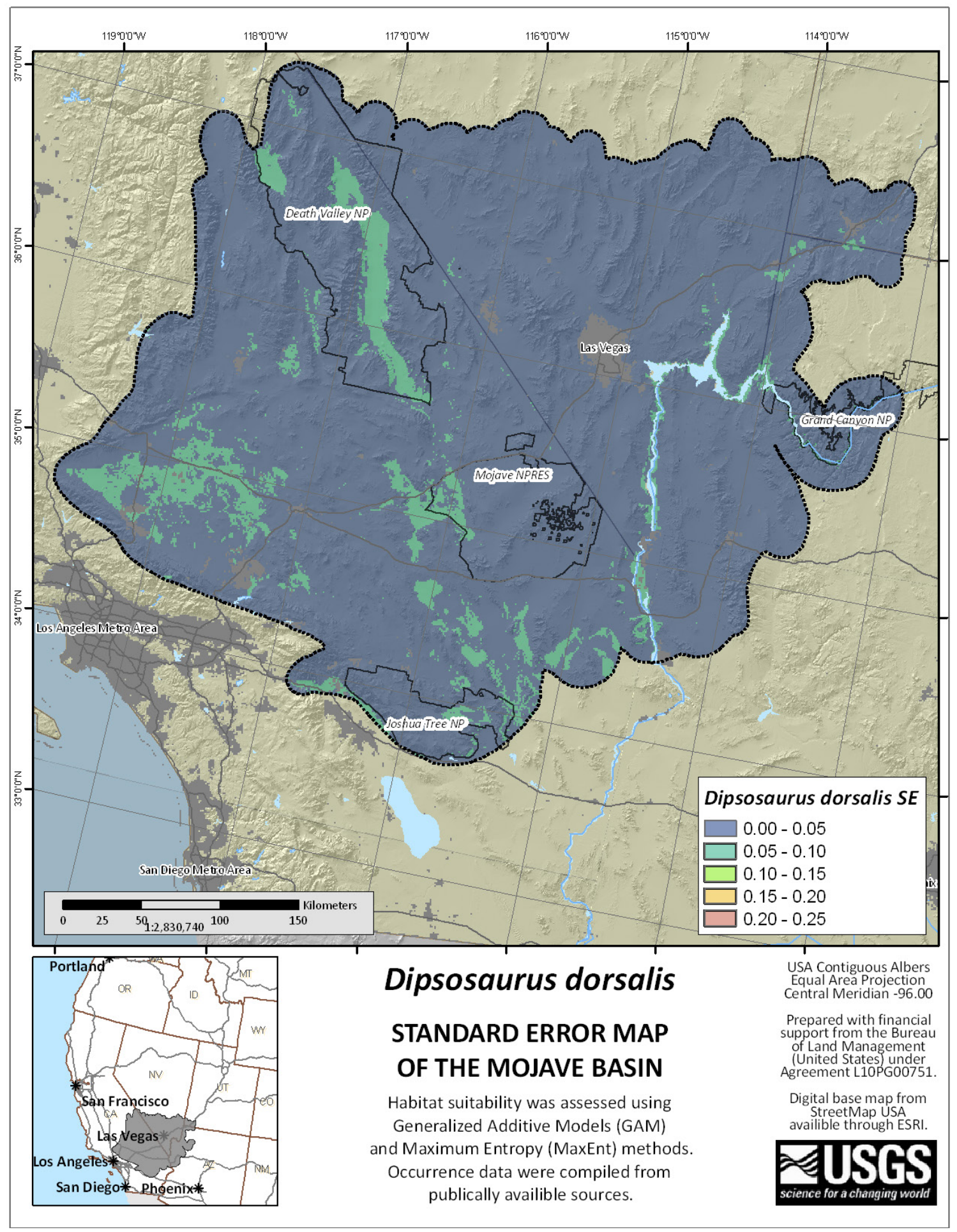

Figure 13. Map showing standard error $(\sigma / N)$ among the selected models for Dipsosaurus dorsalis (Desert Iguana). Areas where the selected models provided similar habitat suitability scores are shown in blue, and areas with low similarity are shown in red. Although not a measure of true model error, these agreement maps provide a general measure of model uncertainty across the landscape and show areas where the selected models agree (or disagree) with respect to habitat suitability. 


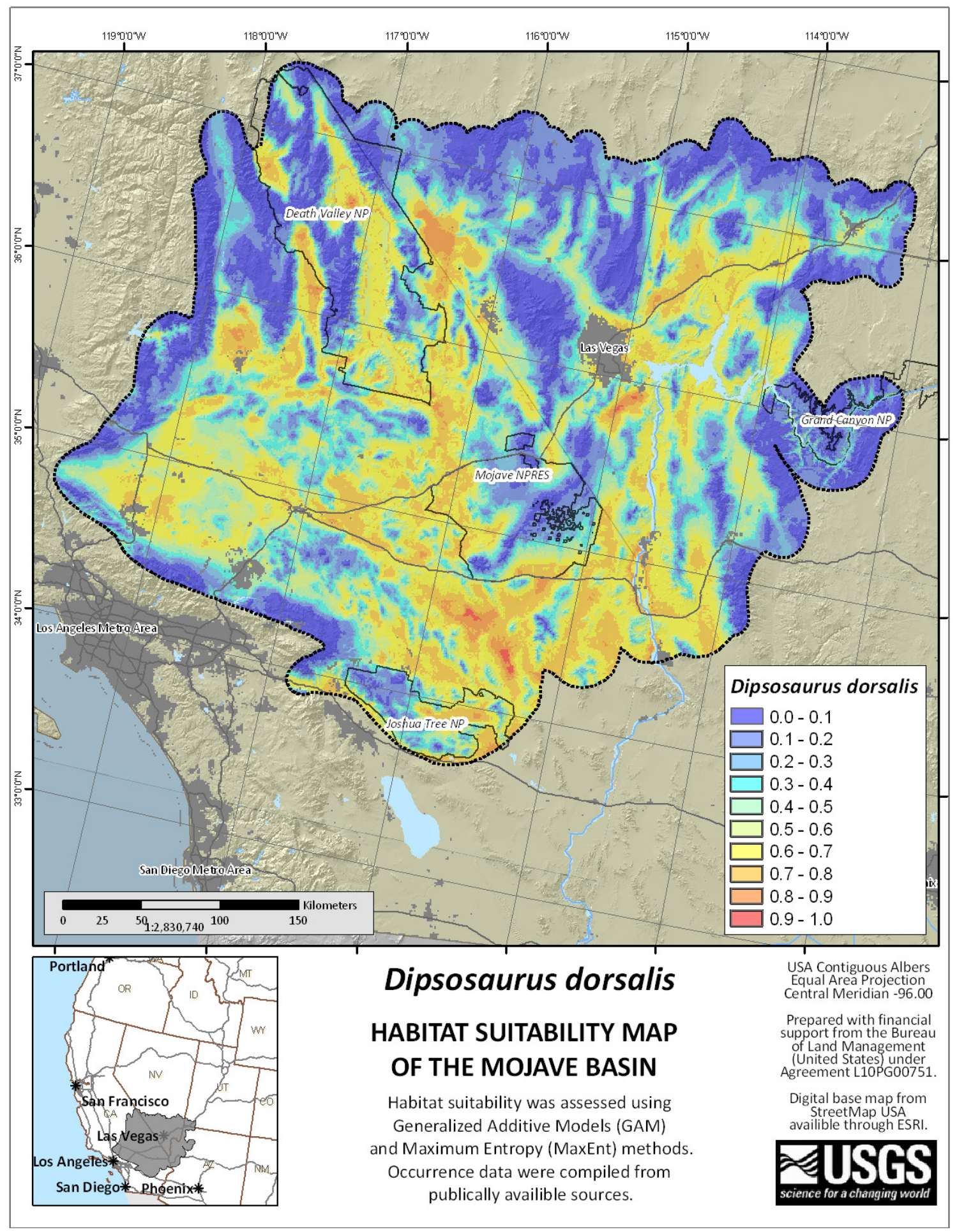

Figure 14. Map showing average habitat suitability among the selected models for Dipsosaurus dorsalis (Desert Iguana). Values range from $0 \sim 1$, and correspond to an index of habitat suitability, where areas with high suitability are shown in red; areas with low suitability are shown in blue. 
Habitat Model Discussion.-We hypothesized that D. dorsalis habitat suitability would be related to habitat types including sandy washes, flat terrain, and alluvial fans. Our environmental covariates surface texture and topographic position supported this, and modeled responses suggested a preference for sandy surfaces (fig. 15B), alluvial fans, and other surface features with high potential for drainage (fig. 15D). Slope was not included among the selected models, although elevation was, and its response curve suggested a preference for areas at low elevation (fig. 15A). These tend to have low slope in the Mojave Desert, and are generally sandier and contain fewer rocks and boulders at their surface. The environmental covariate topographic position, although capturing surface features, such as alluvial fans, was only included in 2 of the selected models and had a small relative contribution of only 3 percent. Winter precipitation showed a unimodal relationship to D. dorsalis habitat suitability (fig. 15C), suggesting a preference for areas with extremely low and extremely high winter precipitation. However, this likely is due to the broad region-wide relationship between elevation and precipitation, wherein high elevations receive more precipitation than low elevations, and not a preference for low or high precipitation in itself. Instead, this relationship is likely the result of a preference for a broad range of habitats sandy soils with creosote bush (Jones and Lovich, 2009), which occur throughout the Mojave Desert.

Only one of the covariate layers representing vegetation characteristics, seasonal greenness timing, was included in the final averaged model and was present in 8 of the 14 selected models. Seasonal greenness timing showed a slight negative association with $D$. dorsalis habitat suitability in the MaxEnt models but a slight positive association in the GAM models, suggesting a complex relationship with $D$. dorsalis habitat suitability. Although inconsistent in its relationship to $D$. dorsalis habitat suitability across the modeling platforms, seasonal greenness timing showed similar relative contributions among the two platforms, suggesting little overall influence on $D$. dorsalis habitat suitability. We did not explore the relationship between seasonal greenness timing and D. dorsalis habitat suitability further, but do suggest future work at finer spatial scales to identify and quantify the phenology of Mojave Desert vegetation communities.

The environmental covariate, seasonal thermal change, showed a negative relationship to D. dorsalis habitat suitability, suggesting an avoidance of areas with greater seasonal fluctuation in surface temperature (fig. 15E), which tended to occur in valley bottoms of the more northern latitudes in the study area. $D$. dorsalis are often found in valley bottoms throughout their range, but are not often found at higher latitudes where seasonal fluctuations in surface temperature are high. The environmental covariate, sandy surfaces, showed a low contribution to $D$. dorsalis habitat suitability, and showed a negative relationship with $D$. dorsalis habitat suitability (fig. 15F). This is likely due to the types of sand that were modeled, wherein the sandy surfaces covariate layer was primarily aimed at identifying areas with aolian sand devoid of vegetation, such as sand dunes. D. dorsalis are not often found on sand dunes and, as such, this negative relationship was not unexpected. The relationship between washes and $D$. dorsalis habitat suitability also was negative, suggesting an avoidance of areas with a high density of washes. Although this relationship was unexpected, the low relative contribution of washes $(<0.4$ percent) and its presence in only two of the selected models suggests that this relationship is marginal, and provided little effect on predicting habitat suitability. 

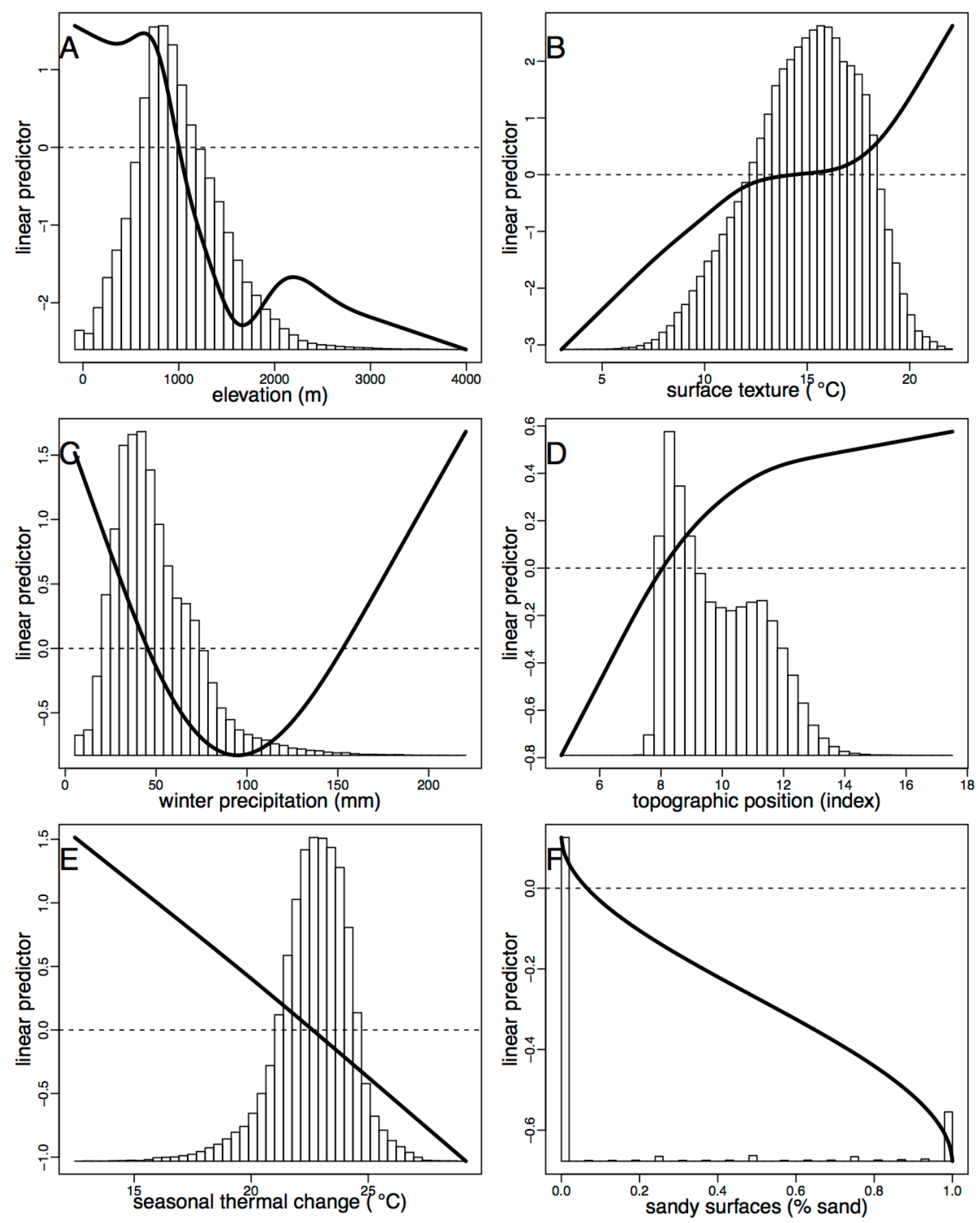

Figure 15. Generalized response curves and histograms for Dipsosaurus dorsalis (Desert Iguana) for environmental covariates. Histograms are derived from a random sample of the study area and illustrate the distribution of covariates across the landscape. Response curves are derived from a single model that is inclusive of all covariates represented in the selected models for $D$. dorsalis, where each of the covariates is held at their study area mean. The dotted line shows linear predictor value of 0 . Only the six highest contributing covariates are shown. 


\section{Homalonychus selenopoides and $H$. theologus}

Summary.- The literature on Homalonychus spiders is sparse, at best. These wandering, nonweb-building spiders inhabit arid environments of the North American Southwest and are found in areas with fine sand or other sandy soils with extensive boulders and rocks, which are used as refugia (Roth, 1984; Domínguez and Jiménez, 2005; Crews, 2009). They are often found under rocks or other debris, on hillsides, or in washes (Crews, 2009). In addition to limited information on habitat preference, presence data for these species were limited to locality records provided in Crews and Hedin (2006). We therefore created a single MaxEnt model with 11 covariate layers that we hypothesized to be important to Homalonychus spiders. These layers represented surface texture, seasonal thermal change, elevation, slope, topographic position, and washes to represent rocky areas with mixed sand, and to capture any geographic variation in terrain that our locality records exhibited. We also included measures of vegetation to capture the hypothetically broad range of vegetation types that Homalonychus spiders may occupy, because very little is known about any associated vegetation communities. These measures included vegetation greenness timing, vegetation greenness, seasonal greenness ratio, and vegetation greenness coefficient of variation.

Covariates contributing less than 10 percent to model explanation were removed, and a reduced model was fit with surface texture, topographic position, vegetation greenness timing, and washes, resulting in relative contributions of 33 percent (surface texture), 29 percent (topographic position), 23 percent (seasonal greenness timing), and 15 percent (washes). Generally, Homalonychus spider habitat suitability was positively related to rocky and moderately sandy terrain (fig. 16A), and Homalonychus spiders' localities were not found on very silty areas, such as dry lakebeds and valley bottoms. This also was supported by the response curves of the topographic position layer, which also suggested their absence on dry lakebeds, valley bottoms (fig. 16B), and a positive association with alluvial fans, valley sides, and mild hillslope. Washes were negatively related to Homalonychus spider habitat suitability (fig. 16D), such that areas with low wash density generally resulted in higher habitat suitability, although the washes covariate layer provided the least contribution of the four covariate layers. The only layer representing vegetation characteristic that was related to Homalonychus spider habitat suitability was the seasonal greenness timing layer, with response curves suggesting a preference for areas where vegetation reached maximum greenness earlier in the growing season (fig. 16C). Areas with earlier onset of maximum greenness tended to be areas at low elevations having sparse perennial vegetation, and had high densities of annual grasses and forbs. These areas likely have greater proportions of moderately sandy textures-another key component to Homalonychus spider habitat.

The reduced model had an AUC score of 0.82 and BI of 0.21 (table 1), and was reclassified into suitable habitat using the fifth quantile of the observation records (break value $=0.21$ ), resulting in $62,058 \mathrm{~km}^{2}$ (fig. 17). Our use of a single model precluded estimation of standard error in habitat suitability for Homalonychus spiders. 

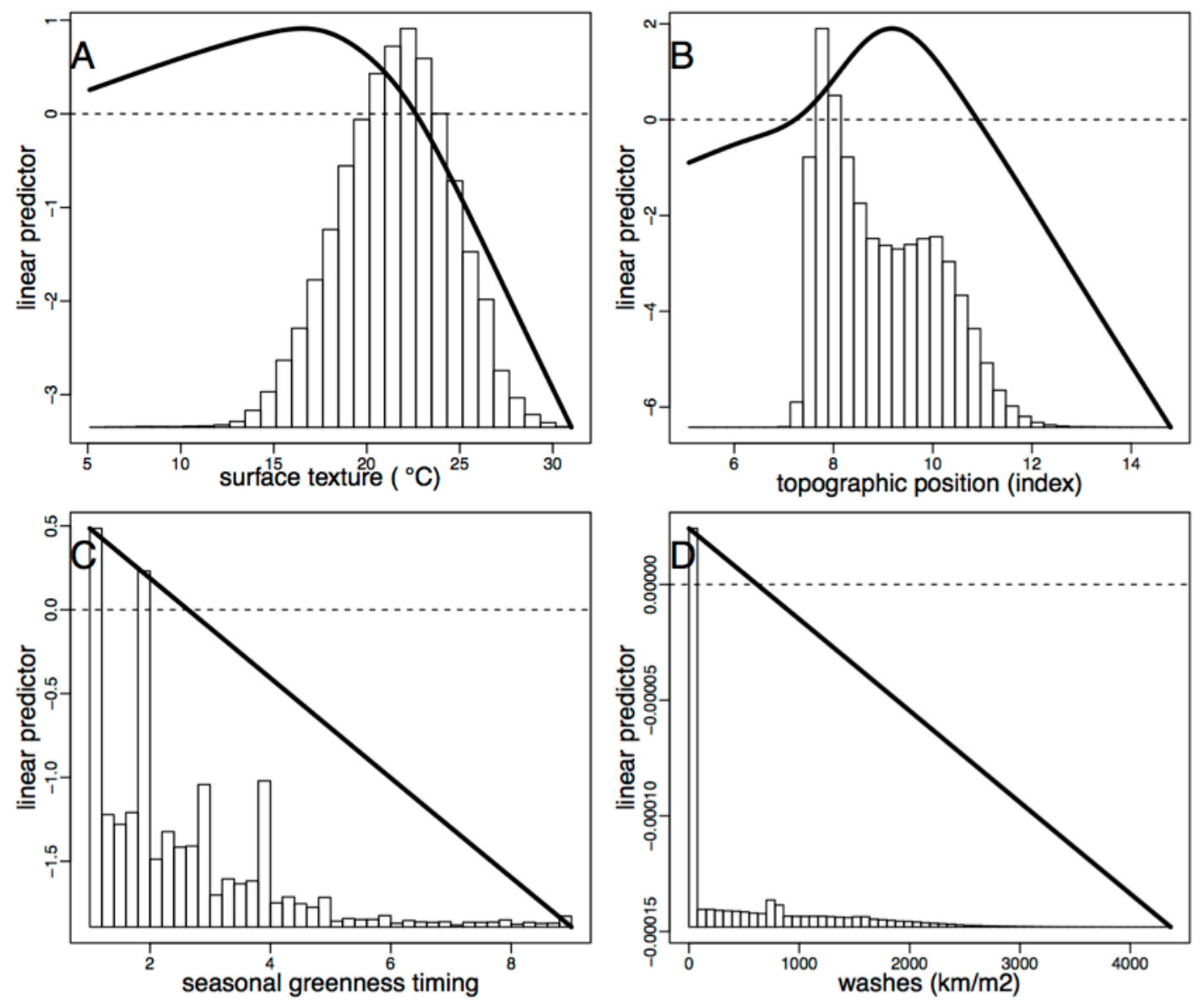

Figure 16. Generalized response curves and histograms for Homalonychus genus (Homalonychus spiders) for environmental covariances. Histograms are derived from a random sample of the study area and illustrate the distribution of covariates across the landscape. Response curves are derived from a single model that is inclusive of all covariates represented in the selected models for the Homalonychus genus, where each of the covariates is held at their study area mean. The dotted line shows linear predictor value of 0 . Only the four highest contributing covariates are shown. 


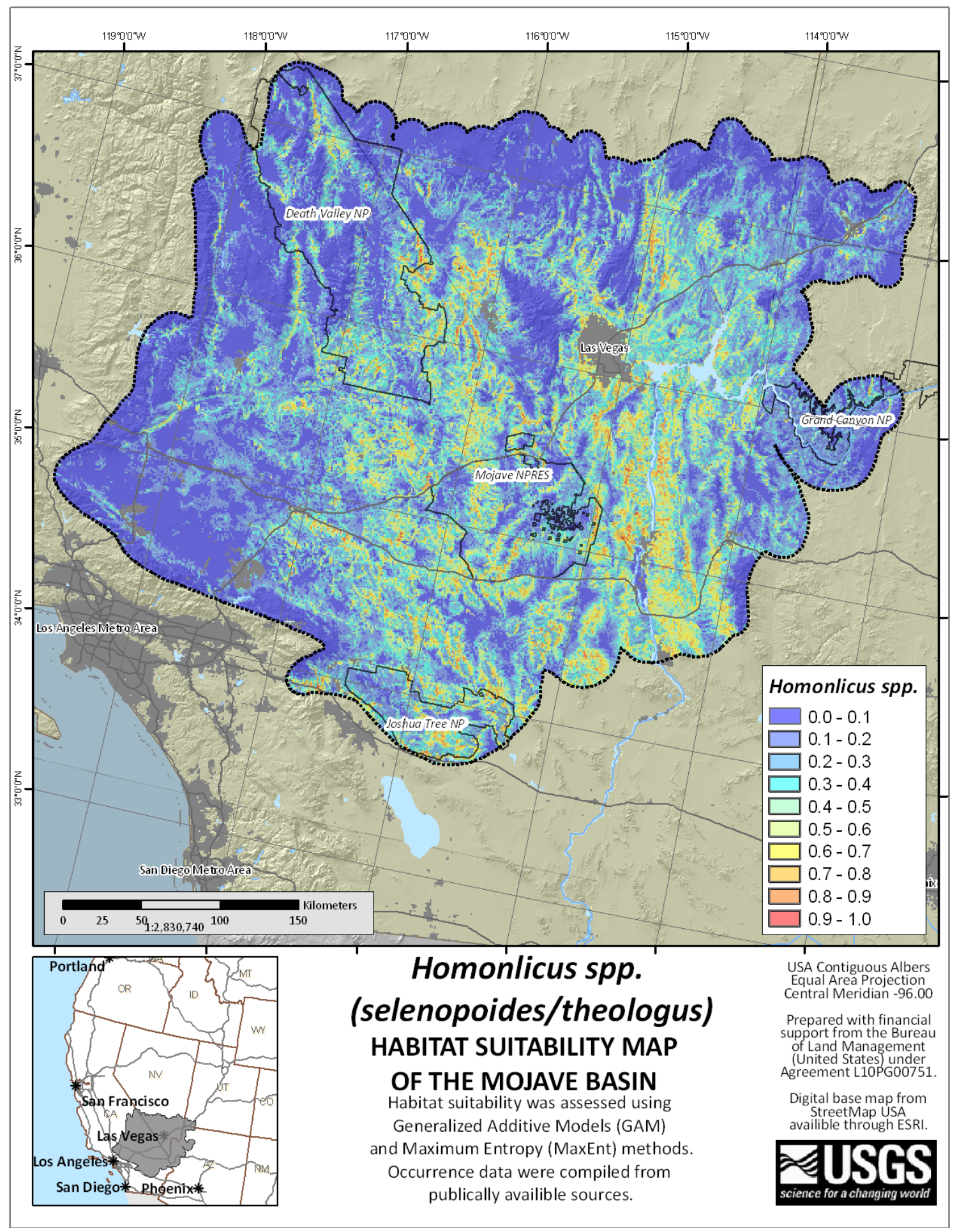

Figure 17. Map showing average habitat suitability among the selected models for Homalonychus spiders. Values range from $0 \sim 1$, and correspond to an index of habitat suitability, where areas with high suitability are shown in red; areas with low suitability are shown in blue. 


\section{Lichanura trivirgata}

Conceptual Model. - L t trivirgata occur in areas with granite boulders and chaparral vegetation associations (Klauber, 1931). Other habitat associations include non-granite rocky substrates, and areas near permanent water sources, such as springs or oases, especially in arid environments (Stebbins, 2003). We characterized surface material and soil texture by including surface texture, rocky surfaces, seasonal thermal change, mountain bases, topographic position, and cliffs. The surface texture and rocky surfaces layers were used to identify areas with suitable surface rock material, although seasonal thermal change was used to capture areas that were more stable throughout the year with respect to surface temperature. We had hypothesized that areas with less thermal stability would be less suitable for L. trivirgata because L. trivirgata are poikilotherms, and must select microhabitats with tolerable climates rather than relying on metabolic thermoregulation. We used mountain bases, cliffs, and topographic position to represent the preference for terrain features, such as low mountain edges, rocky canyons, and rocky outcrops. However, L. trivirgata also have been found in rock-free flats with slopes less than 5 percent in areas where rodent burrows are common in the Sonoran Desert (Arizona Game and Fish Department, 2003). We used alluvial fan proximity, slope, winter precipitation, washes, soil water stress, and seasonal greenness ratio to approximate these habitat characteristics.

Habitat Model Results. - We selected nine models from the suite of possible GAM models to run as MaxEnt models, resulting in a total of 18 models that were reviewed by our collaborators. Twelve of the 18 models were included in the final averaged model, which represented nine covariate layers - elevation, seasonal thermal variance, winter precipitation, topographic position, vegetation greenness timing, washes, cliffs, mountain bases, and alluvial fan proximity. Elevation was in all but 1 of 12 of the selected models and had the highest relative contribution of 33 percent; seasonal thermal change was in 7 of the 12 selected models and had a relative contribution of 22 percent. Winter precipitation was in 6 of the 12 selected models and also had a relative contribution of 22 percent. The remaining covariate layers were each present in fewer than three models, and each had relative contributions less than 10 percent. The covariate layer, alluvial fan proximity, was used in two of the selected models and had a relative contribution of 8 percent, and mountain bases was included in 3 of the 12 selected models and had a relative contribution of 5 percent. Topographic position also was used in 3 of the 12 models and had a relative contribution of 4 percent. The remaining four covariate layers, seasonal greenness timing, cliffs, slope, and washes, were included in one model each, with relative contributions of $3,1,<1$, and $<1$ percent, respectively.

We found moderate to high agreement among the 12 models in the southern parts of the study area, with less agreement in the northern and eastern parts of the study area (fig. 18). In particular, midelevations provided the least agreement among models, while low elevation valley bottoms and high elevation mountain peaks had high agreement. The final averaged habitat suitability model for $L$. trivirgata had an AUC score of 0.91 and a BI score of 0.87 (table 1), which was one of the highest among our study species. The averaged model was reclassified into high and low habitat suitability, which resulted in $59,521 \mathrm{~km}^{2}$ of high habitat suitability based on the fifth quantile of the observation records (break value $=0.34$, fig. 19). In general, areas with high habitat suitability were confined to mid-elevation, rocky terrain near the base of steep mountains. The Baker Sink landform provides a notable break in habitat between the southwestern and northeastern parts of the Mojave Desert Basin. 


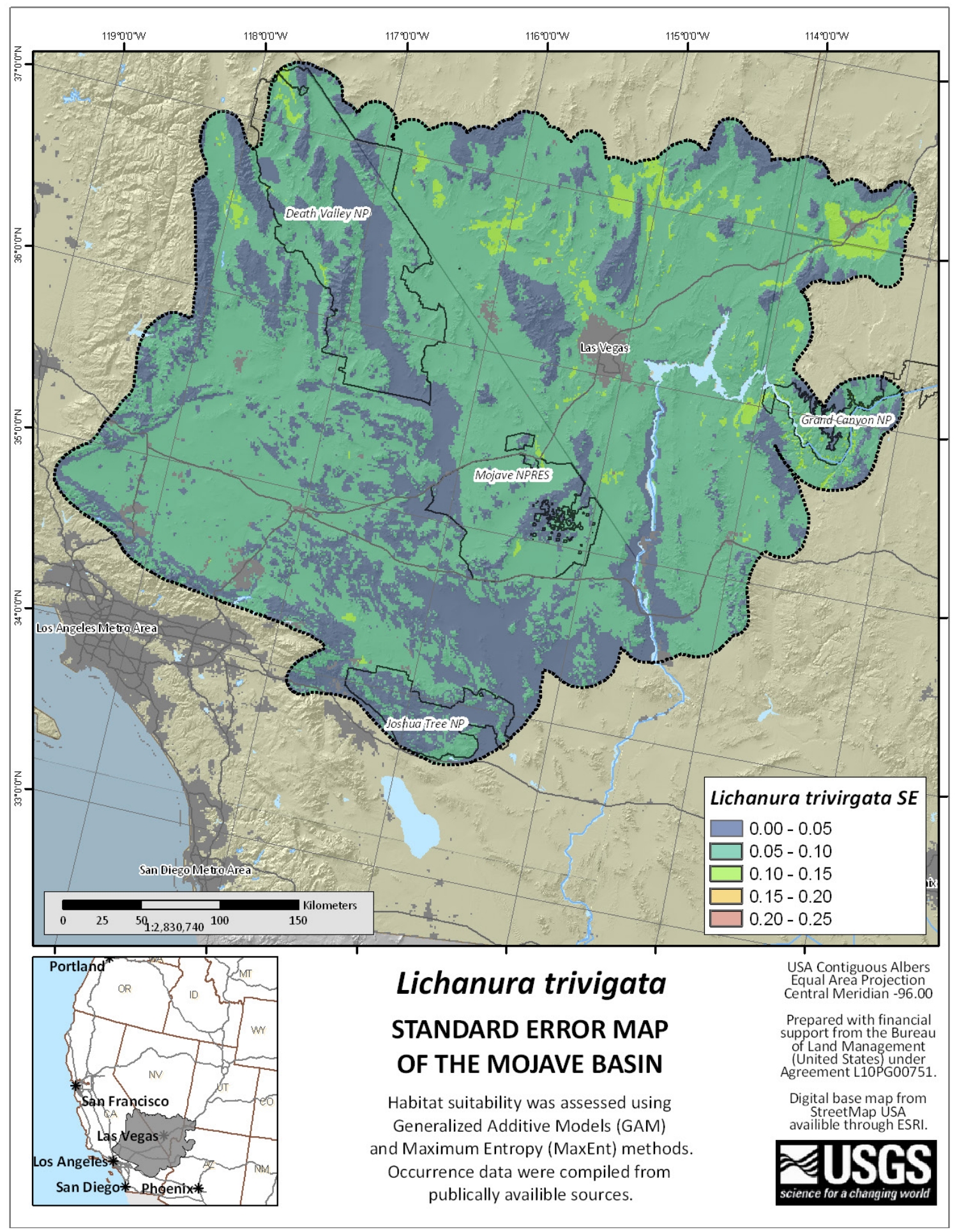

Figure 18. Map showing standard error $(\sigma / \mathrm{N})$ among the selected models for Lichanura trivirgata (Rosy Boa). Areas where the selected models provided similar habitat suitability scores are shown in blue, and areas with low similarity are shown in red. Although not a measure of true model error, these agreement maps provide a general measure of model uncertainty across the landscape and show areas where the selected models agree (or disagree) with respect to habitat suitability. 


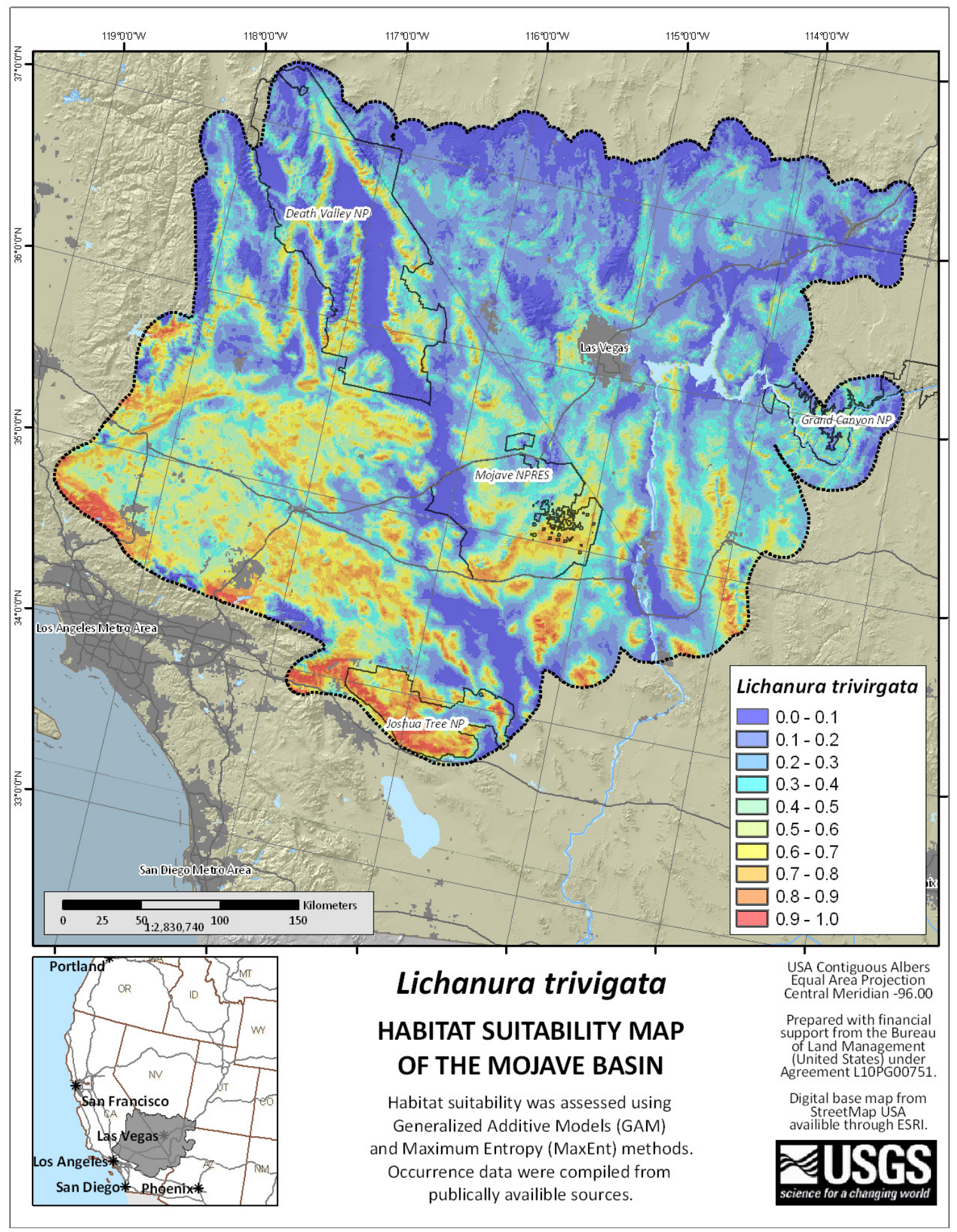

Figure 19. Average habitat suitability among the selected models for Lichanura trivirgata (Rosy Boa). Values range from $0 \sim 1$, and correspond to an index of habitat suitability, where areas with high suitability are shown in red; areas with low suitability are shown in blue. 
Habitat Model Discussion.-We hypothesized that habitat suitability for L. trivirgata would be associated with our modeled environmental covariates representing surface substrates (surface texture and rocky surfaces), but instead found that elevation provided the greatest relative contribution and was the single most prevalent covariate in the selected models. L. trivirgata habitat suitability was negatively related to elevation, suggesting a lower suitability of high elevation areas (fig. 20A). As with many of the other species, we assume that the importance of elevation is not due to a direct explanation of $L$. trivirgata habitat, but rather a coincidence of the correlation between elevation and other habitat covariates that we were unable to measure or model. Surface texture and rocky surfaces covariate layers were derived from MODIS Land Surface Temperature data, at a spatial scale of $1 \mathrm{~km}$, which may be too coarse to identify rocky features (that is, boulders, small cliffs, and outcrops) that L. trivirgata use as habitat. L. trivirgata also tend to occur in areas with relatively stable surface temperatures between summer and winter months (fig. 20B). L. trivirgata can inhabit ridge-like features and mountain slopes, both of which have more similar summer and winter temperatures than valley bottoms. Latitude, however, is the primary determinant of summer and winter surface temperature differences, and in general, L. trivirgata are found in the more southern regions of the study area where winter temperatures are less extreme. Winter precipitation showed a positive trend with habitat suitability and exhibited an apparent threshold near $64 \mathrm{~mm}$ of winter precipitation, above which habitat suitability remained high (fig. 20C). Alluvial fans do not appear to constitute suitable habitat (fig. 20D), although distances just more than $1 \mathrm{~km}$ from them were often suitable. The negative relationship of alluvial fans also was corroborated by the response curves of the topographic position layer (fig. 20F), which also suggested an avoidance of alluvial fans, along with an avoidance of valley bottoms and dry lakebeds.

The modeled response of the mountain bases layer suggested a preference for areas classified as mountain bases (fig. 20E), which often contain granite boulder fields and other rocky terrain. The lack of soil water stress or seasonal greenness ratio in any of the selected models was unexpected due to the known association of $L$. trivirgata with permanent water sources in the Mojave Desert (Stebbins, 2003). Although not a true representation of permanent water sources, we had hypothesized that these two layers would capture some of the geographic variation in L. trivirgata observations near riparian areas. The seasonal greenness timing layer was present in one of the selected models, suggesting a preference for areas where vegetation achieves peak greenness earlier in the season in this instance. The model response to the cliffs layer that suggested a preference for areas without cliffs was unexpected, and the model response for slope suggested a preference for areas with high slope. These two layers were correlated with one another $(\mathrm{r}=0.83, \mathrm{~N}=1,000, \mathrm{p}<0.001)$, but were not included together in any single model, and showed very different relationships with $L$. trivirgata habitat suitability. 

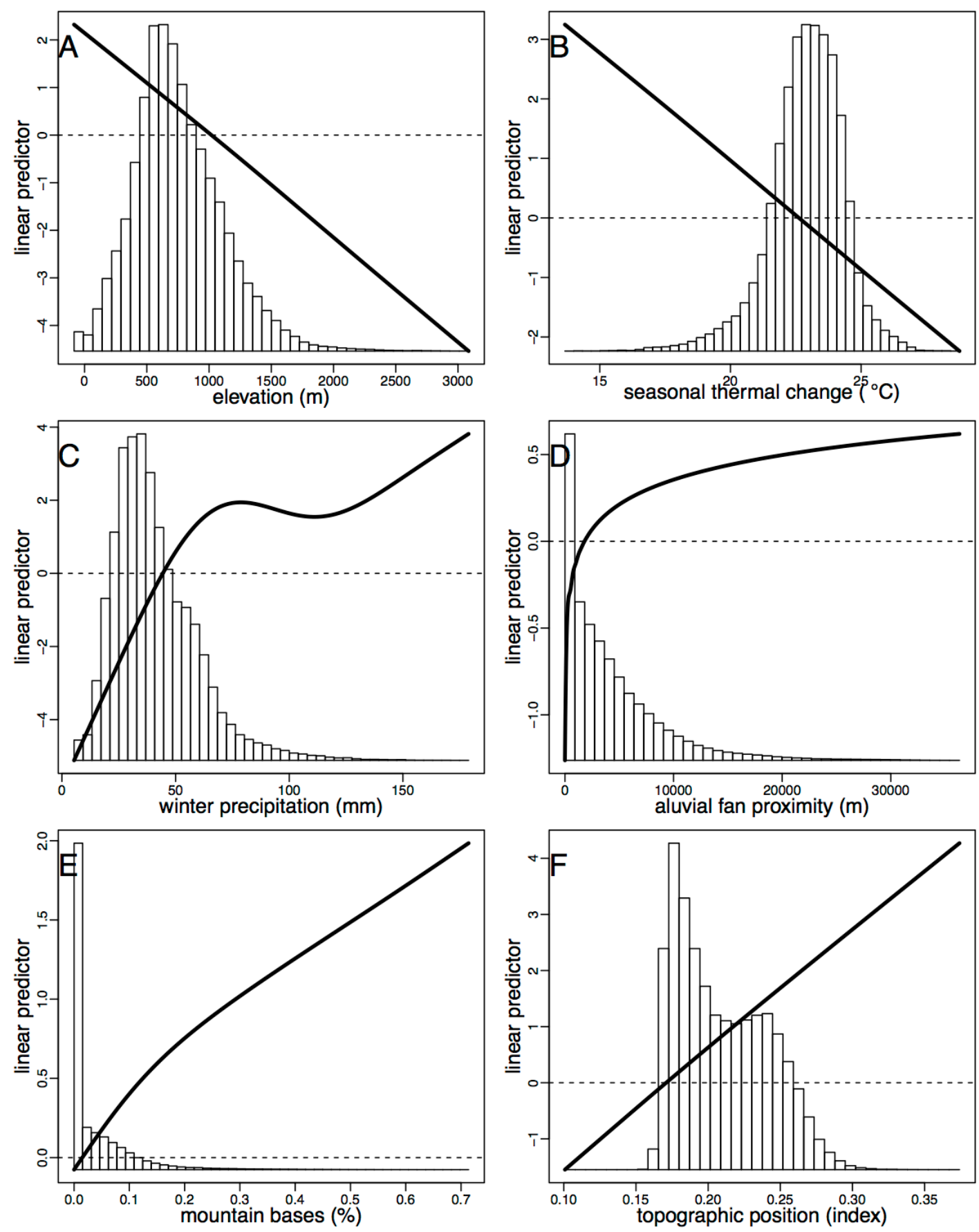

Figure 20. Generalized response curves and histograms for Lichanura trivirgata (Rosy Boa) for environmental covariates. Histograms are derived from a random sample of the study area and illustrate the distribution of covariates across the landscape. Response curves are derived from a single model that is inclusive of all covariates represented in the selected models for $L$. trivirgata, where each of the covariates is held at their study area mean. The dotted line shows linear predictor value of 0 . Only the six highest contributing covariates are shown. 


\section{Perognathus longimembris}

Conceptual Model. - P. longimembris occur in areas with relatively flat, sandy, or gravelly substrates with widely spaced shrubs (Jameson and Peeters, 1988; Zeveloff, 1988). In some parts of their range, $P$. longimembris are found in gravel washes and in areas with L. tridentata and Yucca spp. (Chew and Butterworth, 1964; Miller and Stebbins, 1964), and are rarely found on rocky or steep slopes. We included washes, surface texture, sandy surfaces, and slope to represent these gravelly and wash-like habitat characteristics. Due to their small size, $P$. longimembris are more susceptible to cold weather extremes, and can experience rapid changes in body temperatures if exposed to pronounced environmental variation (Bartholomew and Cade, 1957). This may limit their occupied habitat to areas without cold extremes during winter months and areas that provide longer durations of acceptable surface temperatures. We included winter surface temperature and seasonal thermal change to represent areas where winter temperatures are less severe, and areas with more similar summer and winter surface temperatures. We hypothesized that these areas would be more suitable for P. longimembris. Additional vegetation covariates, vegetation greenness timing, seasonal greenness ratio, and vegetation greenness coefficient of variation were used to capture the yearly persistence of green vegetation, as well as areas with low shrub density.

Habitat Model Results. - We selected 9 models from among the suite of possible GAM models to run as MaxEnt models, resulting in a total of 18 models that were reviewed by our collaborators. Unlike many of the other species, there were very few differences among the 18 models, and therefore all 18 models were included in the final averaged model, which represented 10 covariate layers. The covariate layers represented in the final averaged model and their relative contributions were winter precipitation (49 percent), topographic position (36 percent), seasonal thermal change ( 8 percent), seasonal greenness ratio ( 2 percent), seasonal greenness timing ( 2 percent), soil water stress ( 1 percent), surface texture ( 1 percent), mountain bases $(<1$ percent), and washes $(<1$ percent). Elevation and topographic position were present in all 18 models; seasonal thermal change was present in 12 models; seasonal greenness timing was present in 6 models; seasonal greenness ratio and soil water stress were present in 4 models; and surface texture, mountain bases, and washes were present in 1 model each.

There was high agreement across all selected models (fig. 21), with very few areas showing standard errors greater than 0.05. The final averaged model had an AUC score of 0.78 and a BI score of 0.75 (table 1), and was reclassified into high and low habitat suitability based on the fifth quantile of the observation records (break value $=0.27$ ), which resulted in $98,515 \mathrm{~km}^{2}$ of high habitat suitability. These areas were generally in flat, low elevation terrain, although as with L. trivirgata, the Baker Sink landform provided a notable break in habitat across the study area (fig. 22). 


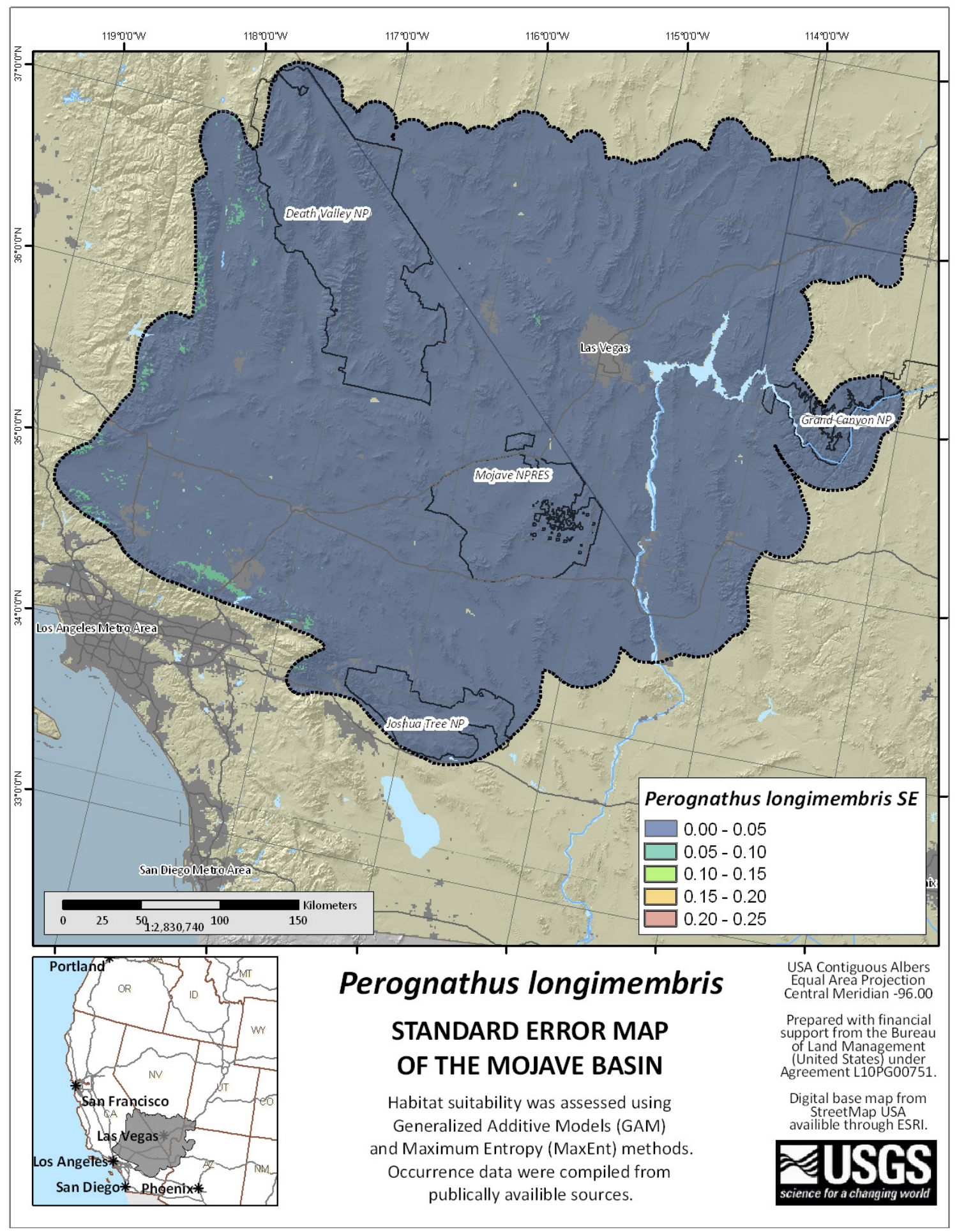

Figure 21. Map showing standard error $(\sigma / \mathrm{N})$ among the selected models for Perognathus longimembris (Little Pocket Mouse). Areas where the selected models provided similar habitat suitability scores are shown in blue, and areas with low similarity are shown in red. Although not a measure of true model error, these agreement maps provide a general measure of model uncertainty across the landscape and show areas where the selected models agree (or disagree) with respect to habitat suitability. 


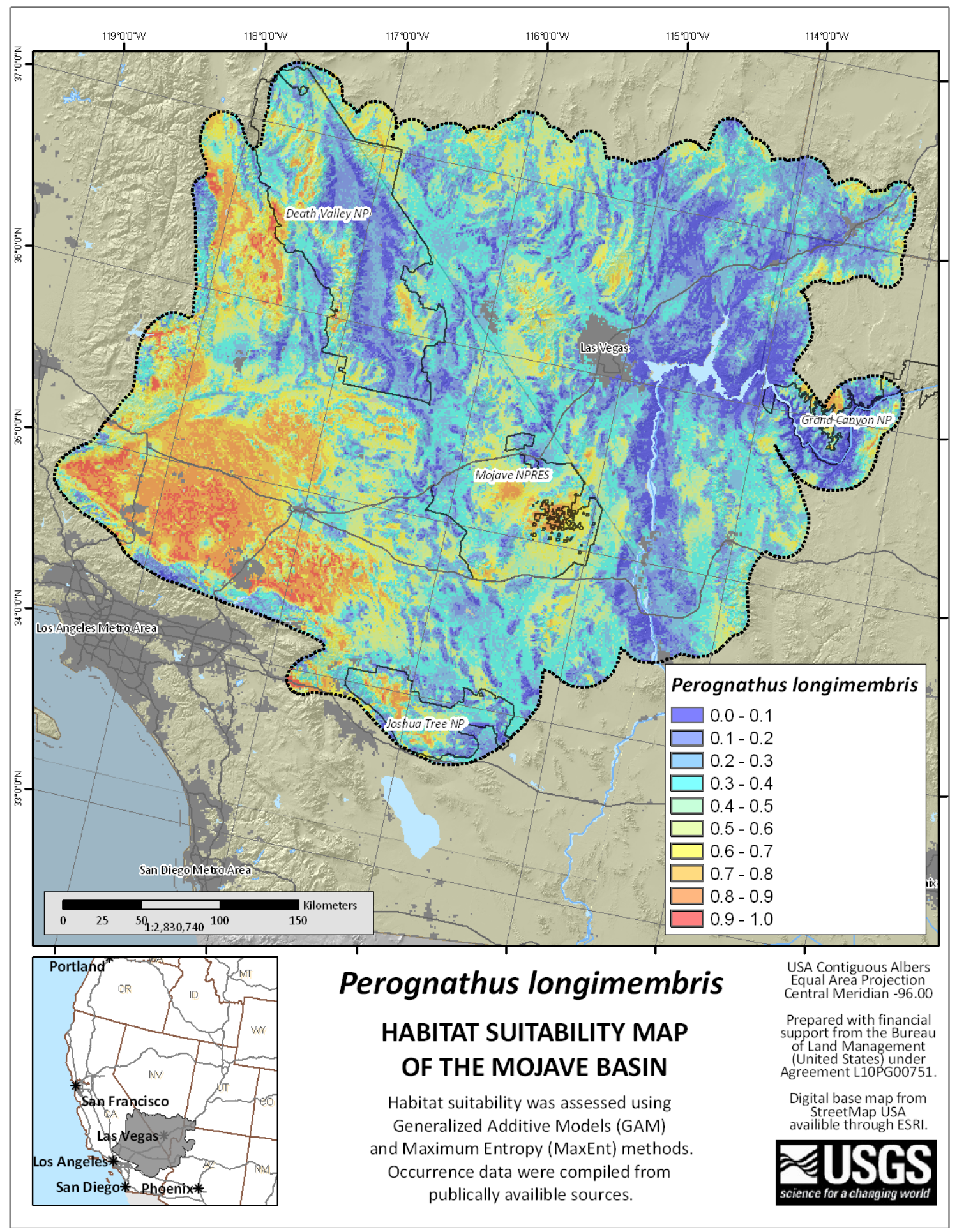

Figure 22. Average habitat suitability among the selected models for Perognathus longimembris (Little Pocket Mouse). Values range from $0 \sim 1$, and correspond to an index of habitat suitability, where areas with high suitability are shown in red; areas with low suitability are shown in blue. 
Habitat Model Discussion. - We hypothesized that $P$. longimembris would be associated with the washes and alluvial fan proximity environmental covariates, but instead found a high association with winter precipitation and topographic position (figs. 23A and 23B). Each of these covariates showed a peaked response, suggesting a preference for intermediate ranges of winter precipitation and topographic position, which generally corresponded to areas with alluvial fans, mildly sloped valleys and areas near the bases of mountains, but not valley bottoms or high drainage areas, such as dry lakebeds and playas. The apparent avoidance of areas with very low or very high winter precipitation suggests a preference for an optimal amount of winter precipitation, likely coinciding with vegetation communities that are tied to intermediate levels of winter precipitation (Beatley, 1976; Turner and Randall, 1989). Areas with moderate winter precipitation were generally in the Western Mojave Desert along valley washes and the bases of mountains, which receive greater winter precipitation than similar terrain in the eastern parts of the Mojave Desert, and less winter precipitation than in the high-elevation mountains.

Alluvial fan proximity was not included in any of the selected models, even though the layer on which it was based (topographic position) showed the second highest relative contribution, and was prevalent in all selected models. The modeled response for the covariate layer seasonal thermal change suggested decreased habitat suitability in areas with high thermal variation from summer to winter (fig. 23C), such as the valley bottoms of northern latitudes in the study area, which have very cold winters and warm summers. However, $P$. longimembris were not found on large mountain tops or ridge-like features at high elevations, both of which also show low thermal variation between summer and winter, but are instead relatively cold throughout the year. The remaining 6 covariate layers showed relative contributions of less than 2 percent, and each was included in fewer than 6 of the 18 selected models. Although these covariates provided relatively little contribution to the final averaged model, each showed relationships to $P$. longimembris habitat suitability that were not unreasonable given our expectations (figs. 23D-23F). 

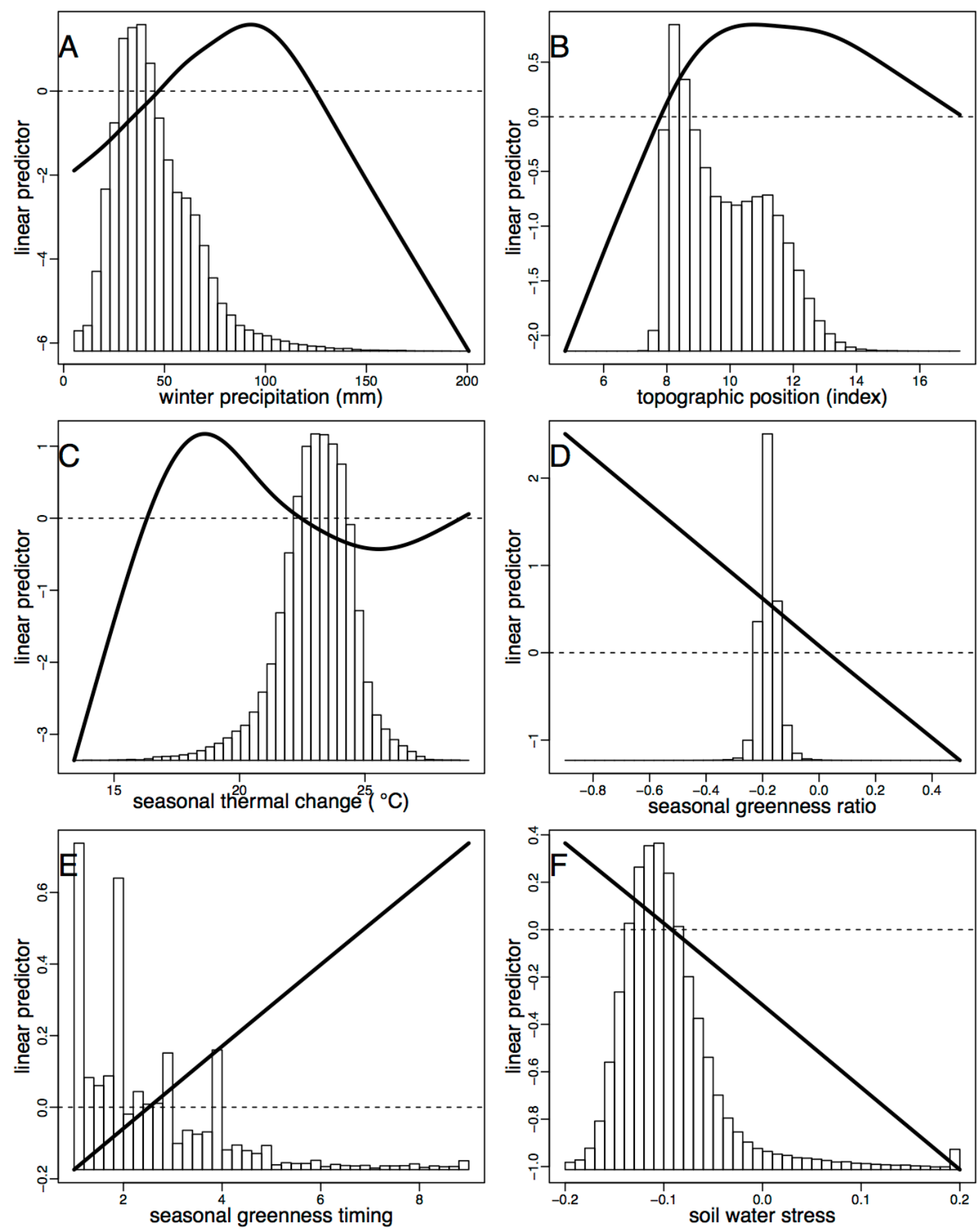

Figure 23. Generalized response curves and histograms for Perognathus longimembris (Little Pocket Mouse) for environmental covariates. Histograms are derived from a random sample of the study area and illustrate the distribution of covariates across the landscape. Response curves are derived from a single model that is inclusive of all covariates represented in the selected models for $P$. longimembris, where each of the covariates is held at their study area mean. The dotted line shows linear predictor value of 0 . Only the six highest contributing covariates are shown. 


\section{Plestidon gilberti}

Conceptual Model.- P. gilberti occur in rocky boulder filled areas with decomposed granite (Jones and others, 1985; Stebbins, 2003). They are often found near permanent or semi-permanent water sources, and near the base of mountains in the Mojave Desert (Rodgers, 1944; Stebbins, 2003). To capture these habitat preferences, we included surface texture, rocky surfaces, cliffs, topographic position, and mountain bases. $P$. gilberti are ubiquitous across their range, occupying a wide range of habitats within and outside of the Mojave Desert. We included the covariate layers soil water stress, vegetation greenness timing, and seasonal greenness ratio to represent geographic variation in surface water and vegetation characteristics, and as a proxy for surface water and riparian vegetation. The environmental covariates washes, alluvial fan proximity, and slope were used to capture the broad range of desert scrub habitat, while seasonal thermal change was used to represent the thermal stability of an area. We hypothesized that areas along the edges of alluvial fans in low to moderate slope with more thermal stability would be more suitable for P. gilberti.

Habitat Model Results. - We selected 8 models from the suite of possible GAM models to run as MaxEnt models, resulting in a total of 16 models that were reviewed by our collaborators. Only two of the MaxEnt models were included in the final averaged model, which represented six covariate layers - soil water stress, surface texture, mountain bases, winter precipitation, elevation, and cliffs. The following covariates were included in both of the selected models (relative contributions shown in parentheses): winter precipitation (73 percent), mountain bases (10 percent), surface texture ( 9 percent), and soil water stress (5 percent).

The final averaged model had an AUC score of 0.86 and a BI score of 0.59 (table 1 ). There was high agreement between the two selected models, but we did not calculate a standard error map due to the low sample size. The averaged $P$. gilberti habitat suitability model was reclassified into high and low habitat suitability, which resulted in $60,983 \mathrm{~km}^{2}$ of high habitat suitability based on the fifth quantile of the observation records (break value=0.14, fig. 24). 


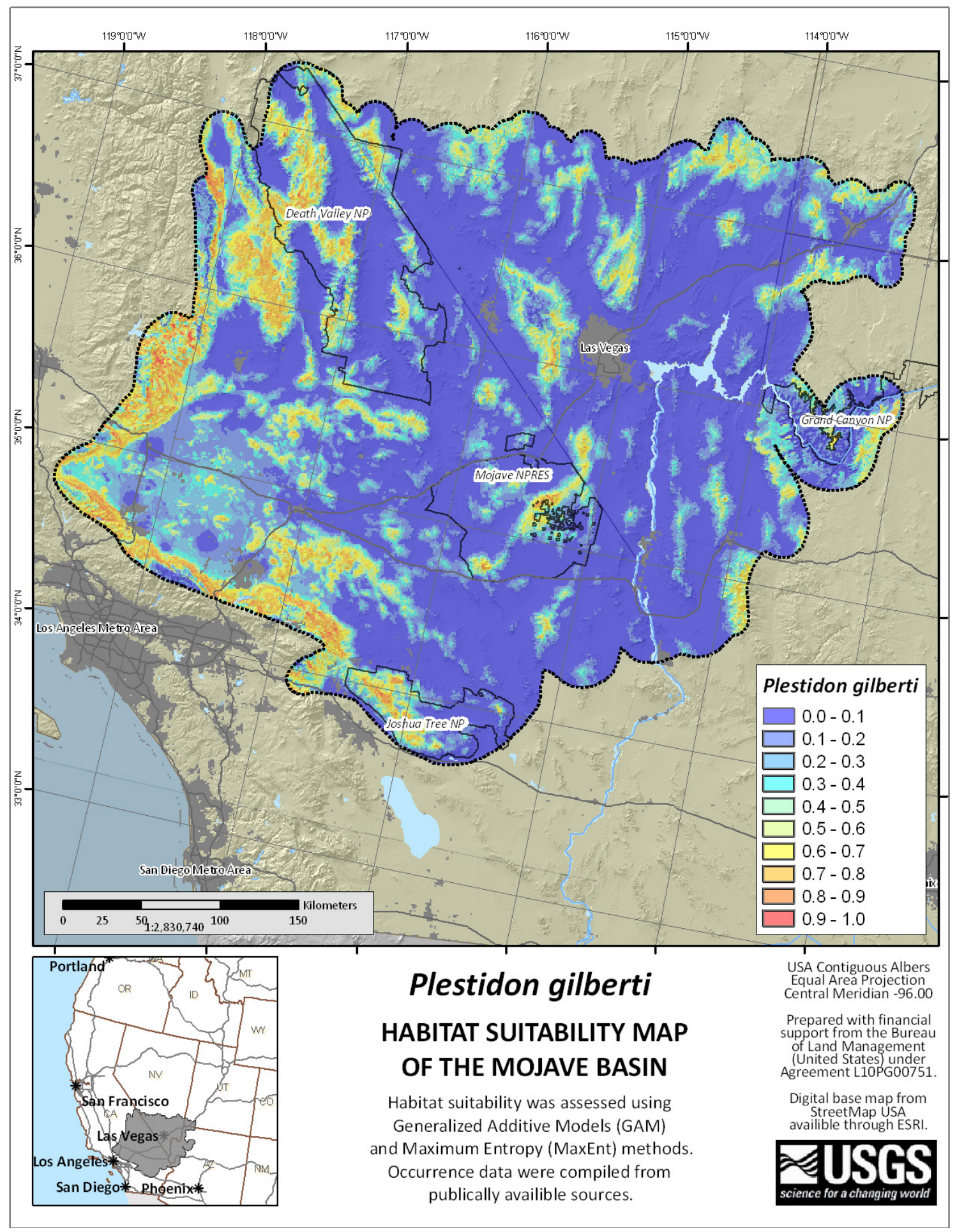

Figure 24. Map showing average habitat suitability among the selected models for Plestidon gilberti (Gilbert's Skink). Values range from $0 \sim 1$, and correspond to an index of habitat suitability, where areas with high suitability are shown in red; areas with low suitability are shown in blue. 
Habitat Model Discussion. - We hypothesized that the covariate layers rocky surfaces, mountain bases, and surface texture would be some of the most important predictors of $P$. gilberti habitat suitability due to $P$. gilberti's prevalence in areas with rocky boulders and decomposed granite. However, of these three layers, only mountain bases and surface texture were included in both of the selected models, and neither showed a high relative contribution to the final averaged model. The modeled response for mountain bases did, however, show a positive relationship to $P$. gilberti habitat suitability (fig. 25B), suggesting an increase in habitat suitability with increased coverage of mountain bases. This is concordant with current evidence suggesting that $P$. gilberti tend to occur in areas with decomposed granite near the base of mountains (Rodgers, 1944; Stebbins, 2003). Similarly, P. gilberti habitat suitability was higher in areas where surface texture showed more rock-like substrates, suggesting decreased suitability in silty, sandy and gravelly areas (fig. 25C), which supported observations of $P$. gilberti in rocky habitats (Jones and others, 1985; Stebbins, 2003).

The surface texture and rocky surfaces covariate layers were derived from MODIS Land Surface Temperature data, and therefore have a spatial scales of $1 \mathrm{~km}$, which is likely too coarse to identify rocky features (that is, boulders, and decomposed granite) that $P$. gilberti use as habitat. Additional work is likely needed to develop covariate layers that accurately reflect the physical properties of the surface substrate at a spatial scale relevant to $P$. gilberti.

Instead of describing the physical terrain of $P$. gilberti, the most influential covariate in the habitat suitability model was winter precipitation, which showed positive relationship with $P$. gilberti habitat suitability (fig. 25A). This relationship suggested an avoidance of areas with low cumulative winter precipitation, and a preference for areas with more than $50 \mathrm{~mm}$ of winter precipitation. The soil water stress covariate was negatively related to habitat suitability, which was likely due to the positive relationship between soil moisture and conifer forests and standing water (Cheng and others, 2006, 2008), both of which are not occupied by $P$. gilberti. 

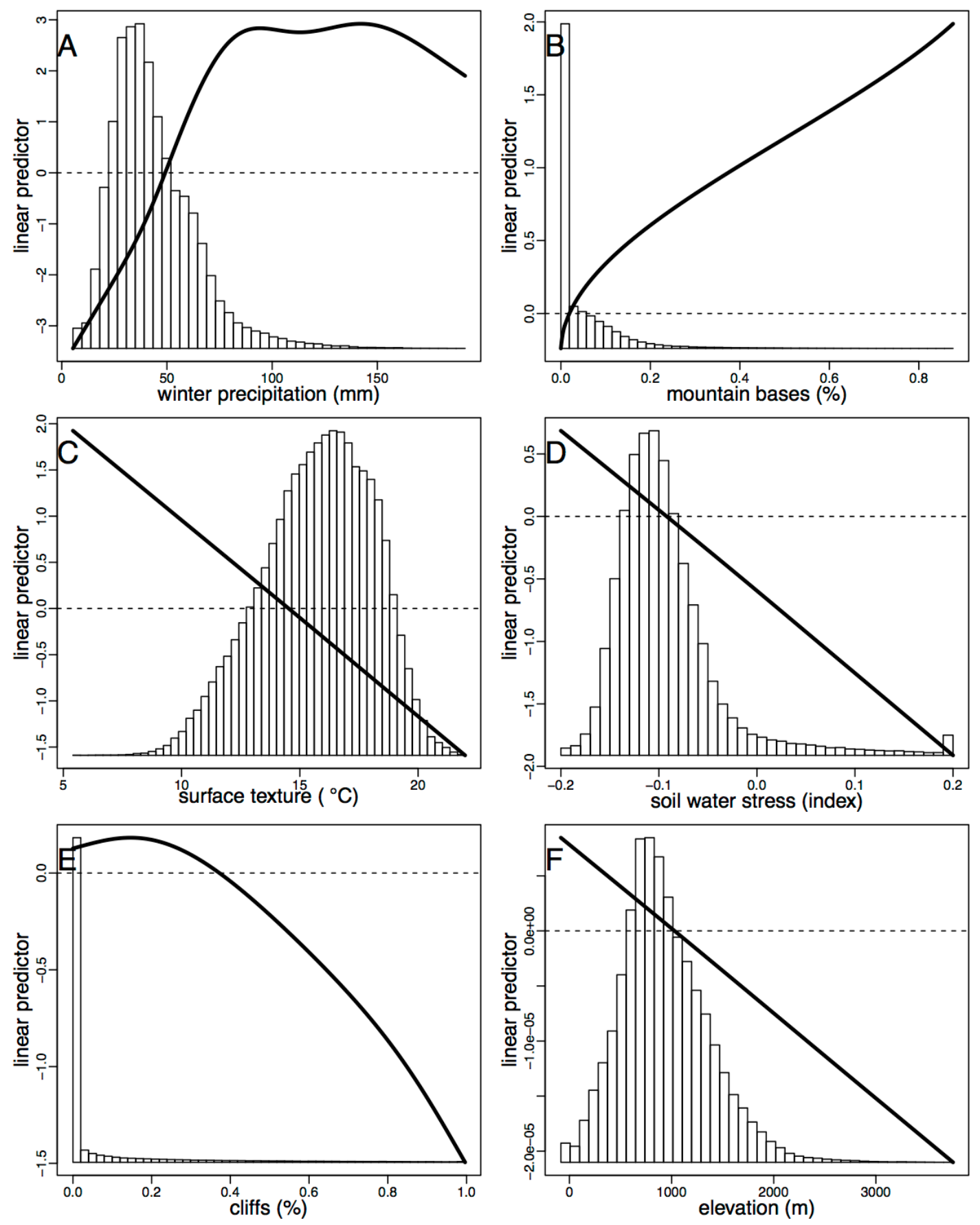

Figure 25. Generalized response curves and histograms for Plestidon gilberti (Gilbert's Skink) for environmental covariates. Histograms are derived from a random sample of the study area and illustrate the distribution of covariates across the landscape. Response curves are derived from a single model that is inclusive of all covariates represented in the selected models for $P$. gilberti , where each of the covariates is held at their study area mean. The dotted line shows linear predictor value of 0 . Only the six highest contributing covariates are shown. 


\section{Sceloporus magister}

Conceptual Model. - S. magister are found in rocky terrain, often with large boulders and large sections of exposed rock (Turner and Wauer, 1963; Parker and Pianka, 1973; Stebbins, 2003). They often occur in canyons, washes, and foothills, up to areas where pinyon-juniper vegetation occurs (Turner and Wauer, 1963; Parker and Pianka, 1973). We included the environmental covariates surface texture, rocky surfaces, slope, alluvial fan proximity, washes, mountain bases, cliffs, and topographic position to capture desert spiny lizards' preference for rocky habitats, canyons, and foothills.

$S$. magister also can be found in upland habitats as well, usually near trees or other large vegetation (Parker and Pianka, 1973) in areas characterized by creosote bush, mesquite, burro bush, and salt bush (among others). Although we did not have covariate layers describing vegetation communities directly, we used vegetation greenness, vegetation greenness timing, seasonal greenness ratio, and soil water stress as proxies for distinguishing vegetation types among Mojave Desert habitats. We also included winter precipitation because of the positive relationship between winter precipitation and spring plant production (Beatley, 1976; Turner and Randall, 1989).

Habitat Model Results. - We selected 9 models from among the suite of possible GAM models to run as MaxEnt models, resulting in a total of 18 models that were reviewed by our collaborators. Seven MaxEnt models were included in the final averaged model, which represents eight covariate layers - topographic position, seasonal thermal change, elevation, vegetation greenness timing, mountain bases, washes, rocky surfaces, and soil water stress. Relative contributions for the eight covariate layers were 51 percent (elevation), 15 percent (topographic position), 11 percent (seasonal thermal change), 6 percent (mountain bases), 6 percent (rocky surfaces), 4 percent (vegetation greenness timing), 4 percent (washes), and 2 percent (soil water stress), and were included in 7, 4, 5, 2, 3, 4, 3, and 1 of the 18 possible models, respectively.

Generally, there was high agreement among the selected models (fig. 26), with few areas showing standard errors greater than 0.05 . The final averaged model had an AUC score of 0.72 and a BI score of 0.33 (table 1), and was reclassified into high and low habitat suitability, and resulted in 111,731 $\mathrm{km}^{2}$ of high habitat suitability based on the fifth quantile of the observation records (break value $=0.31$, fig. 27). 


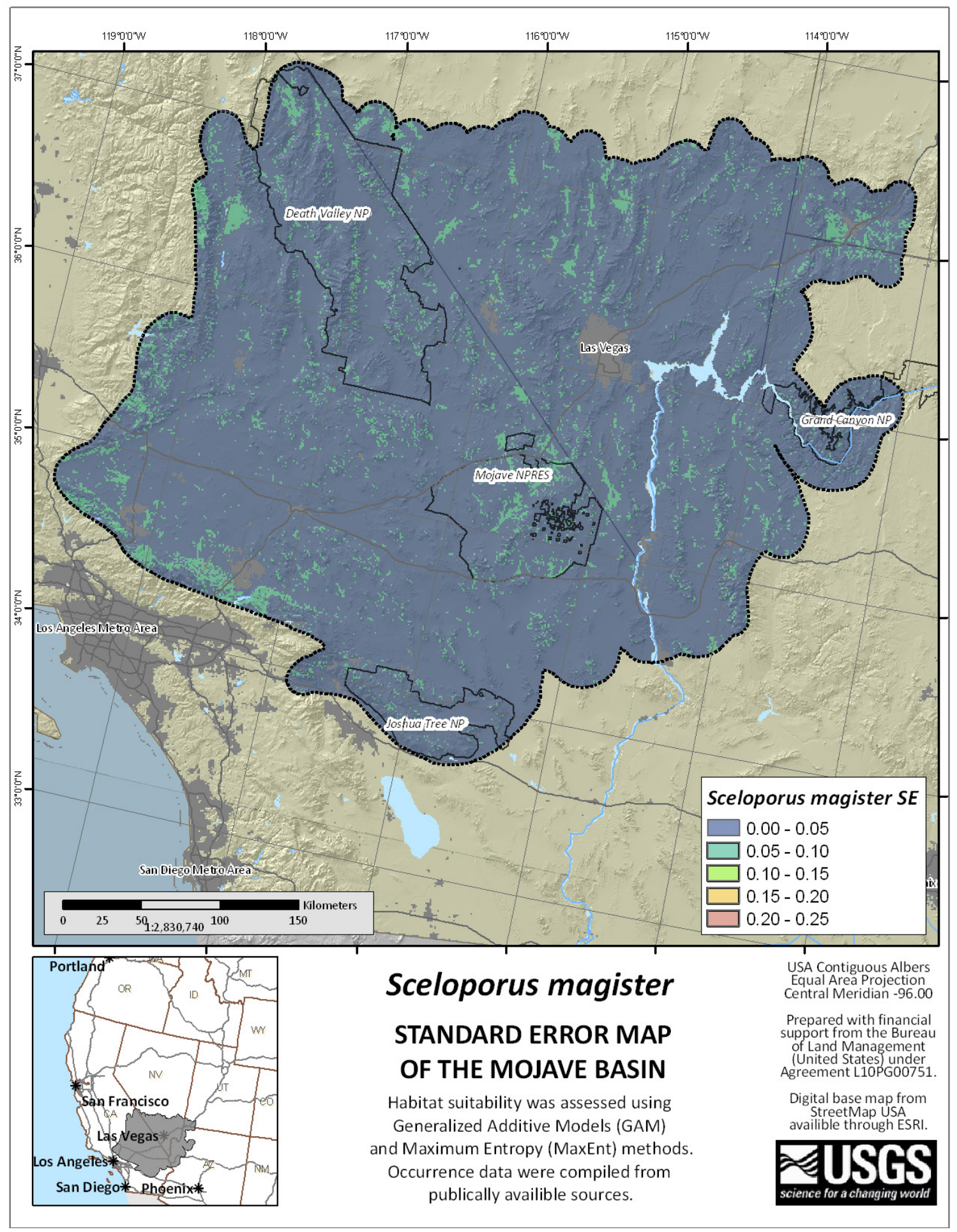

Figure 26. Map showing standard error $(\sigma / \mathrm{N})$ among the selected models for Sceloporus magister (Desert Spiny Lizard). Areas where the selected models provided similar habitat suitability scores are shown in blue, and areas with low similarity are shown in red. Although not a measure of true model error, these agreement maps provide a general measure of model uncertainty across the landscape and show areas where the selected models agree (or disagree) with respect to habitat suitability. 


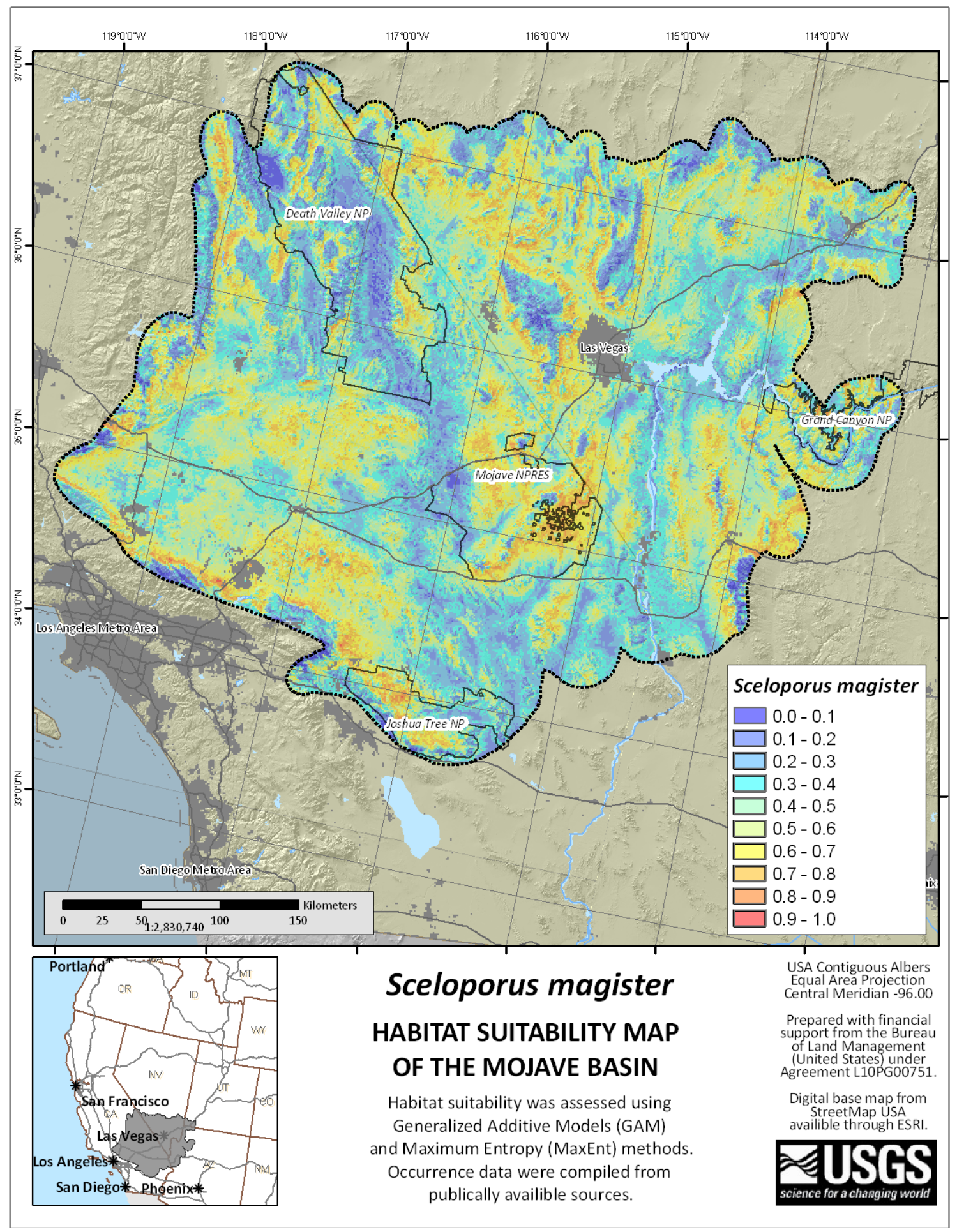

Figure 27. Average habitat suitability among the selected models for Sceloporus magister (Desert Spiny Lizard). Values range from $0 \sim 1$, and correspond to an index of habitat suitability, where areas with high suitability are shown in red; areas with low suitability are shown in blue. 
Habitat Model Discussion. - We hypothesized that S. magister habitat suitability would be related to washes, rocky terrain, mountain bases, or other areas with large boulders. Although each of these covariate layers were present in up to three of our selected models, none were most prevalent among the covariates represented by the final averaged model. This suggests that while washes, rocky terrain, and mountain bases impart some explanatory power on S. magister habitat suitability, these three layers do not fully explain the geographic variation in habitat suitability. Instead, elevation was the single most prevalent covariate, and also had the highest relative contribution of all environmental covariates, suggesting that elevation alone accounted for more of the variation in geographic distribution of $S$. magister habitat suitability than any of the other environmental covariates. Habitat suitability decreased sharply at elevations greater than $1,500 \mathrm{~m}$, with a peak elevation between 700 and $1,400 \mathrm{~m}$ (fig. 28A), which was unlike many descriptions of $S$. magister habitat that suggest high prevalence down to sea level (Stebbins, 2003; Jones and Lovich, 2009). The model response for the topographic position layer confirmed current hypotheses of $S$. magister habitat by suggesting and avoidance of areas, such as valley bottoms or alluvial fan apexes, as well as an avoidance of high ridge tops and high elevation areas (fig. 28B).

Seasonal thermal change also was a strong predictor of $S$. magister habitat suitability, as evidenced by its inclusion in all but one of the selected models and relative contribution of 11 percent. As with elevation and topographic position, seasonal thermal change showed a peak response in the middle of the range found in the Mojave Desert, suggesting decreased suitability of areas with extremely low or extremely high seasonal thermal differences (fig. 28C). These areas were correlated with areas on mountain tops in the southern latitudes and valley bottoms in the more northern latitudes. Although derived as a measure of the seasonal change in surface radiant temperature, seasonal thermal change is related to surface material type, slope, aspect and latitude, and reflects seasonal change in the thermal environment that an organism can experience. As with many of the environmental covariates used in the habitat models presented here, the spatial scale at which seasonal thermal change was derived precludes analyses of microhabitat or fine scale resource selection, such as the preference for a particular type of boulder or specific thermal operative temperature.

Although the mountain bases covariate was present in only two of the selected models, it showed a relative contribution of 6 percent, and suggested an avoidance of areas classified as mountain bases (fig. 28D). This was unexpected, considering the prevalence of $S$. magister in areas with boulders and other large rocks, which are often located at the bases of mountains. However, many of the areas we identified as mountain bases were at elevations greater than $2,000 \mathrm{~m}$, well above the range that $S$. magister are typically found. Similarly, the rocky surfaces layer showed an avoidance of areas with of rocky surfaces (fig. 28E), which was contrary to observations of S. magister's preference for boulders, and other large structures, such as trees, shrubs, and debris piles (Jones and Lovich, 2009). The spatial scale at which the mountain base and rocky surface layers likely were derived is too coarse to represent the habitat features (boulders and other rocky surfaces) that $S$. magister use for habitat, and as such, did not adequately capture $S$. magister habitat suitability. Habitat models derived at finer spatial scales may see covariates, such as rocky surfaces, mountain bases, and surface texture, have greater importance than general indicators, such as elevation. 

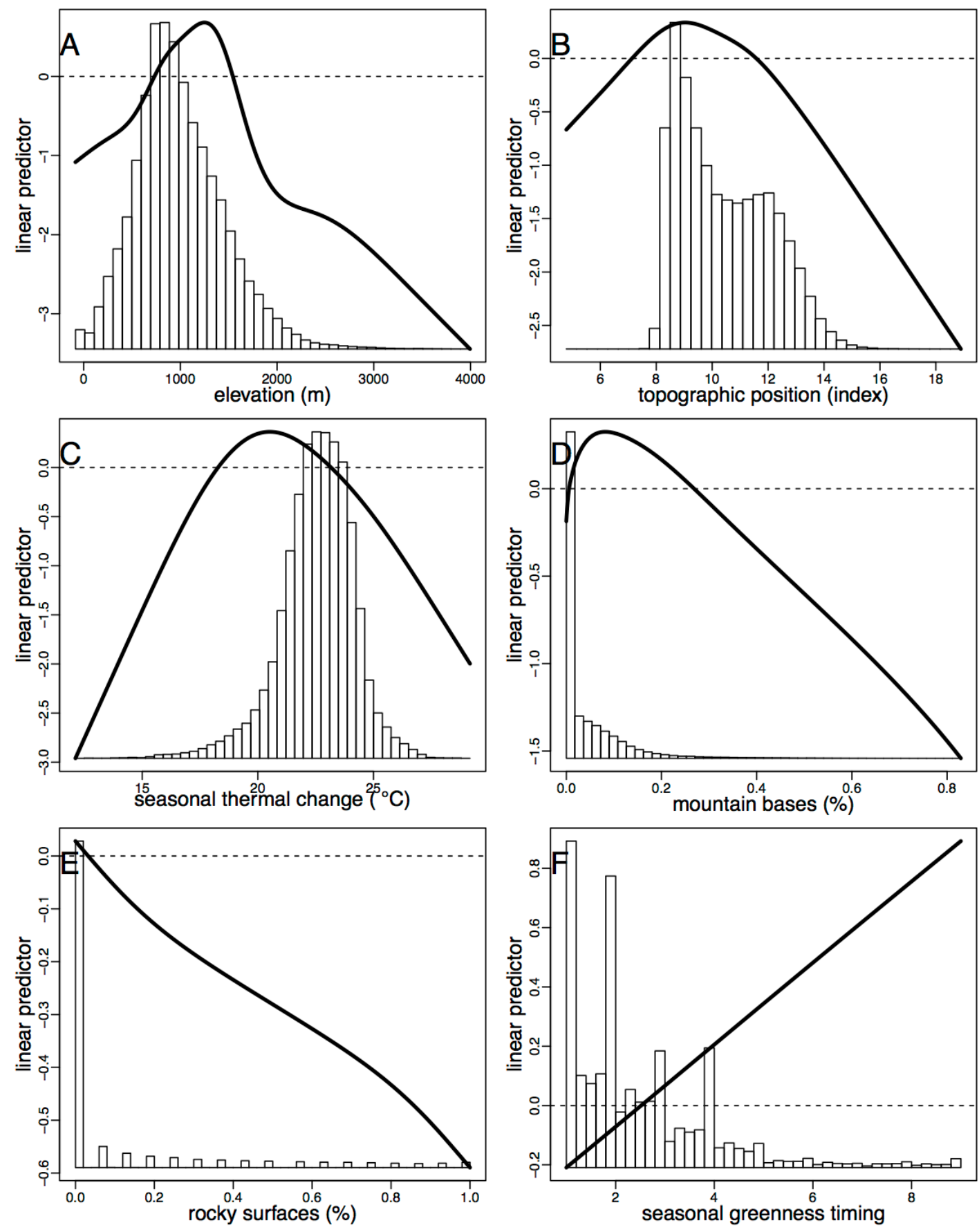

Figure 28. Generalized response curves and histograms for Sceloporus magister (Desert Spiny Lizard) for environmental covariates. Histograms are derived from a random sample of the study area and illustrate the distribution of covariates across the landscape. Response curves are derived from a single model that is inclusive of all covariates represented in the selected models for $S$. magister, where each of the covariates is held at their study area mean. The dotted line shows linear predictor value of 0 . Only the six highest contributing covariates are shown. 


\section{Thomomys bottae}

Conceptual Model.-Thomomys bottae occur in a wide range of habitats, but are primarily found in areas that support burrowing, such as sandy or gravelly soils (Zeveloff, 1988). We included surface texture and sandy surfaces to capture these habitat preferences. T. bottae are also often found in areas with alluvial soils that can support grasses and forbs for forage (Linsdale, 1938; Bond, 1946; Fitch and Bentley, 1949; Smallwood and Morrison, 1999). We included alluvial fan proximity, vegetation greenness timing, seasonal greenness ratio, soil water stress, and winter precipitation to represent areas with high annual plant production. $T$. bottae are not often found in extremely rocky terrain, but can occur in meadows at high elevations (Zeveloff, 1988). We were unable to derive a layer describing high elevation meadows, but instead included elevation and slope to capture high elevation areas with low slope. We also included washes, topographic position, mountain bases, and seasonal thermal change capture the broad characteristics of $T$. bottae habitat.

Habitat Model Results. - We selected 9 models from among the suite of possible GAM models to run as MaxEnt models, resulting in a total of 18 models that were reviewed by our collaborators. Sixteen of them were included in the final averaged model, which represented eight covariate layerswashes, slope, seasonal thermal change, winter precipitation, vegetation greenness timing, seasonal greenness ratio, topographic position, and elevation. Relative contributions for the covariate layers were 61 percent (winter precipitation), 14 percent (topographic position), 8 percent (slope), 7 percent (seasonal greenness timing), 5 percent (elevation), 4 percent (seasonal thermal change), 2 percent (seasonal greenness ratio), and $<1$ percent (washes), with inclusion in 8, 5, 3, 7, 4, 4, 3, and 1 of the 16 models, respectively.

There was moderate agreement across all selected models (fig. 29), although many areas at high elevation had standard errors of greater than 0.1 . This was caused primarily by the GAM models, which tended to predict more suitable habitat at higher elevations than the MaxEnt models. The final averaged model had an AUC score of 0.83 and a BI score of 0.51 (table 1), and was reclassified into high and low habitat suitability, which resulted in $104,675 \mathrm{~km}^{2}$ of high habitat suitability based on the fifth quantile of the observation records (break value $=0.14$, fig. 30 ). 


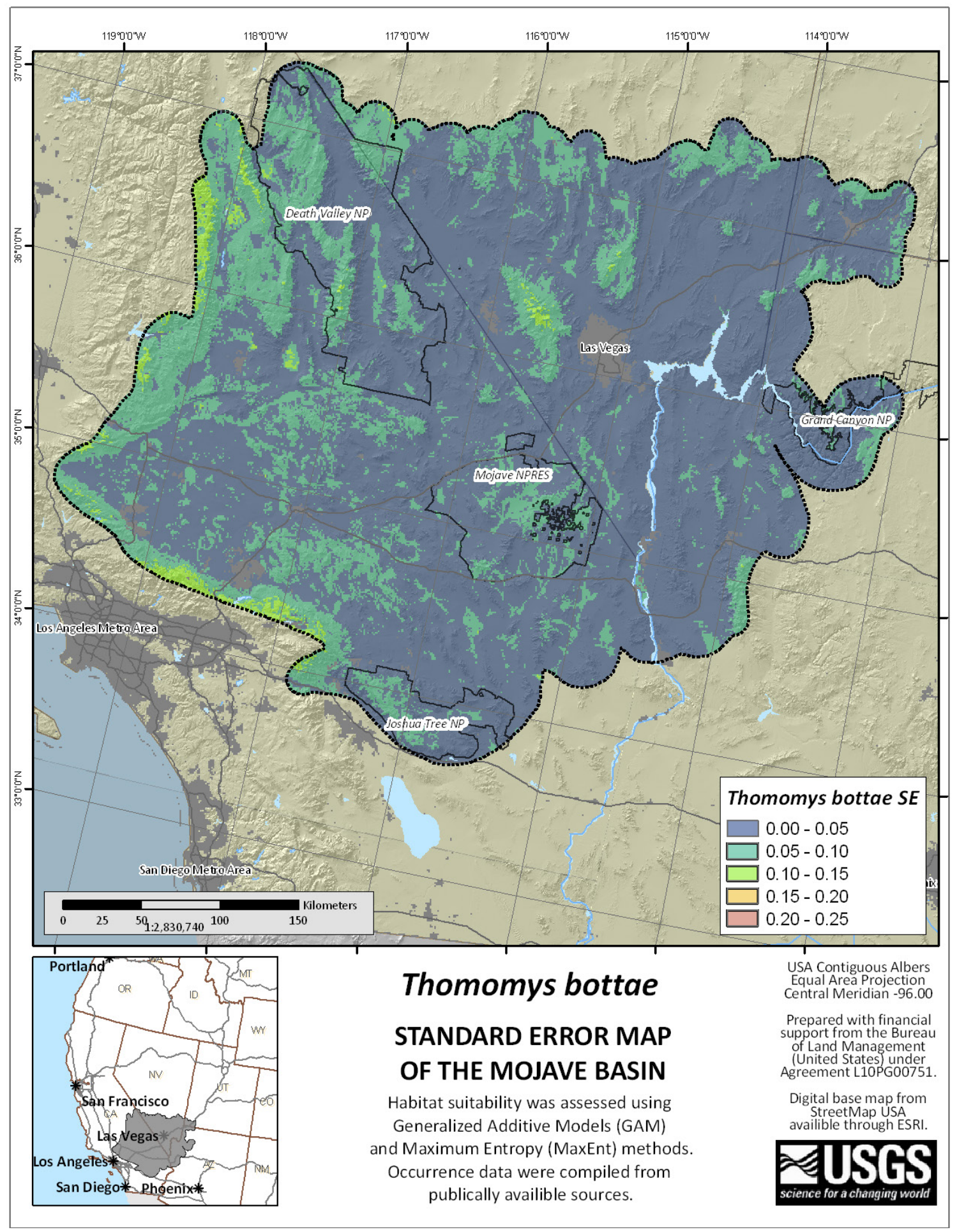

Figure 29. Map showing standard error $(\sigma / \mathrm{N})$ among the selected models for Thomomys bottae (Botta's Pocket Gopher). Areas where the selected models provided similar habitat suitability scores are shown in blue, and areas with low similarity are shown in red. Although not a measure of true model error, these agreement maps provide a general measure of model uncertainty across the landscape and show areas where the selected models agree (or disagree) with respect to habitat suitability. 


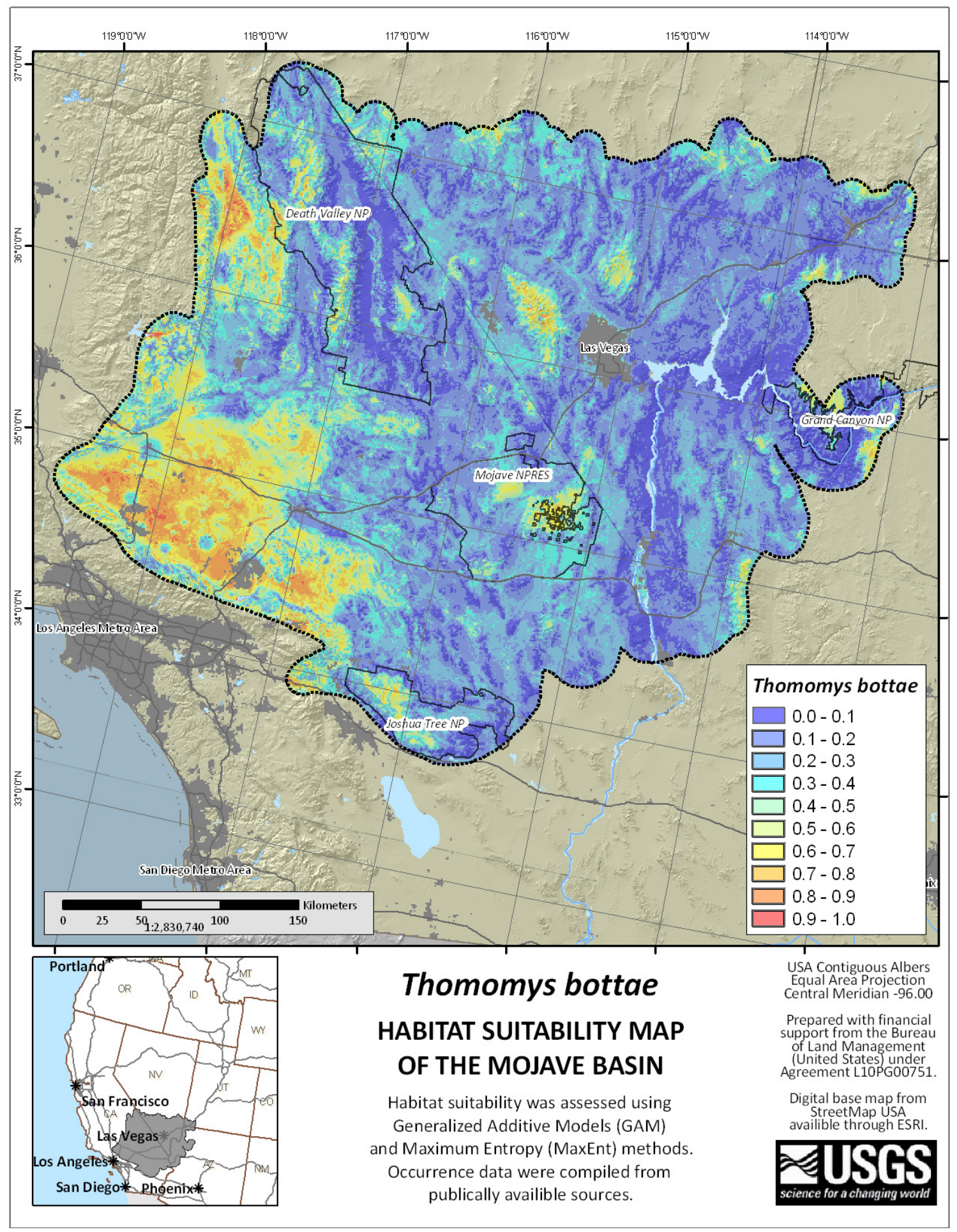

Figure 30. Map showing average habitat suitability among the selected models for Thomomys bottae (Botta's Pocket Gopher). Vaules range from $0 \sim 1$, and correspond to an index of habitat suitability, where areas with high suitability are shown in red; areas with low suitability are shown in blue. 
Habitat Model Discussion. - Contrary to our hypotheses of $T$. bottae habitat, surface texture and sandy surfaces were not among the selected models, and instead, winter precipitation was the most prevalent and had the highest relative contribution. T. bottae use spring grasses and forbs for forage, which in the Mojave Desert, are influenced heavily by winter precipitation (Beatley, 1976; Turner and Randall, 1989). The response curve for winter precipitation suggested a preference for areas with greater than $50 \mathrm{~mm}$ of winter precipitation (fig. 31A), which were often areas at high elevations within the Mojave Desert. The response curves for the topographic position layer suggested an avoidance of valley bottoms and playas, as well as an avoidance of mountain tops and ridges (fig. 31B). This supports current hypotheses of $T$. bottae habitat preference for areas with sandy or gravelly soils, as well as meadows at high elevations, and decreased suitability of extensively rocky terrain or fine silty soils that are found in playas. The modeled response to the slope layer suggested a similar decrease of habitat suitability in steep mountainous terrain (fig. 31C), and a preference for flatter terrain, although the latter was slightly contradictory to the modeled response of the topographic position layer, which suggested an avoidance of certain flat areas (that is, dry lakebeds, and valley bottoms). This apparent difference in habitat preference between topographic position and slope is likely due to the fact that not all areas with low slope are valley bottoms or dry lakebeds, and that areas adjacent to dry lakebeds often have low slope and alluvial soils suitable for fossorial activities. Habitat suitability for $T$. bottae showed a positive trend with seasonal greenness timing (fig. 31D), suggesting that $T$. bottae occur in areas where peak vegetation density occurs in mid-summer rather than in early spring. These areas tended to be high elevation vegetation communities as well as riparian communities, which often maintained greenness later in the season than surrounding vegetation communities. 

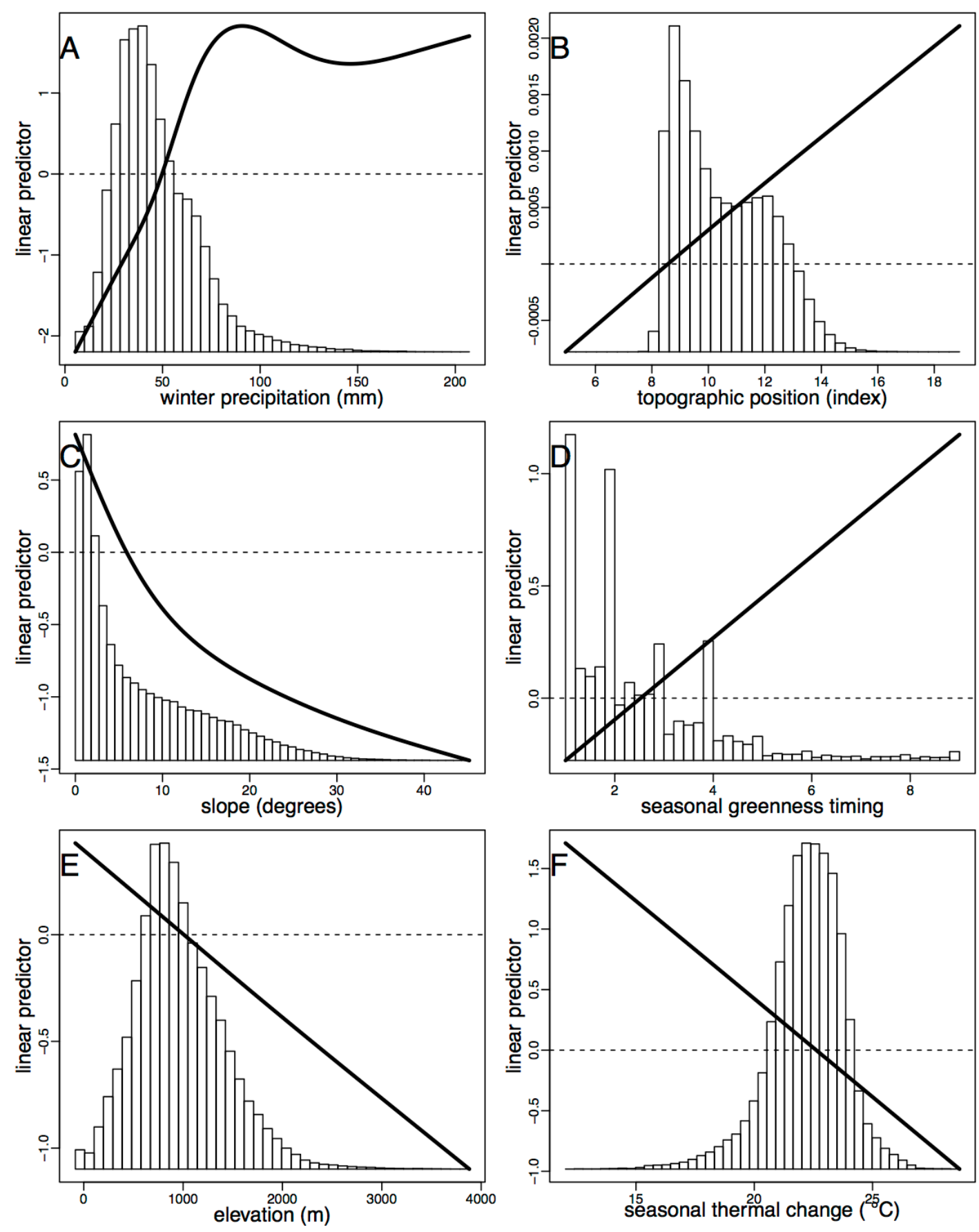

Figure 31. Generalized response curves for Thomomys bottae (Botta's Pocket Gopher) for environmental covariates. Histograms are derived from a random sample of the study area and illustrate the distribution of covariates across the landscape. Response curves are derived from a single model that is inclusive of all covariates represented in the selected models for $T$. bottae, where each of the covariates is held at their study area mean. The dotted line shows linear predictor value of 0 . Only the six highest contributing covariates are shown. 


\section{Uma scoparia}

Conceptual Model. - U. scoparia are arenicolous lizards that occur in areas with very sandy soils, such as windblown sand dunes (Stebbins, 1944; Pianka, 1967; Fromer and others, 1983) and areas with high day-time temperatures, but milder night-time temperatures (Pianka, 1967; Phil Medica, U.S. Geological Survey, oral commun., 2011). We included surface texture, sandy surfaces, and seasonal thermal change to capture the geographic variability in these habitat preferences. We had hypothesized that areas with more thermal stability would be more suitable for U. scoparia due to the additional energetic costs (and opportunistic costs) of thermoregulation when temperatures are above or below optimal. Across their range, U. scoparia tend to occur in areas with elevations less than 1,000 m, and are not found in areas with steep slopes (Stebbins, 1944; Mayhew, 1964; Pianka, 1967; Fromer and others, 1983; Jones and Lovich, 2009). We therefore included elevation and slope to represent these habitat preferences. We also included washes, mountain bases, topographic position, winter precipitation, vegetation greenness timing, seasonal greenness ratio, soil water stress, and alluvial fan proximity to capture other potential variation in habitat for U. scoparia.

Habitat Model Results. - We selected 9 models from among the suite of possible GAM models to run as MaxEnt models, resulting in a total of 18 models that were reviewed by our collaborators. All 9 of the MaxEnt models but none of the GAM models were included in the final averaged model, which represented 10 covariate layers. The covariate layers represented in the final averaged model and their relative contributions were elevation (34 percent), sandy surfaces ( 27 percent), surface texture (18 percent), seasonal thermal change ( 7 percent), soil water stress (6 percent), slope ( 3 percent), topographic position ( 2 percent), winter precipitation ( 1 percent), (seasonal greenness ratio ( 1 percent), and washes ( $<1$ percent). Only 1 of the environmental covariates was present in all 9 models (elevation); surface texture was included in 7 models; sandy surfaces, seasonal thermal change, and soil water stress were each included in 6 models; slope was included in 4 models; topographic position was included in 3 models; seasonal greenness ratio was included in 2 models; and winter precipitation and washes were included in 1 model each.

The final averaged model had an AUC score of 0.90 and a BI score of 0.54 (table 1). There was a fair amount of disagreement among the selected models, especially in areas of low habitat suitability, such as high elevation or near the base of mountains (fig. 32). The averaged $U$. scoparia habitat suitability model was reclassified into high and low habitat suitability, and resulted in $30,127 \mathrm{~km}^{2}$ of high habitat suitability based on the fifth quantile of the observation records (break value $=0.17$; fig. 33). 


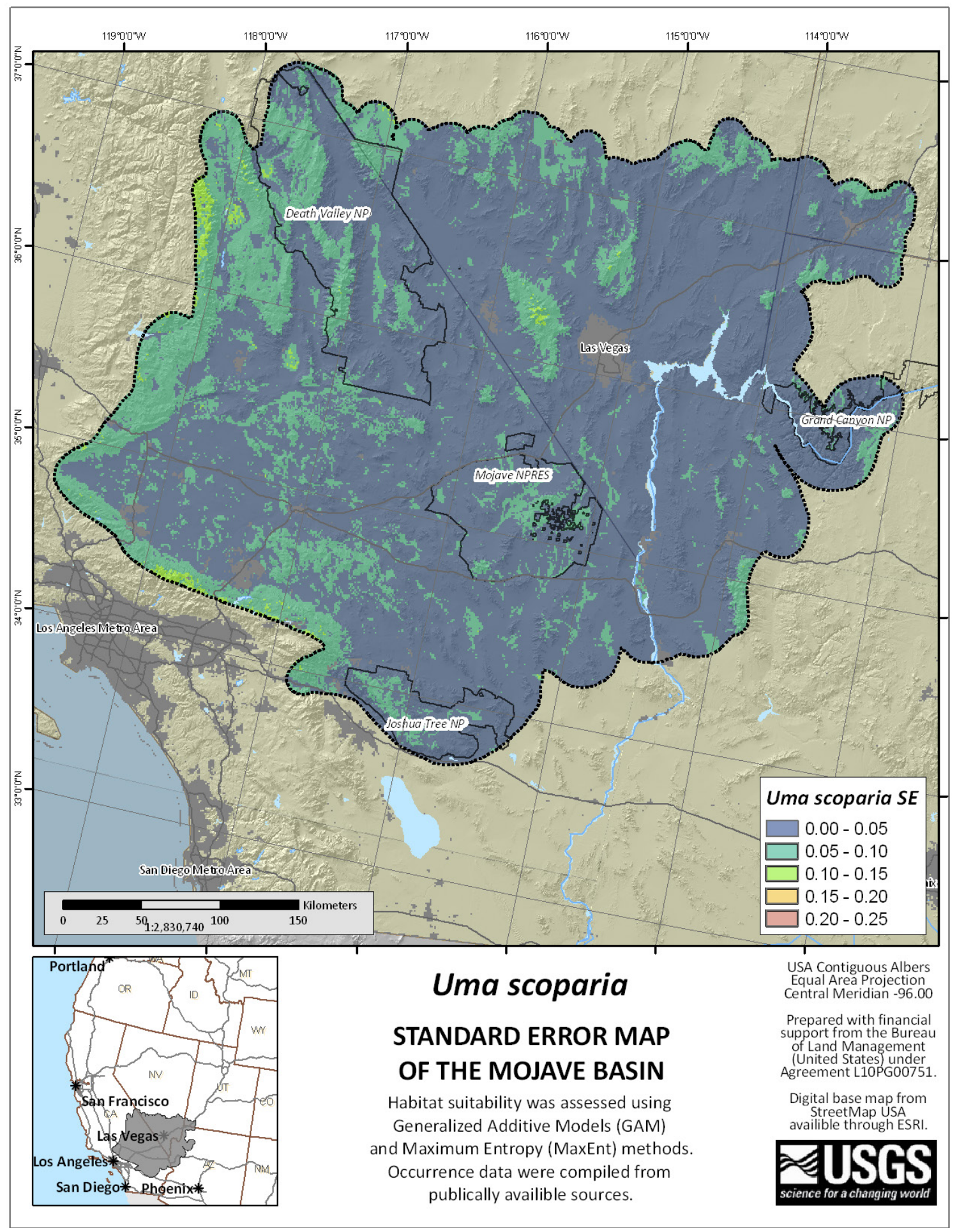

Figure 32. Map showing standard error $(\sigma / \mathrm{N})$ among the selected models for Uma scoparia (Mojave Fringe-toed Lizard). Areas where the selected models provided similar habitat suitability scores are shown in blue, and areas with low similarity are shown in red. Although not a measure of true model error, these agreement maps provide a general measure of model uncertainty across the landscape and show areas where the selected models agree (or disagree) with respect to habitat suitability. 


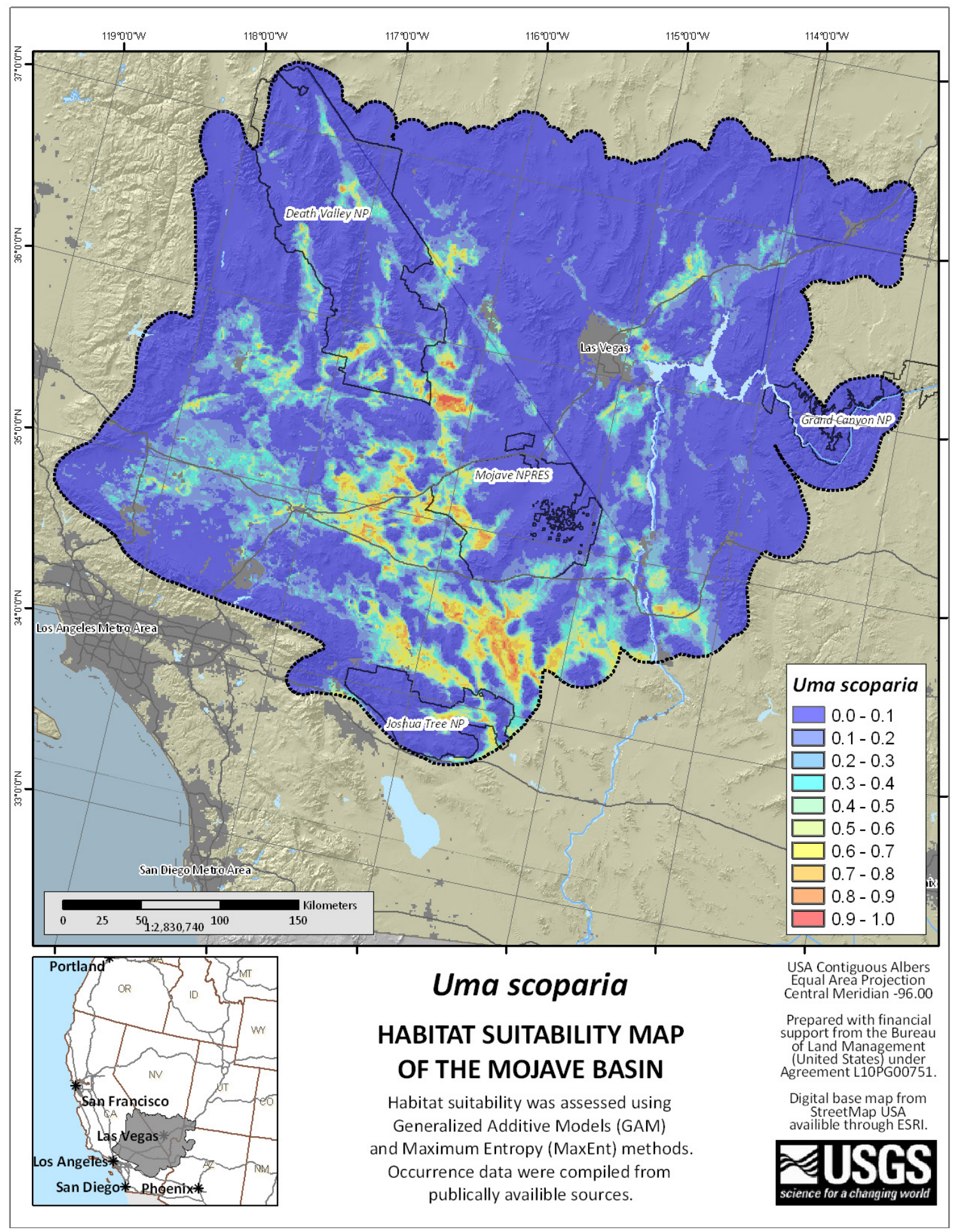

Figure 33. Map showing average habitat suitability among the selected models for Uma scoparia (Mojave Fringetoed Lizard). Values range from 0 1, and correspond to an index of habitat suitability, where areas with high suitability are shown in red; areas with low suitability are shown in blue. 
Habitat Model Discussion. - U. scoparia have a fringe of small scales on their third and fourth hind foot toes, enabling them to run quickly on fine, windblown sand (Stebbins, 1944). They also have extensive adaptations enabling them to burrow down into sand for thermal refugia, such as a counter sunk lower jaw and valved nostrils (Stebbins, 1944). Given these highly specialized traits for living in sandy habitats, the high prevalence and relative contributions of the sandy surfaces and surface texture layers was expected, and each suggested a preference for areas with sandy and finer grained surfaces (figs. 34B and 34C). In terms of elevation, which provided the single largest relative contribution and was present in all of the nine selected models, $U$. scoparia habitat suitability showed a sharp decrease with increasing elevation (fig. 34A). Specifically, habitat suitability was depressed at elevations greater than $1,000 \mathrm{~m}$, which was consistent with the previously suggested cutoff for habitat (Jones and Lovich, 2009). Unlike the other covariates, seasonal thermal change showed a narrow range for suitable habitat relative to the range of values available in the study area (fig. 34D), although with a small relative contribution (7 percent), seasonal thermal change did not provide much influence on U. scoparia habitat suitability. These values corresponded to areas in the southwestern parts of the Mojave Desert, generally in valleys distinct from mountainous terrain. The modeled response to soil water stress suggested that $U$. scoparia habitat suitability increases with increased soil water stress (fig. 34E), but as with seasonal thermal change, provided little influence on habitat suitability throughout the Mojave Desert. The remaining five environmental covariates provided less than 5 percent relative contribution each, and are not discussed. 

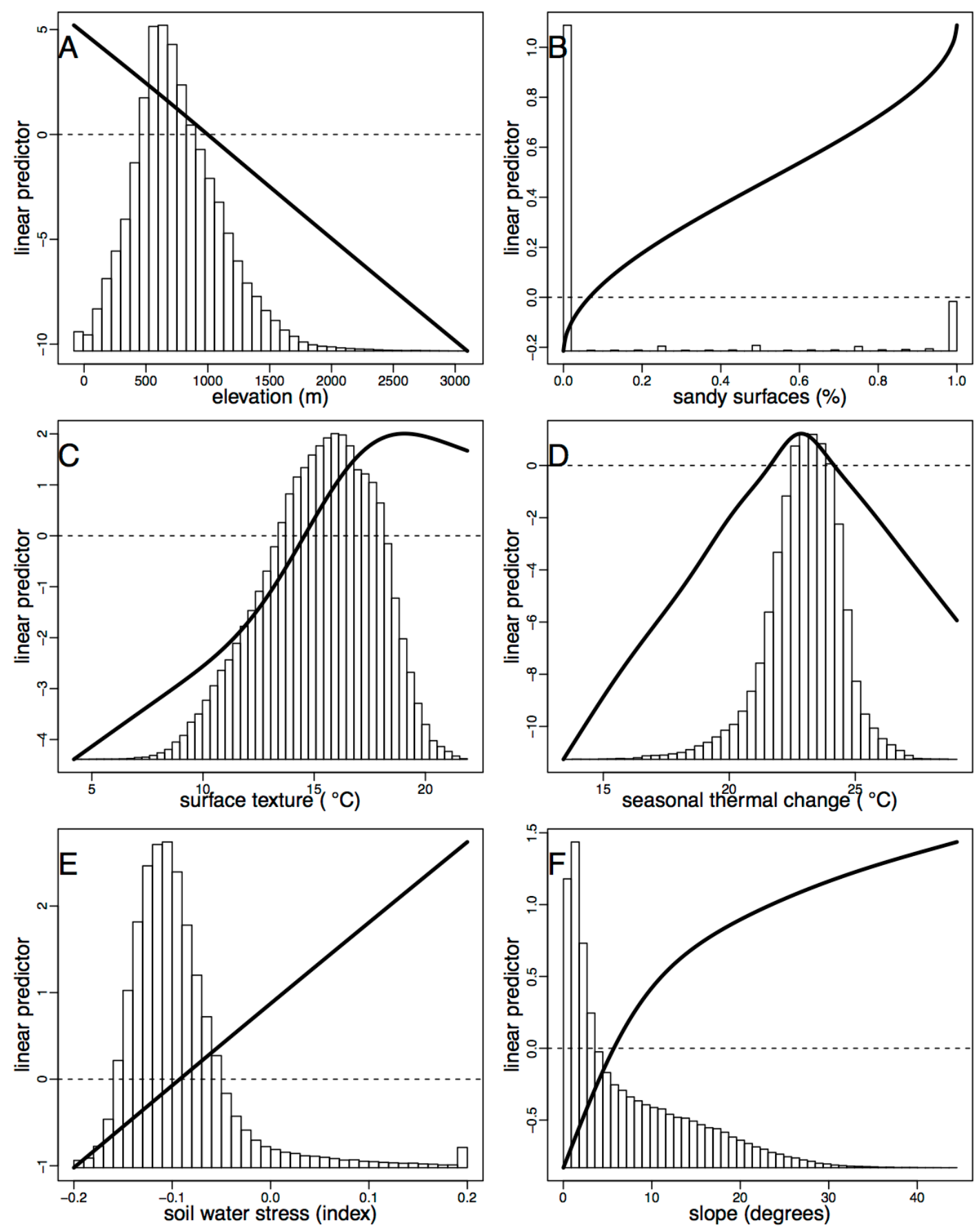

Figure 34. Generalized response curves and histograms for Uma scoparia (Mojave Fringe-toed Lizard) for environmental covariates. Histograms are derived from a random sample of the study area and illustrate the distribution of covariates across the landscape. Response curves are derived from a single model that is inclusive of all covariates represented in the selected models for $U$. scoparia, where each of the covariates is held at their study area mean. The dotted line shows linear predictor value of 0 . Only the six highest contributing covariates are shown. 


\section{Xantusia vigilis}

Conceptual Model. $-X$. vigilis occur in flat areas with an abundance of surface litter, often in stands of Joshua trees and in areas where substantial surface litter is present, often comprised of dead cactus or other woody debris (Stebbins, 1948; Zweifel and Lowe, 1966), especially in western portions of the Mojave Desert. The presence of shade or vertical structures capable of providing shade during the hotter summer seasons are usually present in areas occupied by X. vigilis (Zweifel and Lowe, 1966). Although we were unable to create a layer characterizing the abundance of surface litter, we included several layers representing vegetation characteristics (seasonal greenness ratio, vegetation greenness timing, and soil water stress) to approximate the presence of shade vegetation. Generally, X. vigilis tend to occur in areas with coarse sand, gravelly soils, or silt-like substrates with organic material where topographic slope is minimal (Stebbins, 1948; Miller, 1951; Zweifel and Lowe, 1966) and is often associated with valleys, low hills, and in areas where annual precipitation is relatively high for desert environments (Miller, 1951; Stebbins, 2003). We included surface texture, sandy surfaces, slope, mountain bases, washes, topographic position, alluvial fan proximity, and winter precipitation to capture these habitat preferences.

Habitat Model Results. - We selected 9 models from among the suite of possible GAM models to run as MaxEnt models, resulting in a total of 18 models that were reviewed by our collaborators. All nine of the MaxEnt models were included in the final averaged model, which represented 10 covariate layers. The covariate layers represented in the final averaged model and their relative contributions were elevation (55 percent), topographic position (14 percent), slope (11 percent), soil water stress ( 7 percent), seasonal thermal change ( 5 percent), mountain bases ( 3 percent), surface texture ( 2 percent), washes ( 1 percent), seasonal greenness timing ( 1 percent), and seasonal greenness ratio ( $<1$ percent), and each covariate layer was included in $9,4,4,4,2,3,1,2,2$, and 1 model(s), respectively. The large number of environmental covariates present in three or fewer of the selected models is indicative of poor performing models.

However, even with low performing models, we found high agreement across all selected models (fig. 35), and in particular, areas with high habitat suitability showed the most amount of agreement. Standard errors ranged from 0.001 to 0.11 . Very few areas were present with standard errors greater than 0.1 . The final averaged model had an AUC score of 0.78 and a BI score of 0.05 , which was the lowest among our study species. The averaged model was reclassified into high and low habitat suitability, resulting in $106,994 \mathrm{~km}^{2}$ of high habitat suitability based on the fifth quantile of the observation records (break value $=0.29$, fig. 36). As with many of the other species included in this report, a notable break in habitat suitability occurs near the Baker Sink landform. 


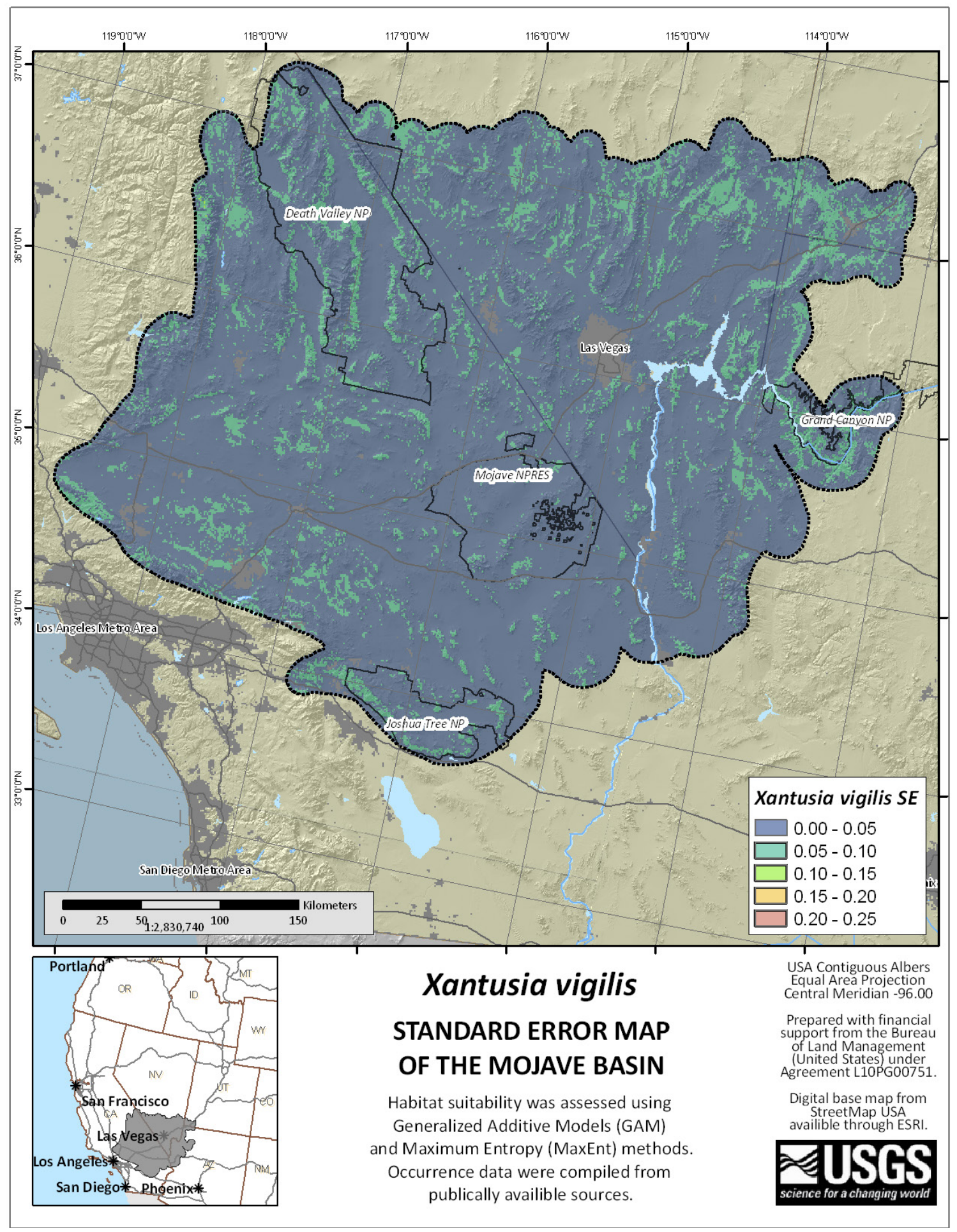

Figure 35. Map showing standard error ( $\sigma / \mathrm{N})$ among the selected models for Xantusia vigilis (Desert Night Lizard). Areas where the selected models provided similar habitat suitability scores are shown in blue, and areas with low similarity are shown in red. Although not a measure of true model error, these agreement maps provide a general measure of model uncertainty across the landscape and show areas where the selected models agree (or disagree) with respect to habitat suitability. 


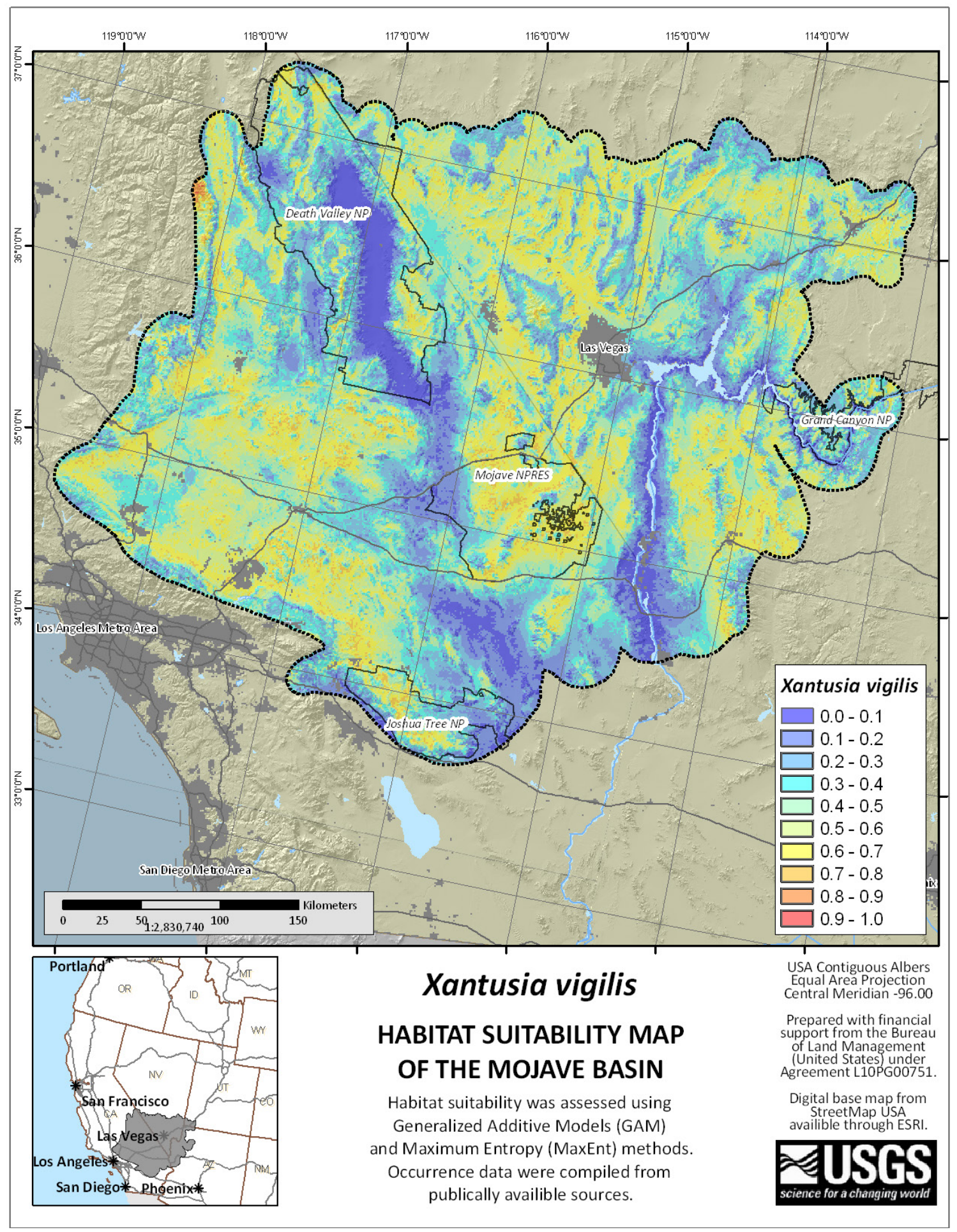

Figure 36. Map showing average habitat suitability among the selected models for Xantusia vigilis (Desert Night Lizard). Values range from $0 \sim 1$, and correspond to an index of habitat suitability, where areas with high suitability are shown in red; areas with low suitability are shown in blue. 
Habitat Model Discussion.-We were unable to derive an environmental covariate representing woody surface debris or Joshua tree communities, both of which are thought to be important predictors of $X$. vigilis habitat. Instead, we used measures of terrain topography (primarily slope and topographic position) and vegetation characteristics (seasonal greenness ratio, vegetation greenness timing, vegetation greenness, and soil water stress) to represent these habitats types. Although none of these covariates provided the greatest relative contribution or were the most prevalent among our selected models, topographic position was present in slightly fewer than one-half of the selected models, and provided 14 percent of the relative contribution in the averaged model. The model response to topographic position suggested decreased suitability on mountain tops and ridges, and a preference for valleys and alluvial fans, with a slight decrease in habitat suitability at high values, representing playas (fig. 37B). This decrease in playas is congruent with observations of $X$. vigilis habitat suggesting a requirement of surface litter, which is often not present in playas. The slope layer was used in nearly one-half of the selected models, and showed a relative contribution of only 11 percent. Counter to hypotheses of $X$. vigilis habitat, and the response curve suggested a preference for low slope areas, and a preference for high slopes instead, although the increase in habitat suitability was less pronounced at higher slopes than lower slopes (fig. 37C).

Instead of the hypothesized covariates describing terrain or vegetation, elevation was the most prevalent covariate and provided the highest relative contribution to the averaged model. Additionally, one of the selected models contained only elevation as a single covariate, suggesting that elevation was by far the single best predictor of X. vigilis habitat in the Mojave Desert. The modeled response to elevation suggested a preference for areas at high elevations, and an avoidance of low elevations, although areas at elevations greater than $3,000 \mathrm{~m}$ also showed a decrease in habitat suitability (fig. 37A). The layer soil water stress, although providing only 7 percent relative contribution to the averaged model, was used in 4 of the 9 selected models, and the response curve suggested a slight preference for areas with less surface water (fig. 37D). This was counter to previous observations of $X$. vigilis, which suggest that habitat suitability is likely higher in areas with greater surface water, although a general avoidance of dense riparian vegetation is also known. Winter precipitation was not among the environmental covariates included in the averaged model, which also contradicted many previous hypotheses of $X$. vigilis habitat stating that areas with high precipitation will provide better habitat than areas with low precipitation (Miller, 1951; Stebbins, 2003). More work is needed to identify how $X$. vigilis respond to winter precipitation and, particularly, why winter precipitation was omitted from the suite of selected models.

Our model of $X$. vigilis habitat had a test AUC of 0.78 , which was one of the lowest of the species modeled here. In conjunction with elevation as the most prevalent and important predictor of $X$. vigilis habitat, this low AUC is indicative of the complex habitat requirements of $X$. vigilis, and general difficulty in modeling them. Additional covariate layers representing Joshua tree communities and surface litter are likely needed to improve models of $X$. vigilis habitat. However, as is often the case for layers representing habitat preferences, spatial scale is an important issue due to the discrepancy between microhabitat features (for example, organic top soil and surface litter) and landscape features (for example, slope and topographic features) used in these models. 

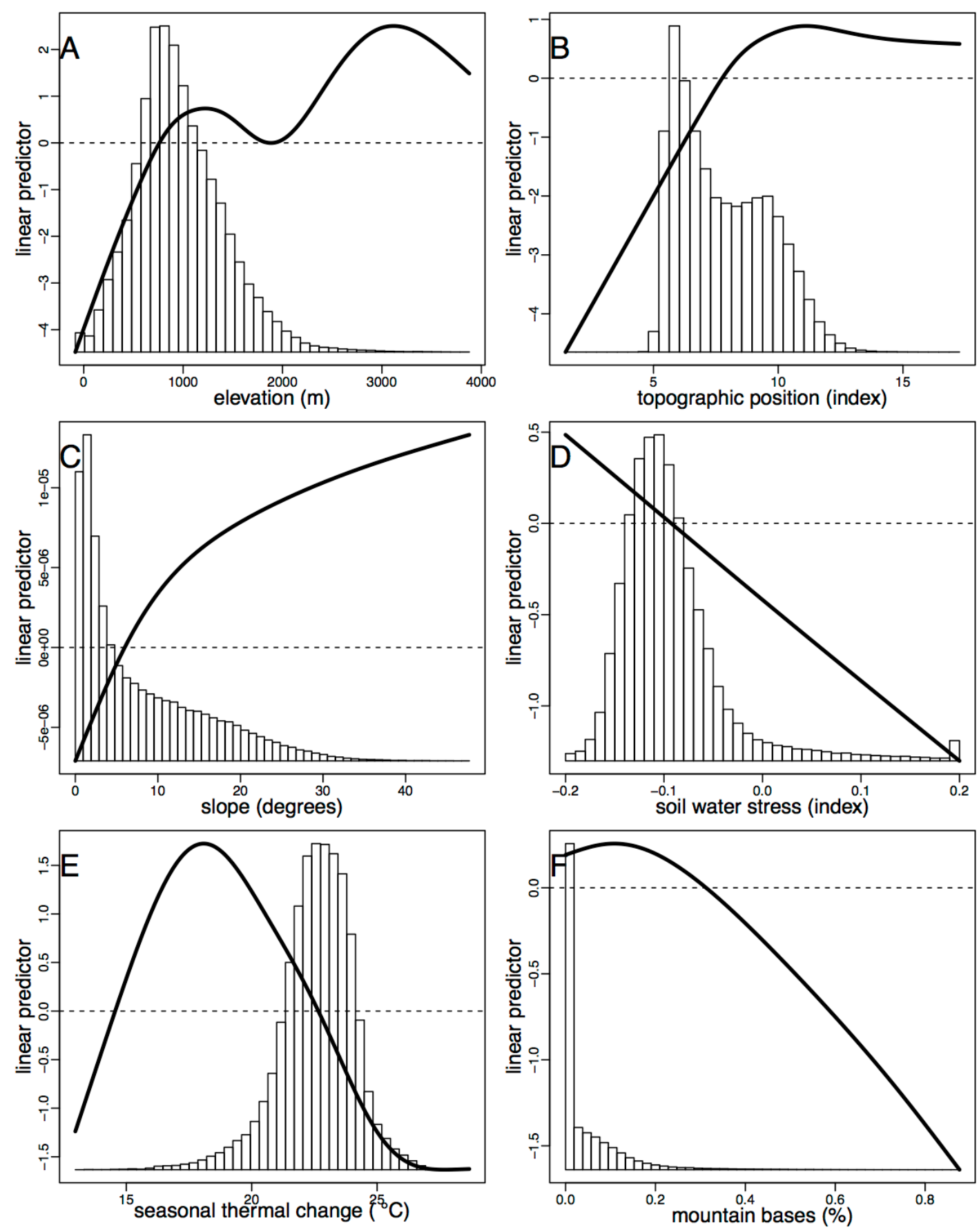

Figure 37. Generalized response curves and histograms for Xantusia vigilis (Desert Night Lizard) for environmental covariates. Histograms are derived from a random sample of the study area and illustrate the distribution of covariates across the landscape. Response curves are derived from a single model that is inclusive of all covariates represented in the selected models for $X$. vigilis, where each of the covariates is held at their study area mean. The dotted line shows linear predictor value of 0 . Only the six highest contributing covariates are shown. 


\section{Discussion}

We modeled habitat suitability in the Mojave Desert Basin for 13 species using Generalized Additive Models and Maximum Entropy methods to define their potential distributions within this region. The primary sources of observation records for this modeling effort were publically available museum records or opportunistic collection records and independent databases provided by our collaborators. Due to the lack of known absence localities in these sources, we chose to use the two afore-mentioned methods to model habitat suitability. However, although these two approaches are prevalent in the modeling literature, they are not without error, and have limitations when heterogeneity in the source of observation records is large (Phillips and Dudik, 2008; Fanklin, 2010; Newbold, 2010). They provide the best quantification of habitat when a single sampling strategy is used, and when adequate samples of the geographic and environmental space of interest are available (Elith and Leathwick, 2009). We were unable to use a single sampling strategy, and instead used many sources of occurrence data, some of which were opportunistic collection records and others of which were observations from specific research efforts with independent sampling strategies. This resulted in considerable heterogeneity in the sampling design and methodology in the assimilation of our input datasets. There also were a wide range of temporal and spatial sampling regimes across the data sources, all of which added variability to the species-environment relationships we were modeling. The observation records we obtained were often geographically aggregated, resulting in large areas where we had no evidence of presence (or absence). In many of these areas, our collaborators had personal knowledge of occurrence generally, but no formal observation records were available. For these species, we often selected models that predicted habitat broadly in these areas, thus ensuring that our models were not over-fit to our limited and geographically biased observation records.

Another drawback to the heterogeneity in our observation records is the time span over which data were collected. When this time span is large, a species may have the opportunity to shift its distribution (Elith and others, 2010). Similarly, the landscape may change through time (for example, disturbance, fire, climate change), such that a species may no longer be present in the location where it once was. All these factors contribute noise to the species-environment signal, and make quantifying habitat difficult. Where sufficient locality records were available, we limited the temporal period of occurrence data to 1950-2011. However, for several species, such as L. trivirgata and P. gilberti, which lacked sufficient observations, we chose to include records dating back to 1900 in order to increase our sample size. Similarly, for many of the occurrence records we did not know the collection date, but chose to include those records to increase sample sizes. 
In general, most habitat models developed here had moderate to good discrimination ability with AUC scores ranging from 0.72 to 0.90 . Although some of these values are not as high as models for other species (see Elith and Graham, 2009, and Jarnevich and Laubhan, 2011, but see Elith and Leathwick, 2009, for similar AUC scores), we think that these values are appropriate given the spatial scale $(1 \mathrm{~km})$ and the inherent sampling bias from the large assortment of museum locality data used (Chefaoui and Lobo, 2008; Phillips and others, 2009; Newbold, 2010). Even though we took measures to avoid over-fitted models, such as replicating the model training (bootstrapping), limiting the number of covariate layers to five per model, and not including interactions among input covariates (although MaxEnt inherently includes interactions of all covariates; Phillips and Dudik, 2008), we were cautious to avoid inferring too much ecological significance from any single model. We also looked at the standard error in habitat suitability scores across the selected models for each of the focal species to identify geographic areas where the suite of selected models did not agree. Although our selected habitat models tended to disagree more in playas and areas with high elevation, they were, in general, very consistent. Other methods have been proposed to avoid over-fitted MaxEnt models (see Anderson and Gonzalez, Jr., 2011); however, because we used model averaging methods to construct consensus models for our species, we were unable to implement these methods and we believe the methods used here are adequately robust and generalized to the Mojave Basin and Range ecoregion in which they were developed.

\section{References Cited}

Anderson, D., Burnham, K., and Thompson, W., 2000, Null hypothesis testing-Problems, prevalence, and an alternative: Journal of Wildlife Management, v. 64, p. 912-923.

Anderson, R.P., and Gonzalez, Jr, I., 2011, Species-specific tuning increases robustness to sampling bias in models of species distributions-An implementation with Maxent: Ecological Modelling, v. 222, p. 2,796-2,811.

Araújo, M.B., and Williams, P.H., 2000, Selecting areas for species persistence using occurrence data: Biological Conservation, v. 96, p. 331-45.

Arizona Game and Fish Department, 2003, Lichanura trivirgata trivirgata in Abstract compiled and edited by the Heritage Data Management System: Phoenix, Arizona Game and Fish Department, p. 5.

Austin, M., 2002, Spatial prediction of species distribution-An interface between ecological theory and statistical modeling: Ecological Modelling, v. 157, p. 101-118.

Bailey, V., 1931, Mammals of New Mexico: North American Fauna, v. 53, p. 1-412.

Bartholomew, G.A., and Cade, T.J., 1957, Temperature regulation, hibernation, and aestivation in the little pocket mouse, Perognathus longimembris: Journal of Mammalogy, v. 38, p. 60-72.

Beatley, J.C., 1976, Rainfall and fluctuating plant populations in relation to distributions and numbers of desert rodents in southern Nevada: Oecologia, v. 24, p. 21-42.

Bond, R.M., 1946, The breeding habits of Thomomys bottae in Orange County, California: Journal of Mammalogy, v. 27, p. 172-174.

Boyce, M., Vernier, P., Nielsen, S., and Schmiegelow, F., 2002, Evaluating resource selection functions: Ecological Modelling, v. 157, p. 281-300. 
Bradford, D.F., Neale, A.C., Nash, M.S., Sada, D.W., and Jaeger, J.R, 2003, Habitat patch occupancy by toads (Bufo punctatus) in a naturally fragmented desert landscape: Ecology, v. 84, p. 1,012-1,023. Brown, D., 1982, Desert Plants; Biotic communities of the American Southwest-United States and Mexico: Superior, Arizona, Boyce Thompson Southwestern Arboretum, p. 342.

Burnham, K.P., and Anderson, D.R, 2002, Model selection and multimodel inference-A Practical Information-Theoretic Approach (2nd ed.): Springer-Verlag, p. 488, ISBN 0-387-95364-7.

Carlson, T.N., Dodd, J.K., Benjamin, S.G., and Cooper, J.N., 1981, Satellite estimation of the surfaceenergy balance, moisture availability and thermal inertia: Journal of Applied Meteorology, v. 20, p. 67-87.

Chefaoui, R.M., and Lobo, J.M., 2008, Assessing the effects of pseudo-absences on predictive distribution model performance: Ecological Modelling, v. 210, p. 478-486.

Cheng, Y.B., Ustin, S.L., Riano, D., and Vanderbilt, V.C., 2008, Water content estimation from hyperspectral images and MODIS indexes in Southeastern Arizona: Remote Sensing of Environment, v. 112 , p. 363-374.

Cheng, Y.B., Zarco-Tejada, P.J., Riaño, D., Rueda, C.A., and Ustin, S.L., 2006, Estimating vegetation water content with hyperspectral data for different canopy scenarios-Relationships between AVIRIS and MODIS indexes: Remote Sensing of Environment, v. 105, p. 354-366.

Chew, R.M., and Butterworth, B.B, 1964, Ecology of rodents in Indian Cove (Mojave Desert), Joshua Tree National Monument California: Journal of Mammalogy, v. 45, p. 203-225.

Collingham, Y., Wadsworth, R., Huntley, B., and Hulme, P., 2000, Predicting the spatial distribution of non-indigenous riparian weeds-Issues of spatial scale and extent: Journal of Applied Ecology, v. 37, p. $13-27$.

Commission for Environmental Cooperation Working Group, 1997, Ecological regions of North America-Toward a common perspective: Montreal, Quebec, Commission for Environmental Cooperation, p. 71.

Creusere, F.M., and Whitford, W.G., 1976, Ecological relationships in a desert anuran community: Herpetologica, v. 32, p. 7-18.

Crews, S.C., 2009, Assessment of rampant genitalic variation in the spider genus Homalonychus (Araneae, Homalonychidae): Invertebrate Biology, v. 128, p.107-125.

Crews, S., and Hedin, M., 2006, Studies of morphological and molecular phylogenetic divergence in spiders (Araneae: Homalonychus) from the American southwest, including divergence along the Baja California Peninsula: Molecular Phylogenetics and Evolution, v. 38, p. 470-487.

Crimmins, T.M., Crimmins, M.A., and Bertelsen, C.D., 2009, Flowering range changes across an elevation gradient in response to warming summer temperatures: Global Change Biology, v. 15, p. $1,141-1,152$.

Cumming, G.S., 2000, Using between-model comparisons to fine-tune linear models of species ranges: Journal of Biogeography, v. 27, p. 441-455.

Dayton, G.H., and Fitzgerald, L.A., 2006, Habitat suitability models for desert amphibians: Biological Conservation, v. 132, p. 40-49.

Domínguez, K., and Jiménez, M.L., 2005, Mating and self-burying behavior of Homalonychus theologus Chamberlin (Araneae, Homalonychidae) in Baja California Sur: Journal of Arachnology, v. 33 , p. 167-174.

Elith, J., and Graham, C.H., 2009, Do they? How do they? WHY do they differ? On finding reasons for differing performances of species distribution models: Ecography, v. 32, p. 66-77. 
Elith, J., Graham, C.H., Anderson, R.P., Dudík, M., Ferrier, S., Guisan, A., Hijmans, R.J., Huettmann, F., Leathwick, J.R., Lehmann, A., Li, J., Lohmann, L.G., Loiselle, B.A., Manion, G., Moritz, C., Nakamura, M., Nakazawa, Y., Overton, J.McC.M., Townsend Peterson, A., Phillips, S.J., Richardson, K., Scachetti-Pereira, R., Schapire, R.E., Soberón, J., Williams, S.M., Wisz, S., and Zimmermann, N.E., 2006, Novel methods improve prediction of species' distributions from occurrence data: Ecography, v. 29, p. 129-151, doi: 10.1111/j.2006.0906-7590.04596.x.

Elith, J., Kearney, M., and Phillips, S., 2010, The art of modelling range-shifting species: Methods in Ecology and Evolution, v. 1, p. 330-342.

Elith, J., and Leathwick, J.R., 2007, Predicting species distributions from museum and herbarium records using multiresponse models fitted with multivariate adaptive regression splines: Diversity and Distributions, v. 13, p. 265-275.

Elith, J., and Leathwick, J.R., 2009, Species Distribution Models_-Ecological Explanation and Prediction Across Space and Time: Annual Review of Ecology Evolution and Systematics, p. 677697.

Elith, J., Phillips, S.J., Hastie, T., Dudik, M., Chee, Y.E., and Yates, C.J., 2011, A statistical explanation of MaxEnt for ecologists: Diversity Distributions, v. 17, p. 43-57.

Engler, R., Guisan, A., and Rechsteiner, L., 2004, An improved approach for predicting the distribution of rare and endangered species from occurrence and pseudo-absence data: Journal of Applied Ecology, v. 41, p. 263-274, doi: 10.1111/j.0021-8901.2004.00881.x.

Esler, K., and Rundel, P., 1999, Comparative patterns of phenology and growth form diversity in two winter rainfall deserts - The Succulent Karoo and Mojave Desert ecosystems: Plant Ecology, v. 142, p. $97-104$.

Fensholt, R., and Sandholt, I., 2003, Derivation of a shortwave infrared water stress index from MODIS near- and shortwave infrared data in a semiarid environment: Remote Sensing of Environment, v. 87, p. $111-121$.

Ferguson, J.H., and Lowe, C. H., 1969, Evolutionary relationships in Bufo punctatus group: American Midland Naturalist, v. 81, p. 435-466.

Fielding, A., and Bell, J., 1997, A review of methods for the assessment of prediction errors in conservation presence/absence models: Environmental Conservation, v. 24, p. 38-49.

Fitch, H.S., and Bentley, J.J., 1949, Use of California annual plant forage by rodents: Ecology, v. 30, p. 306-321.

Franklin, J., 1995, Predictive vegetation mapping - Geographic modelling of biospatial patterns in relation to environmental gradients: Progress in Physical Geography, v. 19, p. 474-499.

Franklin, J., 2010, Mapping species distributions: spatial inference and prediction. Cambridge University Press, Cambridge, UK.

Frey, J.K., 2009, Distinguishing range expansions from previously undocumented populations using background data from museum records: Diversity and Distributions, v. 15, p. 183-187.

Findley, J.S., Harris, A.H., Wilson, D.E., and Jones, C., 1975, Mammals of New Mexico, University of New Mexico Press, Albuquerque.

Fromer, P.S., Dodero, M., and Patterson, C., 1983, A Population Study of the Mojave fringe-toed lizard (Uma scoparia) on the Twentynine Palms MCAGCC: Prepared for the Natural Resources Office Marine Corps Air Ground Combat Center Twentynine Palms, CA 92278.

Fry J., Xian, G., Jin, S., Dewitz, J., Homer, C., Yang, L., Barnes, C., Herold, N., and Wickham, J., 2011, Completion of the 2006 National Land Cover Database for the conterminous United States:

Photogrammetric Engineering and Remote Sensing, v. 77, p. 858-864. 
Funk, R.S., 1967, A new colubrid snake of the genus Chionactis from Arizona: The Southwestern Naturalist, v. 12, p. 180-188.

Graham, C.H., Ferruer, S., Huettman, F., Moritz, C., and Peterson, A.T., 2004, New developments in museum-based informatics and applications in biodiversity analysis: Trends in ecology and evolution, v. 19, p. 497-503.

Guisan, A., and Thuiller, W., 2005, Predicting species distribution-Offering more than simple habitat models: Ecology Letters, v. 8, p. 993-1,009.

Guisan, A., and Zimmermann, N., 2000, Predictive habitat distribution models in ecology: Ecological Modelling, v. 135, p. 147-186.

Hall, E.R., 1981, The mammals of North America_-Volume 1 (2nd ed.): New York, John Wiley \& Sons, p. 1,300 .

Hirzel, A.H., Hausser, J., Chessel, D., and Perrin, N., 2002, Ecological-niche factor analysis-How to compute habitat-suitability maps without absence data?: Ecology, v. 83, p. 2,027-2,036.

Hoffmeister, D.F., 1986, Mammals of Arizona: Tucson, Ariz., University of Arizona Press, 602 p. Jameson, Jr., E.W., and Peeters, H.J., 1988, California Mammals: Barkeley, Calif., University of California Press, 403 p.

Jarnevich, C.S., and Laubhan, M.K., 2011, Balancing energy development and conservation-A Method Utilizing Species Distribution Models: Environmental Management, v. 47, p. 926-936. Jones, K.B., Kepner, L.P., and Martin, T.E., 1985, Species of reptiles occupying habitat islands in western Arizona-A deterministic assemblage: Oecologia, v. 66, p. 595-601.

Jones, L.C., and Lovich, R.E., 2009, Lizards of the American Southwest-A Photographic Field Guide: Tucson, Ariz., Rio Nuevo Publishers, p. 567.

Kahle, A.B., 1987, Surface emittance, temperature and thermal inertia derived from thermal infrared multispectral scanner (TIMS) data for Death Valley, California: Geophysics, v. 52, p. 858-874.

Klauber, L.M., 1931, A new subspecies of the California boa, with notes on the genus Lichanura: Transactions of the San Diego Society of Natural History, v. 6, p. 305-318.

Klauber, L.M., 1951, The shovel-nosed snake, Chionactis, with descriptions of two new subspecies: Transactions of the San Diego Society of Natural History, v. 11, p. 141-204.

Krekorian, C.O., 1977, Homing in the desert iguana, Dipsosaurus dorsalis: Herpetologica, v. 33, p. $123-127$.

Linsdale, J.M., 1938, Environmental responses of the vertebrates in the Great Basin: American Midland Naturalist, v. 19, p. 1-206.

Liu, C., Berry, P., Dawson, T., and Pearson, R., 2005, Selecting thresholds of occurrence in the prediction of species distributions: Ecography, v. 28, p. 385-393.

Lobo, J.M., and Tognelli, M.F., 2011, Exploring the effects of quantity and location of pseudo-absences and sampling biases on the performance of distribution models with limited point occurrence data: Journal for Nature Conservation, v. 19, p. 1-7.

Mateo, R.G., Croat, T.B., Felicísimo, Á.M., and Muñoz, J., 2010, Profile or group discriminative techniques?-Generating reliable species distribution models using pseudo-absences and target-group absences from natural history collections: Diversity and Distributions, v. 16, p. 84-94.

Mayhew, W.W., 1964, Taxonomic status of California populations of the lizard genus Uma: Herpetologica, v. 20, p. 170-183.

McClanahan, L.L., Ruibal, R., and Shoemaker, V.H., 1994, Frogs and toads in deserts: Scientific American, v. 270, p. 82-88.

McGuire, J.A., 1996, Phylogenetic systematics of crotaphytid lizards (Reptilia: Iguania: Crotaphytidae): Bulletin of Carnegie Museum of Natural History, v. 32, p. 1-120. 
Merriam, C.H., 1890, General results, with special reference to the geographical and vertical distribution of species, in North American Fauna No. 3-Results of a biological survey of the San Francisco Mountain Region and Desert of the Little Colorado, Arizona: Washington, D.C., U.S. Department of Agriculture, Division of Ornithology and Mammalogy, Government Printing Office.

Miller, A.H., and Stebbins, R.C., 1964, The lives of desert animals in Joshua Tree National Monument: Berkeley, Calif., University of California Press.

Miller, M.R., 1951, Some aspects of the life history of the Yucca night lizard, Xantusia vigilis: Copeia, v. 2, p. 114-120.

Montgomery, D.R., and Foufoula-Georgiou, E., 1993, Channel network source representation using digital elevation models: Water Resources Research, v. 29, p. 3,925-3,934.

Moore, I.D., Grayson, R.B., and Ladson, A.R., 1991, Digital terrain modeling: A review of hydrological, geomorphological, and biological applications, Hydrological Processes, v. 5, p. 3-30.

Nalder, I.A., and Wein, R.W., 1998, Spatial interpolation of climatic Normals-Test of a new method in the Canadian boreal forest: Agricultural and Forest Meteorology, v. 92, p. 211-225.

Newbold, T., 2010, Applications and limitations of museum data for conservation and ecology, with particular attention to species distribution models: Progress in Physical Geography, v. 34, p. 3-22.

Norris, K.S., 1953, The ecology of the desert iguana Dipsosaurus dorsalis: Ecology, v. 34, p. 265-287.

Parker, W.S., and Pianka, E.R., 1973, Notes on the ecology of the iguanid lizard, Sceloporus magister: Herpetologica, v. 29, p. 143-152.

Pearson, R.G. and Dawson, T.P., 2003, Predicting the impacts of climate change on the distribution of species: are bioclimatic envelope models useful? Global Ecology and Biogeography, v. 12, p. 361-371.

Peters, A.J., Eve, M.D., Holt, E.H., and Whitford, W.G., 1997, Analysis of desert plant community growth patterns with high temporal resolution satellite spectra: Journal of Applied Ecology, v. 34, p. 418-432.

Phillips, S.J., Anderson, R.P., and Schapire, R.E., 2006, Maximum entropy modeling of species geographic distributions: Ecological Modelling, v. 190, p. 231-259.

Phillips, S.J., and Dudik, M., 2008, Modeling of species distributions with Maxent-New extensions and a comprehensive evaluation: Ecography, v. 31, p. 161-175.

Phillips, S.J., Dudik, M., Elith, J., Graham, C.H., Lehmann, A., Leathwick, J., and Ferrier, S., 2009, Sample selection bias and presence-only distribution models-Implications for background and pseudo-absence data: Ecological Applications, v. 19, p. 181-197.

Pianka, E.R., 1966, Convexity, desert lizards, and spatial heterogeneity: Ecology, v. 47, p. 1,055-1,059.

Pianka, E.R., 1967, On lizard species diversity-North American flatland deserts: Ecology, v. 48, p. 333-351.

Posada, D., and Buckley, T., 2004, Model selection and model averaging in phylogenetics-Advantages of Akaike Information Criterion and Bayesian approaches over likelihood ratio tests: Systematic Biology, v. 53, p. 793-808.

Pratt, D., 1979, The thermal inertia approach to mapping of soil moisture and geology: Remote Sensing of Environment, v. 8, p. 151-158.

Qi, J., Chehbouni, A., Huete, A., Kerr, Y., and Sorooshian, S., 1994, A modified soil adjusted vegetation index: Remote Sensing of Environment, v. 48, p. 119-126.

R Core Development Team, 2011, R-A language and environment for statistical computing: Vienna, Austria, R Foundation for Statistical Computing, http://www.R-project.org/.

Rodgers, T.L., 1944, A new skink from the Sierra Nevada of California: Copeia, v. 2, p. 101-104. 
Rosen, P.C., Holm, P.A., and Lowe, C.H., 1996, Ecology and status of shovelnose snakes (Chionactis) and leafnose snakes (Phyllorhynchus) at and near Organ Pipe Cactus National Monument, Arizona: Final Report on the funded project Status and Natural History of U.S. Populations of the Organ Pipe Shovelnosed Snake, Arizona Game and Fish Department Heritage Grant IIPAM 192045, p. $68+17$. Roth, V.D., 1984, The spider family Homalonychidae (Arachnida, Araneae): American Museum Novitates, no. 2790, p. 11.

Rushton, S., Ormerod, S., and Kerby, G., 2004, New paradigms for modelling species distributions?: Journal of Applied Ecology, v. 41, p. 193-200.

Sawyer, J.O., Keeler-Wolf, T., and Evens, J., 2009, A manual of California vegetation: California Native Plant Society, p. 1,300.

Shcheglovitova, M., and Anderson, R.P., 2013, Estimating optimal complexity for ecological niche models - A jackknife approach for species with small sample sizes: Ecological Modelling, v. 269, no. 9-17.

Smallwood, K.S., and Morrison, M.L., 1999, Spatial scaling of pocket gopher (Geomyidae) density: Southwestern Naturalist, v. 44, p. 73-82.

Simley, J.D., and Carswell, Jr., W.J., 2009, The National Map-Hydrography: U.S. Geological Survey Fact Sheet 2009-3054, 4 p.

Stebbins, R.C., 1944, Some aspects of the ecology of the Iguanid Genus Uma: Ecological Monographs, v. 14, p. 311-332.

Stebbins, R.C., 1948, New distributional records for Xantusia vigilis with observations on its habitat: American Midland Naturalist, v. 39, p. 96-101.

Stebbins, R.C., 1951, Amphibians of western North America: Berkeley, Calif., University of California Press, $539 \mathrm{p}$.

Stebbins, R.C., 2003, A field guide to western reptiles and amphibians (3d ed.): Boston, Massachusetts, Houghton Mifflin, Boston, 532 p.

Stokland, J.N., Halvorsen, R., and Stoa, B., 2011, Species distribution modelling-Effect of design and sample size of pseudo-absence observations: Ecological Modelling, v. 222, p. 1-10.

Suarez-Gracida, C.G., and Alvarez-Castaneda, S.T., 2009, Physical and biological variables related to habitat preferences of rodents: Biodiversity and Conservation, v. 18, p. 2,779-2,797.

Sullivan, B.K., 2005, Bufo punctatus, in Lannoo, M.J., ed., Amphibina Declines-The Conservation Status of United States Species: Berkeley, Calif., University of California Press, p. 430-432..

Swetnam, T.W., and Lynch, A.M., 1993, Multicentury, regional-scale patterns of western spruce budworm outbreaks: Ecological Monographs, v. 63, p. 399-424.

Syfert, M.M., Smith, M.J., and Coomes, D.A., 2013, The effects of sampling bias and model complexity on the predictive performance of MaxEnt Species Distribution Models: PLoS ONE, v. 8, no. 2, e55158, doi:10.1371/journal.pone.0055158.

Tevis, L., 1966, Unsuccessful breeding by desert toads (Bufo punctatus) at limit of their ecological tolerance: Ecology, v. 47, p. 766.

Tracy, C., 1976, A model of the dynamic exchanges of water and energy between a terrestrial amphibian and its environment: Ecological Monographs, v. 46, p. 293-326.

Turner, R.M., 1982, Mohave desertscrub, in Brown, D.E., ed., Desert Plants: Biotic communities of the American Southwest-United States and Mexico, v. 4, p. 157-168.

Turner, F.B., and Randall, D.C., 1989, Net productivity by shrubs and winter annuals in southern Nevada: Journal of Arid Environments, v. 17, p. 23-36.

Turner, F.B., and Wauer, R.H., 1963, A survey of the herpetofauna of the Death Valley Area: Great Basin Naturalist, v. 23, p. 119-128. 
Vandergast, A., Inman, R., Barr, K., Nussear, K., Esque, T., Hathaway, S., Wood, D., Medica, P., Breinholt, J., Stephen, C., Gottscho, A., Marks, S., Jennings, W., and Fisher, R., 2013, Evolutionary hotspots in the Mojave Desert: Diversity, v. 5, p. 293-319.

van Leeuwen, W.J.D., Davison, J.E., Casady, G.M., and Marsh, S.E., 2010, Phenological characterization of Desert Sky Island vegetation communities with remotely sensed and climate time series data: Remote Sensing, v. 2, p. 388-415.

Wallace, C.S.A., and Thomas, K.A., 2008, An annual plant growth proxy in the Mojave Desert using MODIS-EVI Data: Sensors, v. 8, p. 7,792-7,808.

Wang, P.X., Li, X.W., Sun, W., Li, X.M., Zhang, S.Y., and Liu, A.L., 2004, Soil thermal inertia estimation by combining afternoon and morning AVHRR data with a modified diurnal land surface temperature change model: in Proceedings of the IEEE International Geoscience and Remote Sensing Symposium: IGARSS '04, p. 4,299-4,301.

Weiss, J., Gutzler, D., Coonrod, J., and Dahm, C., 2004, Long-term vegetation monitoring with NDVI in a diverse semi-arid setting, central New Mexico, USA: Journal of Arid Environments, v. 58, p. 249-272.

Wood, S.N., 2006, Generalized additive models-An introduction with R: Boca Raton, Florida, CRC Press, p. 392.

Wood, S.N., 2011, Fast stable restricted maximum likelihood and marginal likelihood estimation of semiparametric generalized linear models: Journal of the Royal Statistical Society-Series B (Statistical Methodology), v. 73, p. 3-36, doi: 10.1111/j.1467-9868.2010.00749.x.

Zeveloff, S.I., 1988, Mammals of the intermountain west: Salt Lake City, University of Utah Press, p. 365.

Zweifel, R.G., and Lowe, C.H., 1966, The ecology of a population of Xantusia vigilis, the desert night lizard: American Museum Novitates, v. 2,247, p. 1-57. 
Publishing support provided by the U.S. Geological Survey

Publishing Network, Tacoma Publishing Service Center

For more information concerning the research in this report, contact the Director, Western Ecological Research Center

U.S. Geological Survey

3020 State University Drive East

Sacramento, California 95819

http://werc.usgs.gov/ 


\section{हू}

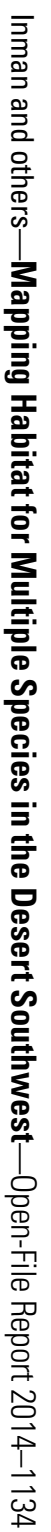

